$$
\text { UNIVERSIDADE DE SÃO PAULO }
$$

FACULDADE DE FILOSOFIA, LETRAS E CIÊNCIAS HUMANAS

PROGRAMA DE PÓS-GRADUAÇÃO EM GEOGRAFIA FÍSICA

\title{
ANÁLISE GEOGRÁFICA DE NASCIMENTOS PRÉ-TERMO NO ESTADO DE SÃO PAULO, NA RMSP E NO MUNICÍPIO DE SÃO PAULO
}

MARINA JORGE DE MIRANDA 


\section{ANÁLISE GEOGRÁFICA DE NASCIMENOS PRÉ-TERMO NO ESTADO DE SÃO PAULO, NA RMSP E NO MUNICÍPIO DE SÃO PAULO}

Tese apresentada ao Programa de Pós Graduação em Geografia Física da Faculdade de Filosofia, Letras e Ciências Humanas da Universidade de São Paulo, como requisito parcial para obtenção do título de Doutor(a) em Geografia.

Orientadora: Profa. Dra. Lígia Vizeu Barrozo

São Paulo

2014 


\section{DEDICATÓRIA}

Com muita gratidão, dedico este trabalhos a DEUS, a minha família, a minha orientadora Lígia Barrozo, aos meus amigos, e as mamães e crianças deste vasto mundo, com quem aprendi e aprenderei constantemente neste bela trajetória do AMOR pela vida! 


\section{AGRADECIMENTOS}

Gostaria de registrar meus agradecimentos às pessoas, órgãos e entidades que tornaram possível a realização desse trabalho:

A Deus por ter colocado a Geografia em meu caminho.

À minha mãe Sônia Favilla Jorge e ao meu pai Joaquim Miranda, por todo amor e apoio dado ao longo dos meus 31 anos.

A professora Lígia Barrozo pela sua sabedoria, comprometimento e atenção ao me orientar, além da amizade e da admiração que adquirimos nesta trajetória.

Aos meus queridos irmãos Marcelo Miranda e Marília Miranda pelo carinho e companheirismo de vida toda, aos meus cunhados Iara Miranda e Matheus Mello, meus irmãos de coração. A minha amada sobrinha Carolina Miranda e ao meu novo sobrinha ou sobrinha que ainda está na barriga da mamãe Iara. E ao Antonio Carlos Elias pelo companheirismo, apoio e amizade.

A toda minha família, destacando meu avô Hilário da Silva Miranda e minha avó Violeta Coelho de Miranda (in memoriam) que me deixaram o despertar pela curiosidade científica e aos meus avós maternos Neusa Favilla Jorge e Milton Jorge pelo carinho.

Aos funcionários da pós-graduação da Geografia Física e Humana da USP, em especial a Cida e ao Firmino, pela cuidadosa atenção. Aos professores Aílton Luchiari, Reinaldo Perez Machado, Emerson Galvani, Luis Bittar Venturi e Alfredo Queiroz pelas proveitosas trocas de conhecimento e aprendizado.

Aos amigos Emerson Santos, Kênia Rezende, Priscilla Ikefuti, Maurício Rangel, William Cabral, Juliana Canduzini, Bete Maia, Danilo de Oliveira, Josildo de Oliveira e Wanderlei Evaristo de Mattos pela amizade, apoio e aprendizado 
durante toda a pesquisa através das boas e proveitosas experiências no Grupo de Pesquisa de Geografia da USP, coordenado pela professora Lígia.

Aos amigos do programa de pós-graduação da Geografia Física da USP: Maria Carolina Gomes, Júlio Barboza Chiquetto, João Paulo Assis Gobo, Aline dos Santos, Tiago Silveira pela amizade e pareceria nas atividades acadêmicas e externas.

Aos queridos amigos Joceley Souza e Ana Elisa Pereira pela LUZ, amizade, cumplicidade de sempre!

Ao professor Paulo Saldiva, médico patologista da Faculdade de Medicina da USP, pelos ensinamentos de Epidemiologia, pelo incentivo a este tema de pesquisa, pelo aprendizado. E a toda equipe do Instituto Saúde e Sustentabilidade de São Paulo, especialmente a professora Evangelina Vormittag, pela parceira e pelos aprendizados na área de saúde e meio ambiente.

Às professoras Zilda Pereira e Susana Pasternak pelas proveitosas dicas fornecidas na apresentação da qualificação desse trabalho.

Aos professores Luiz Amador Pereira, Francisco Chiaravalloti Neto, e às professoras Simone Diniz e Paula Santana pelas valiosas contribuições e sugestões na apresentação de defesa dessa tese.

A Fundação de Pesquisa do estado de São Paulo (FAPESP) pelo financiamento deste pesquisa, pela concessão das bolsa de doutorado, assim como pela viabilização do meu do meu proveitoso estágio no exterior realizado na Universidade de Coimbra.

\section{MUITO OBRIGADA A TODOS!}




\section{RESUMO}

A prematuridade é um dos grandes problemas de saúde pública, contribuindo com elevados números para a morbi-mortalidade infantil, principalmente em países em desenvolvimento como o Brasil. Conceitua-se o nascido prematuro ou pré-termo como aquele que nasce com menos de 37 semanas de gestação. Os fatores de risco individuais associados à incidência da prematuridade são conhecidos. No entanto, os fatores contextuais que podem influenciar na sua incidência têm sido pouco estudados. Sabe-se que a prematuridade é variável conforme a raça, as condições socioeconômicas, ambientais e culturais em que as mães estão inseridas. Assim, a presente tese teve por objetivo analisar o padrão da distribuição geográfica do risco relativo da prematuridade infantil em diferentes escalas: no estado de São Paulo, na Região Metropolitana de São Paulo e na esfera intra-urbana do município de São Paulo, durante o período de 2002 a 2007 (estado de SP), 2000 a 2010 (RMSP) e 2002 a 2013 (MSP) por meio da análise espacial exploratória. Investigamos como o contexto geográfico tem afetado o risco relativo de nascimentos pré-termo, através de testes de associação espacial global e local (I Moran e LISA) para estado de SP e para RMSP. Pela regressão multivariada global (OLS) e regressão geograficamente ponderada (GWS), estudamos quais variáveis explanatórias tiveram melhor capacidade explicativa para compreender espacialmente os riscos de nascimentos pré-termo no estados de SP (variável dependente). As variáveis explanatórias (independentes) foram representadas: pelas condições socioeconômicas das mães e foram mensuradas pelo índice de privação sociomaterial (IP), assim como pelo acesso ao sistema de saúde materna e do recém-nascido, representados pela porcentagem de cesáreas, pelo número de consultas pré-natal acima de 7 e pelo número de UTIs neonatais por 1000 nascidos vivos. Para isso, utilizamos dados de saúde do Sistema de Nascidos Vivos (SINASC) do Ministério da Saúde (DATASUS), dados socioeconômicos da Fundação SEADE, e dados de acesso da saúde materna e do recém-nascido do Cadastro Nacional de Estabelecimentos de Saúde (CNEs). Tanto os riscos relativos de nascimentos pré-termo como as variáveis socioeconômicas apresentaram autocorrelação espacial global significativa. Houve associação espacial local significativa entre os riscos relativos de nascidos prematuros com todas as variáveis socioeconômicas testadas para o estado de SP e para RMSP. As distribuições geográficas destas associações ocorreram de maneira não aleatória e heterogênea pelo estado de SP e pela RMSP, demonstrando a forte e complexa relação entre indicadores de saúde dos recém-nascidos com as condições socioeconômicas em que mães estão inseridas. Apenas o número de UTIs neonatais foi a única variável estatisticamente significativa do modelo global OLS, que melhor explicou a distribuição geográfica dos riscos relativos de nascimentos pré-termo no estado de SP. O modelo GWR ajudou a identificar separadamente e localmente quais os munícipios do território paulista que apresentaram riscos mais altos de nascimentos pré-termo pela privação sócio-material, pela porcentagem de cesáreas, pela porcentagem de consultas pré-natal acima de 7 e pelo número de UTIs neonatais por 1000 nascidos vivos. 
Palavras-chave: nascimentos pré-termo, contexto geográfico, análise espacial, estado de São Paulo, RMSP e município de São Paulo.

\begin{abstract}
Prematurity is a serious public health issue, increasing significantly the child morbidity and mortality cases, especially in developing countries such as Brazil. A premature or preterm birth is defined when the birth occurs with less than 37 gestational weeks. While the individual risk factors associated with the incidence of prematurity are known, contextual factors able to impact it have not been given the same attention. It is known that prematurity is influenced by the ethnic group and socio-economic, environmental and cultural conditions experienced by the mother. In this context, the present thesis aimed to analyze the spatial distribution patterns of the relative risk of premature birth, through exploratory spatial data analysis, in three different spatial scales: the state of São Paulo (SP), the São Paulo Metropolitan Area (SPMA), and in the intra-urban scale of the municipality of São Paulo (SPM). The time period studied ranged from 2002 to 2007 (SP), 2000 to 2010 (SPMA) and 2002 to 2013 (SPM). We investigated how the geographical context has affected the relative risk of preterm birth through global and local spatial association tests (Moran's I and LISA) for the state of SP and the SPMA. Using the global multivariate regression (OLS) and the geographically weighted regression (GWR), we studied which explanatory variables best explained, spatially, the risk of preterm birth in the state of SP (dependent variable). The explanatory variables (independent) were represented by the socioeconomic conditions of the mothers and were measured by the sociospatial deprivation index (DPi), as well as the health system access by the mothers and premature infants, represented by the number of caesarian deliveries, number of prenatal testings above 7 and number of newborn emergency entries by 1000 live births. For that, we used data from the national Live Birth System (SINASC) from the Ministry of Health (DATASUS), socioeconomic data from the SEADE foundation, and newborn and maternal health access data from the National Registry of Health Facilities (CNEs) from Brazil. Both the preterm birth relative risks and the socioeconomic variables presented significant global spatial autocorrelation. There was significant spatial local association between the premature birth relative risks with all socioeconomic variables tested for the state of SP and for the SPMA. The geographical distribution of such associations occurred in a non-random pattern, and heterogeneously distributed through the territory of the state of SP and the SPMA, revealing the strong and complex relation between the newborn health indicators and the socioeconomic conditions to which their mothers are subject. The number of emergency entries was the statistically significant variable form the global model that best explained the geographical distribution of the preterm birth relative risks in the state of SP. The GWR helped to identify locally which municipalities of the state presented higher risks of preterm birth due to the sociospatial deprivation index, the number of caesarian deliveries, number of prenatal testings above 7 and number of newborn emergency entries by 1000 live births.
\end{abstract}

Keywords: Preterm Birth, Geographical Context, Spatial Analysis, State of São Paulo, SPMA, São Paulo Municipality. 


\section{LISTA DE FIGURAS}

Figura 1- Fluxograma de uma pesquisa de cunho exploratório, segundo Gumuchian \&

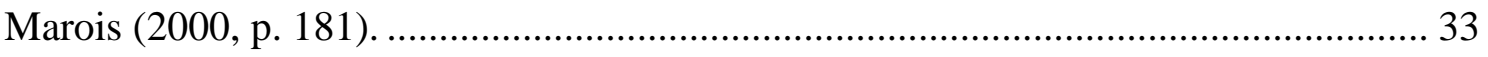

Figura 2 - Localização do estado de São Paulo no território brasileiro.......................... 36

Figura 3- Mapa da Divisão Político Administrativa por Regiões Administrativas, Regiões de Governo e Regiões Metropolitanas do estado de São Paulo, Fundação SEADE (2003)......

Figura 4 - Mapa da Divisão Político-administrativa dos municípios da Região Metropolitana de São Paulo, Fonte: CEM/Cebrap, 2006. 38

Figura 5 - Mapa da Divisão Administrativa dos 96 distritos do município de São Paulo. 39

Figura 6 -Proporção de bebês prematuros pelo total de nascidos vivos no estado de São Paulo, de acordo com o número de consultas pré-natal durante os anos de 2002 a 2007.

Figura 7- Proporção de bebês prematuros pelo total de nascidos vivos no estado de São Paulo, de acordo com a faixa-etária das mães durante os anos de 2002 a 2007. 51

Figura 8- Proporção de bebês prematuros pelo total de nascidos vivos no estado de São Paulo, de acordo com os anos de instrução das mães durante os anos de 2002 a 2007. 52 Figura 9 - Proporção de bebês prematuros pelo total de nascidos vivos no estado de São Paulo, de acordo com o estado civil das mães durante os anos de 2002 a 2007. 53

Figura 10- Proporção de bebês prematuros pelo total de nascidos vivos no estado de São Paulo, de acordo com o tipo de gravidez das mães durante os anos de 2002 a 2007.

Figura 11 - Riscos Relativos da prematuridade infantil padronizado pela idade das mães no estado de São Paulo, entre 2002 e 2007 (Mapa da esquerda); e Agrupamentos significativos - 5\% da População em Risco (Mapa superior do canto direito) e 50\% da População em Risco (Mapa do canto inferior direito). 55

Figura 12 - Riscos Relativos da prematuridade infantil padronizada pela escolaridade das mães no estado de São Paulo, entre 2002 e 2007 (Mapa da esquerda); e Agrupamentos significativos - 5\% da População em Risco (Mapa superior do canto direito) e 50\% da População em Risco (Mapa do canto inferior direito). 
Figura 13 - Riscos Relativos da prematuridade infantil padronizada pelo número de consultas pré-natais realizadas pelas mães no estado de São Paulo, entre 2002 e 2007 (Mapa da esquerda); e Agrupamentos significativos - 5\% da População em Risco (Mapa superior do canto direito) e 50\% da População em Risco (Mapa do canto inferior direito).

Figura 14 - Riscos Relativos da prematuridade infantil em função dos partos cesáreos realizados nas mães no estado de São Paulo, entre 2002 e 2007 (Mapa da esquerda); e Agrupamentos significativos - 5\% da População em Risco (Mapa superior do canto direito) e 50\% da População em Risco (Mapa do canto inferior direito).

Figura 15 - Riscos Relativos da prematuridade infantil em função dos partos normais realizados nas mães no estado de São Paulo, entre 2002 e 2007 (Mapa da esquerda); e Agrupamentos significativos - 5\% da População em Risco (Mapa superior do canto direito) e 50\% 5\% da População em Risco (Mapa do canto inferior direito). 66

Figura 16 - Mapa dos Agrupamentos espaciais locais (LISA) da associação entre Risco relativo e porcentagem de assentamentos precários. 71

Figura 17- Mapa dos Agrupamentos espaciais locais (LISA) da associação entre Risco relativo e taxa de desemprego.

Figura 18 - Agrupamentos espaciais locais (LISA) da associação entre Risco relativo e taxa de analfabetismo.

Figura 19 - Agrupamentos espaciais locais (LISA) da associação entre Risco relativo e índice de privação sócio-material. 73

Figura 20 - Mapa dos valores observados normalizados e preditos do risco relativo de nascimentos pré-termo. 78

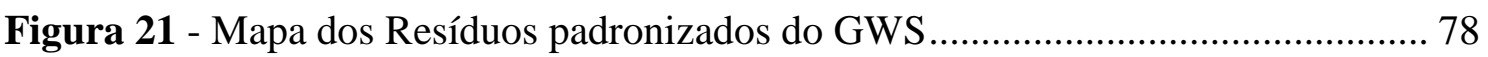

Figura 22 - Mapa do coeficiente do Índice de Privação-sociomaterial ......................... 79

Figura 23- Mapa do coeficiente da porcentagem de partos cesáreos. .......................... 79

Figura 24 - Mapa do coeficiente da porcentagem de consultas pré-natais acima de 7. 80 Figura 25 - Mapa do coeficiente do número de UTIs neonatais por 1000 nascidos vivos.

Figura 26- Variação da Taxa de nascimentos pré-termo na RMSP entre 2000 e 2010. 81 Figura 27 - Mapa dos Riscos Relativos de nascimentos pré-termo na RMSP, entre 2000 e 2010, tendo como co-variável a faixa-etária das mães.

Figura 28- Mapa dos Agrupamentos espaciais dos nascimentos pré-termo na RMSP entre 2000 e 2010 . 83 
Figura 29 - Porcentagem de nascimentos pré-termo no município de São Paulo entre 2003 e 2012 de acordo com a faixa-etária das mães. 85

Figura 30 - Mapa dos Riscos Relativos de nascimentos pré-termo no município de São Paulo entre 2003 e 2007, co-variável: faixa-etária das mães.

Figura 31- Mapa dos Agrupamentos Espaciais para 5\% da População em Risco, entre 2003 e 2007, no município de São Paulo. 88

Figura 32 - Mapa dos Riscos Relativos de nascimentos pré-termo no município de São Paulo entre 2008 e 2012, co-variável: faixa-etária das mães. 90

Figura 33 - Mapa dos Agrupamentos Espaciais para 5\% da População em Risco, entre 2008 e 2012, no município de São Paulo. 91

Figura 34 - Mapa dos Riscos Relativos de nascimentos pré-termo no município de São Paulo entre 2003 e 2012, co-variável: faixa-etária das mães. 93

Figura 35- Mapa dos Agrupamentos Espaciais para 5\% da População em Risco, entre 2002 e 2013, no município de São Paulo. 94 


\section{LISTA DE TABELAS}

Tabela 1 - Nascimentos por residência das mães por ano do nascimento segundo Unidade da Federação - estado de São Paulo. 48

Tabela 2 - Número total e porcentagem de nascimentos prematuros por tipo de parto de 2002 a 2007 no estado de São Paulo. 48

Tabela 3 - Correlação simples entre o risco relativo e as variáveis socioeconômicas no estado de São Paulo entre 2002 e 2007

Tabela 4- Autocorrelação espacial global das variáveis no estado de São Paulo entre 2002 e 2007.

Tabela 5 - Correlação espacial global entre o risco relativo e as variáveis socioeconômicas no estado de São Paulo entre 2002 e 2007. 69

Tabela 6 - Teste de Regressão da OLS - Regressão dos Mínimos Quadrados Ordinários 74

Tabela 7 - Diagnóstico da OLS 74

Tabela 8 - Teste de autocorrelação espacial dos resíduos da OLS ................................ 75

Tabela 9 - GWR - Regressão Geograficamente ponderada ........................................ 76

Tabela 10 - Autocorrelação espacial global das variáveis na RMSP entre 2000 e 201083 Tabela 11- Correlação espacial global entre o risco relativo e as variáveis socioeconômicas na RMSP entre 2000 e 2010. 84 


\section{LISTA DE SIGLAS}

ABCD - Municípios da Região Metropolitana de São Paulo: Santo André, São

Bernardo, São Caetano e Diadema.

BPN - Baixo peso ao nascer

CEM - Centro de Estudos da Metrópole

CNES - Cadastro Nacional dos Estabelecimentos de Saúde

DATASUS - Departamento de Informática do SUS

IBGE - Instituto Nacional de Geografia e Estatística

IG - Índice de Gini

IP - Índice de Privação Sócio-Material

MS - Ministério da Saúde

MSP- Município de São Paulo

RMSP - Região Metropolitana de São Paulo

OMS - Organização Mundial da Saúde

SEADE - Fundação Sistema Estadual de Análise de Dados do estado de São Paulo

SIG - Sistemas de Informação Geográfica

SINASC - Sistema de Informações sobre Nascidos Vivos

SUS - Sistema Único de Saúde

USP - Universidade de São Paulo

UTIs - Unidades de Terapia Intensiva Neonatais 


\section{Sumário}

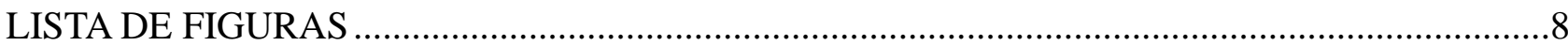

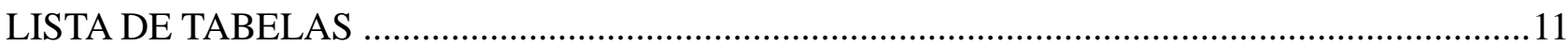

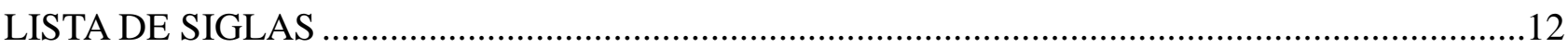

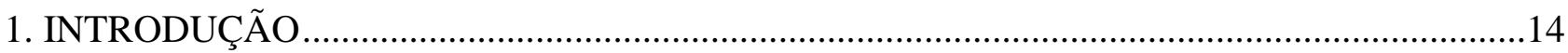

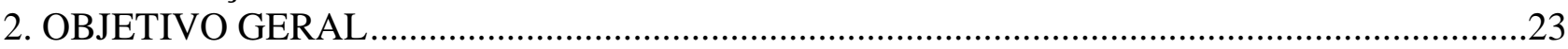

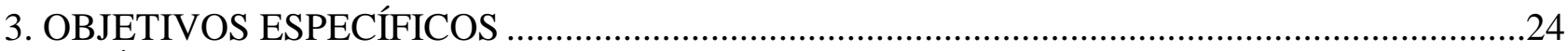

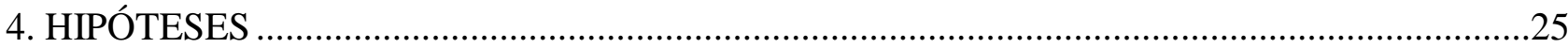

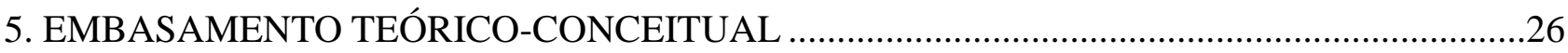

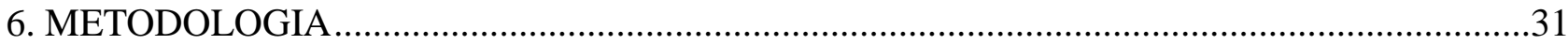

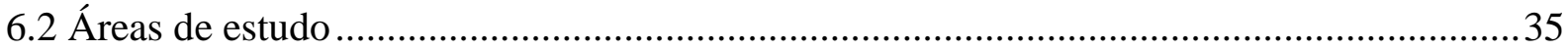

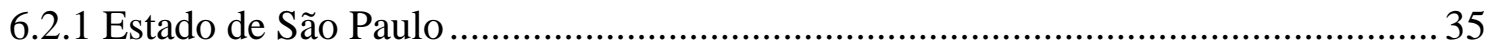

6.2.2 Região Metropolitana de São Paulo (RMSP) ....................................................... 37

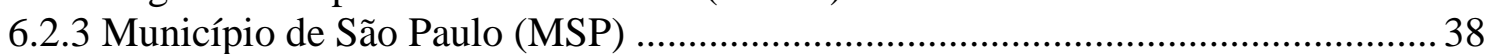

6.3. MATERIAIS E PROCEDIMENTOS TÉCNICO-OPERACIONAIS ............................... 40

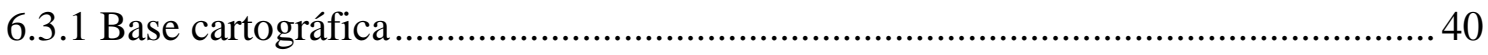

6.3.2 Dados epidemiológicos, demográficos e socioeconômicos ................................... 40

6.3.3 Dados de Atendimento destinados a Saúde Materna e Infantil.............................. 41

6.3.4 Dados de equipamentos de saúde relacionados à Saúde Materna e Infantil .......... 41

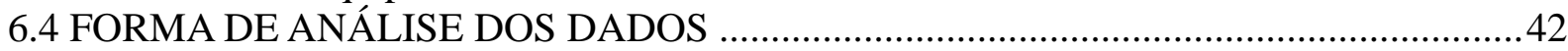

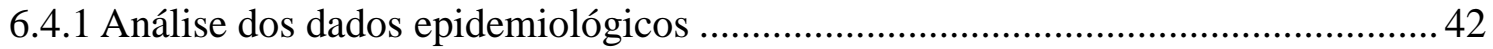

6.4.2 Cálculo dos riscos relativos de prematuridade infantil ....................................... 42

6.4.3 Análise de varredura espacial para detecção de agrupamentos espaciais .............. 43

6.4.4. Análise de associação espacial dos riscos relativos de nascimentos pré-

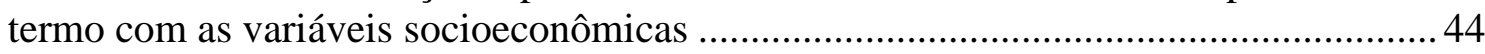

6.4.5 Teste de regressão pelos métodos OLS e GWR ................................................ 46

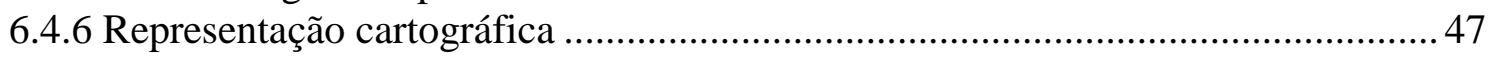

7. RESULTADOS .............................................................................................................

das mães e dos nascidos prematuros do estado de São Paulo entre 2002 e 2007 ....................48

7.2 Análise espacial exploratória dos riscos relativos da prematuridade infantil em

relação à idade e escolaridade das mães, ao atendimento pré-natal e ao tipo de parto (normal e cesarianas) no estado de São Paulo entre 2002 e 2007 ...........................................54

7.3. Análise espacial exploratória de associação entre os riscos relativos e as

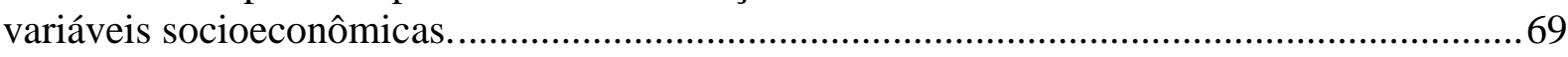

7.4 Aplicação dos Testes de Regressão OLS e GWR ........................................................ 74

7.5 Análise espacial exploratória retrospectiva do padrão espacial dos riscos relativos de nascimentos pré-termo para Região Metropolitana de São Paulo .......................................81

7.6 Análise espacial exploratória retrospectiva do padrão espacial dos riscos relativos

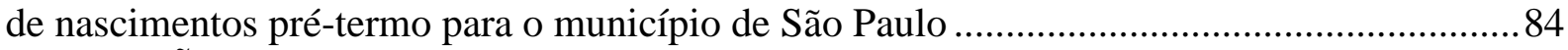

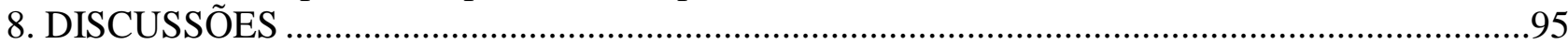

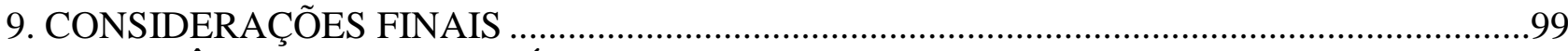

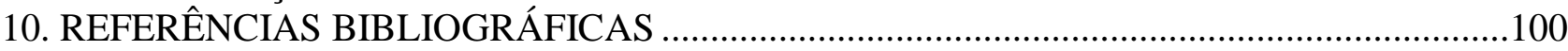




\section{INTRODUÇÃO}

A saúde é um pré-requisito básico para o desenvolvimento econômico e social (Wilkinson e Marmot, 2003). Assim, é necessário reanalisar as necessidades das pessoas que vivem em cidades (que estão se tornando maior e mais complexo o tempo todo) para garantir a provisão adequada de bens e serviços (Santana et al., 2009). De fato, a urbanização acelerada e mobilidade trouxeram novos desafios para $o$ planejamento da cidade e, conseqüentemente, para a saúde pública (Santana et al., 2009). Embora tenha havido avanços consideráveis os indicadores de saúde no Brasil nos últimos anos (Bezerra-Filho et al., 2007), as taxas de mortalidade e prematuridade infantil continuam a ser um dos maiores problemas de saúde pública (Szwarcwald et al., 2002; Victora et al., 2011).

Nesse contexto, é necessário salientar o papel importante que a Geografia da Saúde exerce nas investigações sobre os processos de saúde-doença sob a perspectiva espacial. Trata-se de uma área do conhecimento científico que articula assuntos da Geografia Física (Climatologia, Biogeografia) e temas da Geografia Humana (Demografia, Urbanização, Planejamento Ambiental e Territorial, por exemplo), envolvendo tanto a perspectiva ecológica e espacial das doenças, assim como dos serviços de saúde, além de contemplar a relação dinâmica entre a saúde das populações com os lugares que elas habitam (Santana, 2004; Nogueira e Remoaldo, 2010; Barrozo, 2011).

Além disso, hoje, um pouco por todo o mundo, com especial ênfase nos países em desenvolvimento como o Brasil, o espaço urbano ainda é um espaço crítico quando associado a valores como a qualidade de vida, bem-estar e saúde das populações. 
No Brasil, a rápida concentração dessas populações nos centros urbanos como São Paulo e Rio de Janeiro, entre as décadas de 50 e 70, fez emergir a maior necessidade de atuar ao nível do planejamento urbano para que se pudessem alterar algumas das circunstâncias de grande precariedade em que vivia parte dessa população. Por outro lado, a saúde pública reconhecia também a urgência de conhecer as causas de determinadas doenças que se proliferavam nestes lugares para melhor adequar a atuação de programas específicos de prevenção e vigilância em saúde, visando a sua erradicação. Estes aspectos têm como premissa ser a saúde condição essenciais para o desenvolvimento dos lugares, das regiões e dos territórios, sendo estes indissociáveis dos fatores sociais, econômicos, políticos, culturais e ambientais (Santos, 2005).

Contudo, a urbanização em si não é um mal. Do ponto de vista da saúde, a urbanização trouxe muitos benefícios tanto no nível individual quanto no coletivo. De modo geral, houve queda nas taxas de mortalidade e de mortalidade infantil tardia e aumento na expectativa de vida, em função dos vários benefícios trazidos pelos equipamentos urbanos, como o acesso à água potável, saneamento básico e energia, bem como pelos programas de vacinação, acesso aos serviços médicos, educação e informação, entre outros (Santos, 2005; Ribeiro, 2006).

Parcelas crescentes da população mundial estão se concentrando em cidades e em megacidades ${ }^{1}$. A intensidade do processo global de urbanização fez com que, em 2008, atingíssemos uma marca histórica com mais de 50\% da população vivendo em cidades, o que corresponde a 3,4 bilhões de pessoas concentradas em áreas urbanas (Nobre et al., 2010).

No Brasil, por exemplo, $80 \%$ da população vive em cidades e juntamente com o crescimento urbano acelerado, tem-se ampliado a desigualdade sócio-espacial e a

1 A definição de megacidades pela ONU se refere a centros urbanos com populações acima de 10 milhões de habitantes como o município de São Paulo com 11 milhões. 
degradação ambiental. Entre 1950 e 2000, o Brasil viveu sua curva demográfica (a taxa de fecundidade recuou de 5,9 para 1,3 filhos por mulher) e se tornou um país urbano (a população vivendo em cidades passou de $36 \%$ para $81 \%$ ) - (Santos, 2005)

Esta transformação gigantesca foi ainda mais acentuada na cidade. Neste meio século, a população do país cresceu três vezes, a do Estado de São Paulo quatro vezes e a da cidade de São Paulo cinco vezes, passando esta de pouco mais de 2 milhões de habitantes em 1950 para mais de 10 milhões em 2000. No entanto, hoje já se deu a reversão do processo demográfico, a cidade caminha para a estabilização de sua população. Vários fatores contribuem para isso: redução nos fluxos migratórios e seu redirecionamento para outras regiões de desenvolvimento mais recente, o elevado custo de vida e a explosão dos preços da terra na cidade, a redução na demanda por mão-deobra de baixa qualificação. A cidade hoje cresce pouco e tende a expulsar as populações de mais baixa renda para os municípios em seu entorno (Pasternak e Bógus, 2011).

Por isso, a ocupação crescente de municípios periféricos, sobretudo onde a terra é mais barata, como é o caso dos trabalhadores populares e operários tradicionais, faz com que parcelas pobres da população metropolitana vivam de forma precária, o que se traduz numa piora das condições de saúde. Condições de moradia ruins, infraestrutura deficiente, aumento do tempo de transporte para o trabalho, falta de equipamentos sociais traduzem-se em aumento da mortalidade, da morbidade e da violência (Pasternak e Bógus, 2011).

Em contrapartida, a região metropolitana de São Paulo se caracteriza por ser ao mesmo tempo especializada e diversificada. Utilizando uma classificação de atividades produtivas baseada em intensidade tecnológica, a região apresenta concentrações acima da média em quase todas as atividades de maior conteúdo tecnológico, sejam elas industriais ou de serviços. Entre as atividades mais intensivas em tecnologia e 
conhecimento destacam-se: microeletrônica, automação industrial, fabricação de equipamentos ópticos, equipamentos de informática, equipamentos médico-hospitalares e odontológicos e fármacos, desenvolvimento de software e consultoria em sistemas, telecomunicações, engenharia, publicidade, pesquisa, atividades financeiras, atividades de mídia, de educação e de saúde (Santos, 2005).

Assim, a heterogeneidade espacial do município de São Paulo reflete diferentes épocas e formas de ocupação, expressando desigualdades sócioespaciais, num processo de diferenciação das áreas, através de distintas formas de integração às atividades econômicas metropolitanas. Expressa-se, assim, tanto em termos da configuração urbana dos municípios, como de sua função na divisão territorial do trabalho, refletindose também num processo diferenciado de redistribuição espacial da população (Santos, 2005).

Desse modo, as grandes concentrações urbanas como São Paulo abrigaram esses trabalhadores, não apenas porque esses tenderam a ocupar lugares mais densos e diversificados devido a maior possibilidade de emprego, como também por conta de outras facilidades propiciadas pelas grandes cidades como equipamentos de consumo, cultura e lazer mais sofisticados, serviços de saúde e de educação.

A modernização, no entanto, levou a uma mudança no perfil da morbimortalidade, logo os problemas relativos à concentração da população em cidades estão cada vez maiores, assim como as diferenças sociais e econômicas que se revelam em maus resultados em saúde, cada vez mais desafiadores e difíceis de resolver (Pasternak e Bógus, 2011).

Segundo estudo do Instituto Brasileiro de Geografia e Estatística (IBGE), com o ritmo de crescimento populacional menor e a expectativa de vida maior, o Brasil terá de enfrentar novos desafios na saúde pública devido ao envelhecimento da população. 
Junto com a queda na taxa de fecundidade, caiu também a mortalidade infantil nas últimas décadas. As doenças infecciosas e parasitárias perderam importância nas mortes de crianças e aumentou a proporção de complicações relacionadas a enfermidades que surgem antes ou depois do parto (Ibge, 2009).

O estudo também apontou que o crescimento da rede de saúde a precisa se expandir para atender as gestantes. A proporção de mães que tiveram assistência prénatal subiu de $43,7 \%$ para $54,5 \%$ entre 2000 e 2006, e a proporção de mulheres que não realizaram nenhuma consulta caiu de $4,7 \%$ para 2,1\%. Em São Paulo, mais de $70 \%$ das mulheres passaram por sete ou mais consultas (Ibge, 2009).

Especificamente no estado de São Paulo, a fecundidade das mulheres paulistas diminuiu pela metade entre 1980 e 2008 , passando de 3,4 para 1,7 filho por mulher. A diminuição na taxa de fecundidade foi observada em todas as regiões do Estado de São Paulo A maior queda foi registrada na Grande São Paulo de 1,84 filho por mulher e a menor, em São José do Rio Preto 1,4 filho por mulher (SEADE, 2010b).

A cada ano, aproximadamente 602 mil mulheres tornam-se mães em todo o Estado. Do total, $44 \%$ vivenciam a maternidade pela primeira vez e $32 \%$, pela segunda. Apenas $10 \%$ delas passam pela experiência mais de quatro vezes. O boletim mostrou que a fecundidade é relativamente baixa nas mulheres com 15 a 19 anos. Em 2008, foram cerca de 55 nascimentos para cada mil garotas nessa faixa etária. A maioria das paulistas que deu à luz no período tinha entre 20 e 30 anos (SEADE, 2010b).

Apesar de a maioria destes indicadores de saúde materna e infantil mostrar progressos, alguns demonstram piora. Uma revisão sistemática de estudos de base populacional de nascimentos pré-termo no Brasil mostrou que a prevalência aumentou cerca de 4\%, no início dos anos 1980, para mais de 10\%, após o ano 2000. Essa tendência de aumento foi confirmada por estudos periódicos realizados em duas cidades 
brasileiras, utilizando-se métodos padronizados ao longo do tempo (Betiol et al., 2000; Silveira et al, 2008).

Nascidos prematuros ou pré-termos são considerados os recém-nascidos com idade gestacional inferior a 37 semanas, o que resulta num grupo heterogêneo de crianças com idades próximas ao termo, ou ainda aquelas com idades gestacionais abaixo de 32 semanas. (Araujo et al, 2007, Silveira, 2008; Táscon, 2012).

O CID -1012 define idade gestacional: termo - de 37 a 42 semanas de gestação (de 260 a 293 dias); prétermo - menos de 37 semanas (menos de 259 dias); pós-termo 42 semanas ou mais (mais de 293 dias). Quanto menor a idade gestacional, maior a probabilidade de risco para a mortalidade, abandono, problemas de saúde etc. (CID-10, 1997). O nascimento prematuro afeta desproporcionalmente minorias raciais e mulheres desfavorecidas as socioeconomicamente, ao mesmo tempo é uma consequência comum de uma convergência complexa de fatores biológicos, genéticos, sociais e econômicos (Berhrman e Butler, 2007);

Os riscos biológicos de nascimento pré-termo incluem fatores que comprometem a saúde das mães como: baixo peso, sobrepeso, disfunção cervical, infecção, gestação múltipla, ruptura prematura de membranas, e histórico de partos prematuros anteriores (Assunção et al, 2012). Os fatores culturais e psicossociais, incluindo o estresse crônico, raça africano-americana, pobreza, tabagismo e acesso a cuidados médicos têm uma grande importância também (South et al., 2012).

Os fatores de risco individuais associados à prematuridade infantil já apontados pela literatura médica (Silveira et al, 2008) são a gravidez na adolescência (Silva, 2004) ou precoce (10 a 19 anos), a gravidez tardia (Susuki, et al 2007) com a maternidade acima dos 35 anos, as condições socioeconômicas da mãe e o acesso ao sistema de saúde materna e do recém nascido. 
Sabe-se que a maior participação das mulheres no mercado de trabalho tem propiciado o aumento da gravidez tardia (SEADE, 2010b), além disso, o aumento da insegurança neste mercado de trabalho, o aumento dos custos habitacionais, o interesse por parte das mulheres em assegurar independência financeira podem ajudar a explicar as quedas nas taxas de natalidade e fecundidade. Ao mesmo tempo, as mães brasileiras têm adotado mais opção pelo parto cesáreo do que pelo parto normal.

De acordo com levantamento realizado pela Organização Mundial da Saúde, o Brasil é o $10^{\circ}$ país no mundo em número de nascimentos prematuros. São cerca de 280 mil bebês prematuros por ano, ao mesmo tempo em que somos o líder mundial em partos cesáreos.

Enquanto a OMS recomenda um máximo de $15 \%$ de cesáreas, o Brasil alcança os $90 \%$ em instituições privadas. Facilidades, comodismo e baixa remuneração dos médicos, além das questões culturais e da própria falta de conhecimento existente na formação profissional dos médicos nos cursos de Medicina no Brasil, que, já na faculdade, aprendem mitos sobre o parto normal preferindo fazer cesáreas e desconhecendo a verdadeira assistência a um parto natural e humanizado (OMS, 2013).

Entre as justificativas mais comuns para agendar a cesárea, encontramos: circular de cordão, bacia pequena da mãe, pressão alta, diabetes, sofrimento fetal, pouco líquido, muito líquido, bebê muito grande. (Zorzam, 2013)

No Brasil, agendamos a cirurgia para um dia qualquer sem que o bebê tenha dado sinal de que está pronto para nascer. Existe a falsa ideia de que a partir da $37^{a}$ semana contada pela data da última menstruação o bebê já não seria mais considerado prematuro. Mas esse cálculo não consegue precisar a idade do feto, já que a concepção pode ter ocorrido em outra data. Em muitos casos, bebês de 38 semanas necessitam da UTI por conta de "desconforto respiratório" e “água no pulmão" (Höfelmann, 2009). 
No estado de São Paulo, em 2004, 52,5\% do total de partos eram cesarianas.Esse número só vem aumentando, chegando a 60\% em 2011. Alguns municípios chegam a ter $\mathbf{1 0 0 \%}$ de cesáreas como Marapoama, Santa Rita D'Oeste, Santana da Ponte Pensa, Sebastianópolis do Sul, São João d'Alho e Borá (SEADE, 2013).

Estudos realizados para o estado de São Paulo (Raspatini, 2012), para o Brasil (Leal et al, 2012) e para os EUA (Malloy, 2008) diagnosticaram que as altas taxas de cesarianas e indução do parto podem ser responsáveis pelos elevados níveis de prematuridade e de baixo peso ao nascer. Em contrapartida, outras análises mostram associações negativas entre cesáreas e nascimentos pré-termo, sendo as cesáreas fatores de proteção ao nascimento pré-termo. Há casos em que os partos ocorrem por indicações médicas, devido a situações de risco da mãe ou do feto o que leva a contraindicação da continuidade da gravidez, por exemplo (Goldemberg et al, 2008; Silva et al, 2009).

Por isso, mais estudos detalhados são necessários para elucidar esta questão, inclusive sob a perspectiva geográfica que é a questão central desta pesquisa.

Estudos atuais que ajudem a explicar a prematuridade infantil sob a perspectiva espacial em diferentes escalas geográficas (estadual, metropolitana e intramunicipal) para São Paulo ainda foram pouco estudados. Dentro de qualquer população, a heterogeneidade desses fatores ou combinações de fatores podem obscurecer a identificação de fatores de risco passíveis de intervenções destinadas a evitar o nascimento prematuro. Isso pode ser especialmente verdadeiro em grandes e diversos ambientes urbanos, onde as disparidades de risco de parto prematuro são consideráveis.

A análise ecológica leva em conta informações de saúde de grupos de populações por unidade geográfica, num dado tempo. Quando há interesse nas características sociais, culturais, políticas e econômicos do processo saúde-doença, as 
inferências são sobre a sociedade como um todo, não somente pelo indivíduo (Medronho, 2009).

Dessa maneira, estudos ecológicos, de cunho exploratório, têm analisado o perfil de nascimentos no território brasileiro (Almeida, 2011; Lima et al, 2013); e em alguns municípios brasileiros através de técnicas de estatística espacial ${ }^{2}$. Alguns deles foram desenvolvido no Rio de Janeiro (D’orsi e Carvalho, 1998), em Belo Horizonte (Franceschini el al, 2009), São Paulo (Montero, 2004; Silva, 2008; Santos et al, 2013) e para a região do Vale do Paraíba (Haul et al, 2009) no estado de São Paulo.

Outra pesquisa recente e bastante relevante desenvolvida em Seine Saint Denis, distrito do nordeste da França, também usou a analise espacial para identificar os setores censitários, onde se localizavam as gestantes de bebês prematuros mais vulneráveis em relação às condições socioeconômicas e de acesso ao sistema de saúde da mãe e do recém-nascido (Charreire e Combier, 2009).

Em Hamilton County, em Ohio, nos Estados Unidos, pesquisadores também reconheceram a importância da perspectiva espacial para detecção das áreas mais vulneráveis ao alto risco de bebês prematuros através da análise espacial (South et al., 2012).

Outros trabalhos reforçam a relação da influência entre os condicionantes ambientais (como a poluição do ar) e os efeitos adversos na gravidez como prematuridade e baixo peso ao nascer: para o município de São Paulo (Medeiros e Gouveia, 2005), São Vicente na Baixada Santista (Guimarães, 2012) e Volta Redonda no estado do Rio de Janeiro (Reis, 2009).

2 "Denomina-se estatística espacial o ramo da estatística que permite analisar a localização espacial de eventos. Ou seja, além de identificar, localizar e visualizar a ocorrência de fenômenos que se materializam no espaço, tarefas possibilitadas pelo uso do Sistema de Informação Geográfica (SIG), utilizando-se a estatística espacial é possível modelar a ocorrência desses fenômenos, incorporando, por exemplo, os fatores determinantes, a estrutura de distribuição espacial ou identificação de padrões" (MINISTÉRIO DA SÁUDE, SVS, FIOCRUZ, 2008, p. 17). 
Diante destas características sócio-demográficas e problemáticas levantadas, o presente trabalho pretende investigar como o contexto geográfico interfere na distribuição espacial dos riscos relativos de nascimentos pré-termo nas diferentes escalas propostas: no estado de São Paulo, na RMSP e intra-urbana de São Paulo.

\section{OBJETIVO GERAL}

O objetivo geral é compreender a influência do contexto geográfico na incidência da prematuridade infantil em diferentes escalas: no estado de São Paulo, na Região Metropolitana e na esfera intra-urbana do município de São Paulo, durante o período de 2002 a 2007. 


\section{OBJETIVOS ESPECÍFICOS}

$\checkmark$ Calcular os riscos relativos da prematuridade infantil nas diferentes escalas geográficas sugeridas;

$\checkmark$ Verificar a ocorrência de agrupamentos espaciais dos riscos relativos da prematuridade infantil nos níveis estadual, metropolitano e intra-urbano;

$\checkmark$ Averiguar se ocorrem agrupamentos espaciais de riscos relativos da prematuridade infantil em função de seus fatores de risco individuais da mãe como idade e escolaridade; do tipo de parto (normal e cesariana) e do acesso ao sistema de atendimento à saúde materna e do recém-nascido através do número de consultas pré-natal;

$\checkmark$ Examinar se ocorre correlação espacial entre os riscos relativos da prematuridade infantil e indicadores do contexto geográfico: como Taxa de Desemprego, Taxa de Analfabetismo, Porcentagem de Assentamentos Precários, Índice de Privação Sócio-Material e, Porcentagem de partos cesáreos, Porcentagem de consultas pré-natal acima de 7 e Número de UTIS neonatais por 1000 nascidos vivos;

$\checkmark$ Avaliar a associação espacial entre variáveis individuais e do contexto geográfico e prematuridade infantil por meio de modelo de Regressão múltipla, considerando o componente espacial, se for o caso; 


\section{HIPÓTESES}

H1 - Os riscos relativos de nascimentos pré-termo devem apresentar um padrão espacial não aleatório no estado de São Paulo, na região metropolitana e no município de São Paulo; ou seja, possuem um padrão espacial de distribuição nestas diferentes escalas geográficas.

H2 - As variáveis do contexto geográfico apresentam associação espacial com a distribuição geográfica dos riscos relativos de nascimentos pré-termo nas diferentes escalas geográficas; 


\section{EMBASAMENTO TEÓRICO-CONCEITUAL}

Hoje se compreende que a saúde e a qualidade de vida, enquanto condições básicas e prioritárias para a população. Necessita-se de uma atenção reforçada nos aspectos relativos não só aos grupos sociais (atributos composicionais), mas, fundamentalmente, às circunstâncias que os rodeiam (atributos de contexto). As necessidades dos residentes na cidade devem orientar as formas de organizar socialmente o espaço urbano através do seu planejamento. (Santana, 2004)

No contexto urbano, a análise do contexto geográfico pode se assemelhar à comunidade, onde a vizinhança seria de fato, frequentemente considerada a unidade mais primária de solidariedade real ou potencial e de coesão social (Barcelos, 2010).

Uma revisão da literatura identificou 31 artigos relevantes publicados entre janeiro de 1999 e março de 2004, com atenção especial para a medição das características da vizinhança e do bairro (Ocampo, et al 2006). Doze categorias de características da vizinhança foram representados. Embora a maioria dos autores forneceram explicações teóricas de sua escolha para examinar as amplas construções da vizinhança, poucos foram explícitos sobre o porquê de certos indicadores. Existem barreiras teóricas, metodológicas e práticas na medição do contexto do bairro (Ocampo, et al 2006).

Outro desafio para as pesquisas da Geografia da Saúde é uma aproximação ou mensuração dos contextos socioeconômicos. Por isso, está cada vez mais frequente o uso de informações de áreas censitárias para se definir a localização e o padrão espacial de diferentes eventos da saúde, quando associados às condições socioeconômicas dos indivíduos, sejam estes por local de residência ou de ocorrência. Assim há maior necessidade das distribuições territoriais em unidades de maior homogeneidade interna para identificação destas áreas a partir da aplicação de técnicas de análise espacial. 
Também índices sintéticos podem ser calculados para diferentes níveis territoriais, já que se buscam essa aproximação dos contextos, por exemplo: linha de pobreza (LP), qualidade de vida (QV), exclusão e índice de desenvolvimento humano, índice de privação-sociomaterial (IP) etc. (Rojas, 2008).

Ao mesmo tempo, o termo contexto é de uso muito amplo e comum, e em determinadas áreas do conhecimento se identificam segundo o conteúdos de múltiplas formas. Assim se reconhece o contexto político, histórico, sociocultural, linguístico, de saúde e outros. (Rojas, 2008, p.99).

A análise ecológica leva em conta informações de saúde de grupos de populações por unidade geográfica, num dado tempo. Quando há interesse nas características sociais, culturais, políticas e econômicas do processo saúde-doença, as inferências são sobre a sociedade como um todo, não somente sobre o indivíduo (Santana, 2004).

Ambas são complementares para compreender as relações individuais e coletivas entre os processos de diferentes desfechos nas diferentes escalas.

Ao explorarmos efeitos de vizinhança sobre a saúde, uma importante questão tem preocupado os papéis de contexto e composição na contabilização de variações locais. Há pouca dúvida de que as estatísticas de saúde em um área são influenciadas pela composição da população local. Idade, educação, emprego, etnia, habitação, classe social e outros fatores podem todos influenciar a saúde dos indivíduos. Mas estes fatores de composição são suficientes para explicar as variações geográficas, ou há um efeito contextual, algum tipo de influência local que faz com que a saúde de uma área seja melhor (ou pior) do que seria de esperar pela composição da população? (Flowerdew et al., 2008)

Uma explicação contextual sugere que as diferenças espaciais em saúde também 
foram um produto de exposição de particularidades e características da área em que os indivíduos viveram (Cummins et al., 2005).

Tais efeitos de contexto pode ser de vários diferentes tipos. Por exemplo, o ambiente natural, que pode ser favorável a boa ou má saúde. A disponibilidade local de cuidados de saúde é um efeito contextual, bom acesso a um clínico geral ou outros prestadores de serviços médicos podem ter uma influência direta na saúde. Mesmo que as instalações médicas não são localizadas na própria área, boas ligações de transportes ainda podem dar aos moradores uma vantagem de saúde (Flowerdew et al, 2008).

Ao mesmo tempo, diferentes áreas com composição populacional semelhante podem diferir das normas sociais e culturais e dos valores que são dominantes. Alguns desses fatores, relacionados com o espírito de comunidade, participação e confiança, são agrupados no conceito de capital social (Santana, 2014).

Se a área tem uma comunidade forte e vizinhança são coesas, os moradores vão falar uns com os outros e, talvez, influenciar o comportamento do outro, com implicações, positivo ou negativo, para a saúde.

Nas tentativas para quantificar os efeitos relativos de contexto (fatores locais) e composição (fatores mais globais) sobre as variações espaciais dos indicadores de saúde, geralmente os efeitos composicionais são dominantes. Desse modo, os efeitos de privação socio-material podem interferir nas variações espaciais de indicadores de saúde como efeitos composicionais da população (Cummins et al, 2005).

As analises multi-nível aplicadas à saúde reúnem dados individuais e de contexto para avaliarem desigualdades espaciais nos resultados de saúde. Alguns pesquisadores consideram o Indíce de Desenvolvimento Humano (IDH) ou Produto Interno Bruto (PIB) de um país como característica de contexto geográfico, que tem sua influência da escala global (Santana, 2014). 
As características do ambiente social e material podem afetar a saúde dos indivíduos nas mais variadas escalas geográficas e os dados contextuais, assim como os composicionais devem ser coletados e utilizados plausivelmente de acordo com o objetivo da sua pesquisa, sendo que ambos se complementam na avaliação dos impactos sobre a saúde de indivíduos, dos bairros, dos municípios, dos diferentes territórios.

Por fim, percebemos que ainda existe uma flexibilidade na literatura médica, da geográfica médica e da saúde, assim da Epidemiologia em relação à conceituação do contexto geográfico, que pode ser influenciada desde o nivel da escala local à escala global, dependendo do estudo.

O notável movimento de investigação dos determinantes sociais em saúde se revelam úteis no processo de entendimento conceitual da saúde urbana. São eles: desigualdade, definido como as diferenças sistemáticas entre grupos populacionais em termos de indicadores de saúde, iniquidade, definida como as desigualdades injustas e evitáveis e, finalmente, vulnerabilidade, definida como a capacidade diferenciada de indivíduos, grupos, classes de indivíduos ou mesmo regiões ou lugares de manejar riscos, baseados em suas posições, nos mundos físico e social (Caiaffa et al. 2008).

Esse modelo conceitual de saúde urbana sustenta-se na caracterização de uma rede urbana interligada, fundamentada na premissa de que a interação dos grupos sociais com meio físico constituem o meio ambiente construído (Harvey, 1980), definindo o contexto urbano.

Dessa maneira, a divisão social do trabalho e a hierarquia da rede urbana do estado de São Paulo (Correa, 1994; Correa, 2006) através da participação das mulheres paulistas no mercado de trabalho, da distribuição espacial de equipamentos médicohospitalares (como os hospitais com especialidade em Neonatologia e Obstetrícia e das Unidades de Terapia Intensiva Neonatais) e do acesso ao sistema de saúde materna e do 
recém-nascido, podem interferir no modo de vida urbano e na saúde das mulheres, assim como no perfil dos nascidos vivos paulistas.

1 


\title{
6. METODOLOGIA
}

\subsection{Delineamento do estudo}

1. Análise exploratória retrospectiva do padrão espacial de nascimentos prétermo nas três escalas;

2. Análise ecológica de associação entre os riscos relativos de nascimentos prétermo nas escalas do estado e da RMSP e as variáveis operacionais que permitem inferir sobre o contexto geográfico;

Muitos pesquisadores evocam para a necessidade urgente de investigar e compreender espacialmente as variáveis explicativas que determinam as desigualdades em saúde nas diferentes escalas geográficas (Guimarães, 2009; Rojas, 2008). Conforme nos alerta Barrozo (2011):

\begin{abstract}
"O enfoque dos estudos das questões de saúde pelo geógrafo é a dimensão espacial, qualquer que seja a teoria adotada, a representação cartográfica é a técnica fundamental, que permite visualizar a distribuição espacial do tema estudado e auxilia na elaboração de hipóteses sobre as relações dos problemas de saúde com aspectos ambientais e/ou socioeconômicos e demográficos. Os mapas também constituem importantes instrumentos de apoio na identificação de áreas e grupos de risco ou que requerem maior atenção. Deve-se fazer um alerta quanto ao preconceito em relação às técnicas quantitativas. Em Geografia da Saúde, devido à proximidade com outras ciências como Epidemiologia e Biomedicina e às respostas que se pretende encontrar, o domínio das técnicas quantitativas como estatística, estatística espacial e cartografia é necessário em muitas abordagens, fornecendo base empírica para a análise crítica dos fenômenos. (Barrozo, 2011, p. 290)
\end{abstract}

Como nos lembra Buzai (2009) a Geografia como ciência tem metodologias e técnicas geradas devido ao avanço no desenvolvimento das tecnologias de informação geográfica; elas são utilizadas amplamente para resolução de problemáticas de natureza sócio espacial. Os sistemas de informação geográfica (os SIGs) e os sistemas de ajuda a decisões espaciais possuem desenvolvimento tecnológico que materializam importantes possibilidades de aplicação. 
Estas técnicas, combinadas com funções de visualização, formam, em alguns SIGs atuais, um conjunto de ferramentas que suporta a Análise Exploratória de Dados Espaciais (Exploratory Spatial Data Analysis - ESDA) .

Este conjunto de ferramentas é definido na literatura como sendo uma coleção de técnicas para descrever e visualizar distribuições espaciais, identificar situações atípicas, descobrir padrões de associação espacial, agrupamento de valores semelhantes (clusters) e sugerir regimes espaciais ou outras formas de heterogeneidade espacial (Carvalho et al, 1996, Anselin e Bao, 1997; Santana, 2005).

Nesse sentido, a Geografia da Saúde tem incorporado nas suas linhas temáticas o uso de tecnologias digitais baseadas na quantificação, ampliando o espectro de metodologias tanto para o estudo das distribuições geográficas e associações espaciais entre a população e as enfermidades, mas também para análise espacial dos serviços de atenção (Carvalho e Santos, 2005; Buzai, 2009;)

Nesta perspectiva, a presente pesquisa configura-se inicialmente de cunho exploratório (Figura 1) que consiste em estudar uma questão ou um assunto sobre um território que ainda foi pouco analisada(o). Ela permite a descoberta de um meio, de uma região, ou de um problema com objetivo de explorar os contornos e de lançar as bases de trabalho para estudos posteriores. Ela se define como uma primeira pesquisa, o desbravamento de uma questão, um começo de estudo a fim de assegurar um ponto de referência, um reconhecimento diante do conhecimento (Brunet et al, 1992, p.205 apud Gumuchian e Marois, 2000, p. 181).

Esta modalidade de pesquisa encontra evidências nas características do fenômeno a fim de propor uma teorização ou ao menos novas hipóteses ou pistas de pesquisa. A pesquisa exploratória impõe os recursos da descrição. Ela necessariamente é útil para colocar os vários problemas, de definir os contornos de um problema 
particular e de sugerir novas orientações para a pesquisa. Frequentemente a pesquisa exploratória é de percurso indutivo, ou seja, um que leva a generalizações, além de descrever ou até mesmo explicar em certa medida (Gumuchian e Marois, 2000, p. 181).

Terreno, espaço geográfico (Observação)

Definição de um problema ou de um assunto

$\downarrow$

Formulação das hipóteses - a priori (antes)

$\downarrow$

Modelos operacionais (região de estudo, período de estudo, população alvo)

Coleta de dados: estratégia de coleta dos dados

Fontes Primárias $\quad$ Fontes Secundárias

$\downarrow$

Tratamento dos dados e cartografia (ou análise espacial exploratória)

(por exemplo: análise de componentes principais, classificação ou métodos tipológicos, etc.)

Análise e Interpretação dos Resultados

$\downarrow$

Descrição, formulação de novas hipóteses ou modelização

Figura 1- Fluxograma de uma pesquisa de cunho exploratório, segundo Gumuchian \& Marois (2000, p. 181).

Além disso, as contribuições dos estudos geográficos para a saúde pública são reforçadas quando estas são reconhecidas pelos tomadores de decisão das políticas públicas de saúde e do planejamento tendo em vista a promoção da saúde. Nesta perspectiva, podemos dar ênfase à avaliação das desigualdades geográficas no acesso 
aos serviços de saúde enquanto condicionadores da sua utilização, potencializando situações e comportamentos de maior ou menor risco para a saúde das populações.

Fizemos uma análise descritiva das condições sócio-demográficas e de saúde das mães dos nascidos prematuros do estado de São Paulo entre 2002 e 2007.

Entre os anos de 2002 e 2007, calculamos os riscos relativos da prematuridade infantil, padronizando pela faixa etária das mães, pelos nascimentos de acordo com tipo de parto (cesariana ou normal), pela escolaridade das mães, e pelo número de consultas pré-natal na escala do estado de São Paulo.Em seguida, verificamos a ocorrência de agrupamentos espaciais (clusters de alto e baixo risco) dos riscos relativos da prematuridade infantil e elaboramos os mapas temáticos dos riscos e agrupamentos espaciais associados à prematuridade infantil, de acordo com a mesma padronização. Os resultados preliminares dessas análises estão descritos a seguir.

É necessário destacar que os testes de varredura espacial considerando até $5 \%$ da população em risco não incluem o município de São Paulo devido à sua enorme população. Assim, para avaliação da distribuição espacial da prematuridade que inclua o município de São Paulo, aplica-use o teste nas escalas geográficas: metropolitana e intra-municipal.

Desenvolvemos uma análise de Associação espacial dos riscos relativos de nascimentos pré-termo com as variáveis do contexto geográfico (Taxa de Desemprego, Índice de Gini, Taxa de Analfabetismo, Porcentagem de Assentamentos Precários e Índice de Privação Sócio-Material) em que mães estão inseridas. E por fim, aplicamos testes de regressão pelos métodos OLS e GWR.

Para a Região Metropolitana de São Paulo (RMSP), estendemos a análise para o período de 2000 a 2010. Calculamos os riscos relativos de nascimentos pré-termo para RMSP, padronizada pela faixa-etária das mães e fizemos uma Análise de associação 
espacial entre variáveis socioeconômicas (Taxa de Desemprego, Índice de Gini, Taxa de Analfabetismo, Porcentagem de Assentamentos Precários e Índice de Privação SócioMaterial) e os nascimentos pré-termo.

Para o município de São Paulo, calculamos os riscos relativos dos nascimentos pré-temo para os anos de 2003 a 2007, 2008 a 2012 e 2003 a 2012. Por fim, realizamos uma Análise espacial exploratória retrospectiva do padrão espacial dos riscos relativos de nascimentos pré-termo para os três períodos citados.

Também elaboramos os mapas temáticos dos riscos relativos e dos agrupamentos espaciais associados à prematuridade infantil de acordo com a faixa-etária das mães tanto para a RMSP como para o município de São Paulo.

\section{2 Áreas de estudo}

\subsubsection{Estado de São Paulo}

O Estado de São Paulo subdivide-se em 645 municípios, distribuídos em 42 regiões de governo, 14 regiões administrativas e quatro regiões metropolitanas: de São Paulo, da Baixada Santista (que tem a conformação espacial da RA de Santos) e de Campinas (contida na RA do mesmo nome) e do Vale do Paraíba e Litoral Norte; (SEADE, 2010a) (Figura 2). 


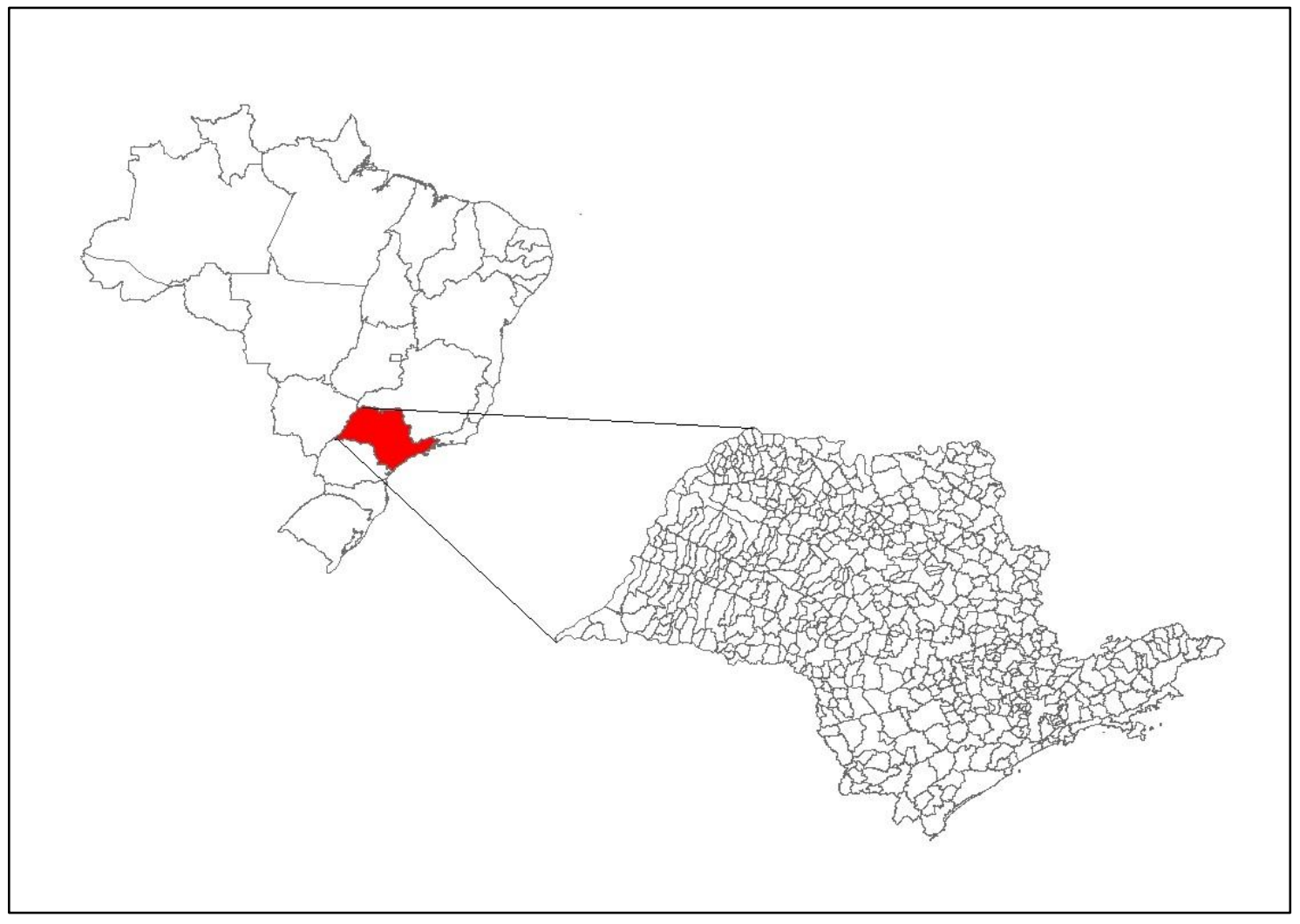

Figura 2 - Localização do estado de São Paulo no território brasileiro

A Região Metropolitana de São Paulo (RMSP) agrega 39 municípios onde convivem aproximadamente 20 milhões de pessoas em uma área urbanizada de 2.139 $\mathrm{km}^{2}$ (IBGE, 2006). Em termos espaciais, é praticamente o mesmo que incorporar, em quarenta anos, uma cidade do porte de Piracicaba (EMPLASA, 2010). Ela mantém o papel de liderança em termos econômicos e de concentração populacional, respondendo em 2005 por $47,9 \%$ da população paulista. As regiões com maior concentração da população também se caracterizam pela maior densidade demográfica. Os contrastes regionais em relação a esse indicador mostram-se bastante pronunciados, oscilando de 2.376,2 hab. $/ \mathrm{km}^{2}$, na RM de São Paulo, até um valor mínimo de 23,6 hab./km², na RA de Registro (SEADE, 2010a). 


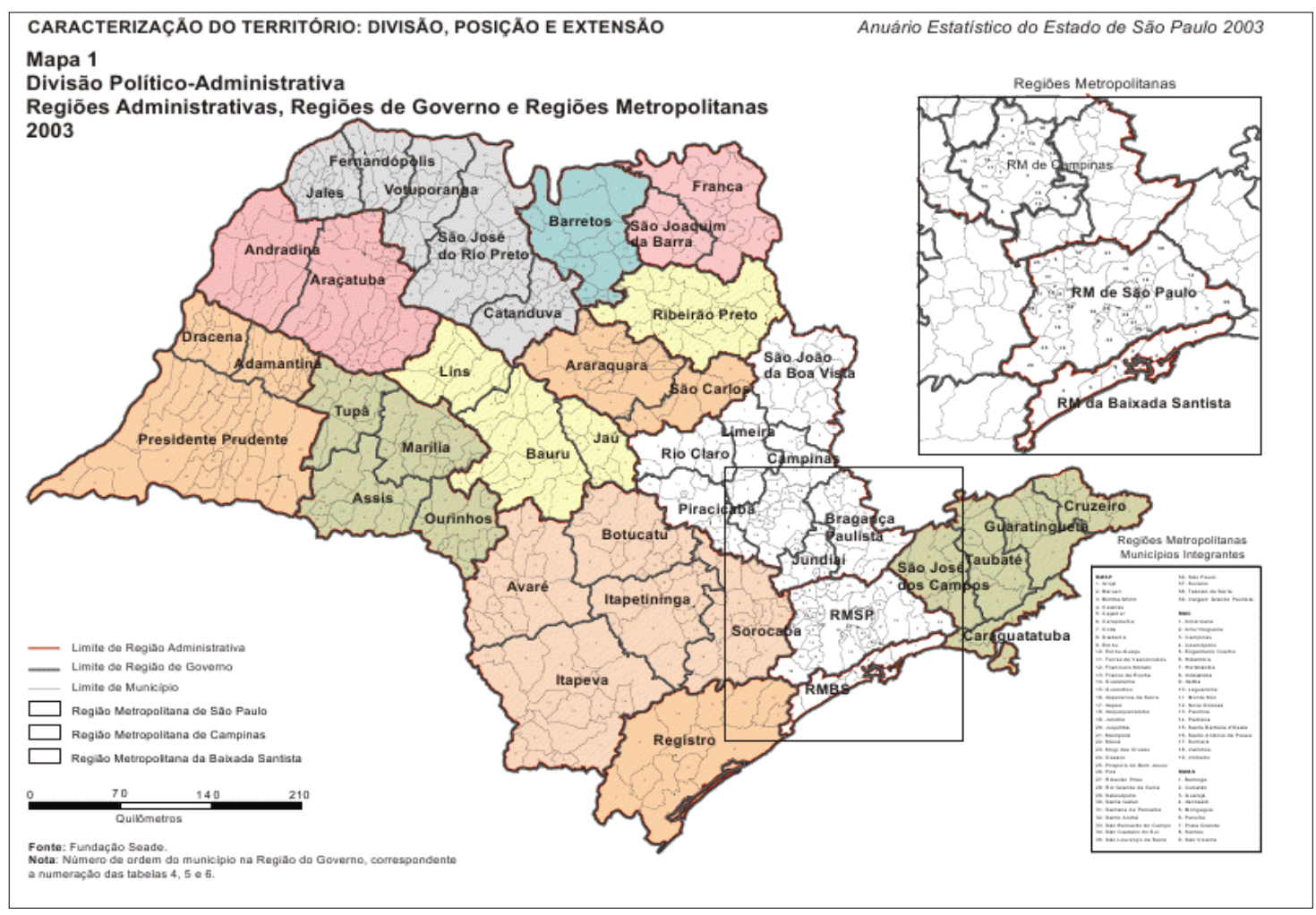

Figura 3- Mapa da Divisão Político Administrativa por Regiões Administrativas, Regiões de Governo e Regiões Metropolitanas do estado de São Paulo, Fundação SEADE (2003).

Utilizamos o mapa da Divisão Político-Administrativa, segundo Regiões Administrativas, Regiões de Governo e Regiões Metropolitanas do Anuário Estatístico do estado de São Paulo da Fundação SEADE (2003) - (Figura 3) para avaliação dos resultados obtidos.

\subsubsection{Região Metropolitana de São Paulo (RMSP)}

A Região Metropolitana de São Paulo é composta por 39 municípios, incluindo o município de São Paulo (Figura 4). De acordo com os dados do último censo de 2010, a população total registrou 19,7 milhões de habitantes, o que significa que aproximadamente um em cada 10 brasileiros mora nesta metrópole paulista. Tal contingente é cerca de $72 \%$ superior ao da Região Metropolitana do Rio de Janeiro, a segunda do País, com 11,8 milhões de pessoas (EMPLASA, 2013). 


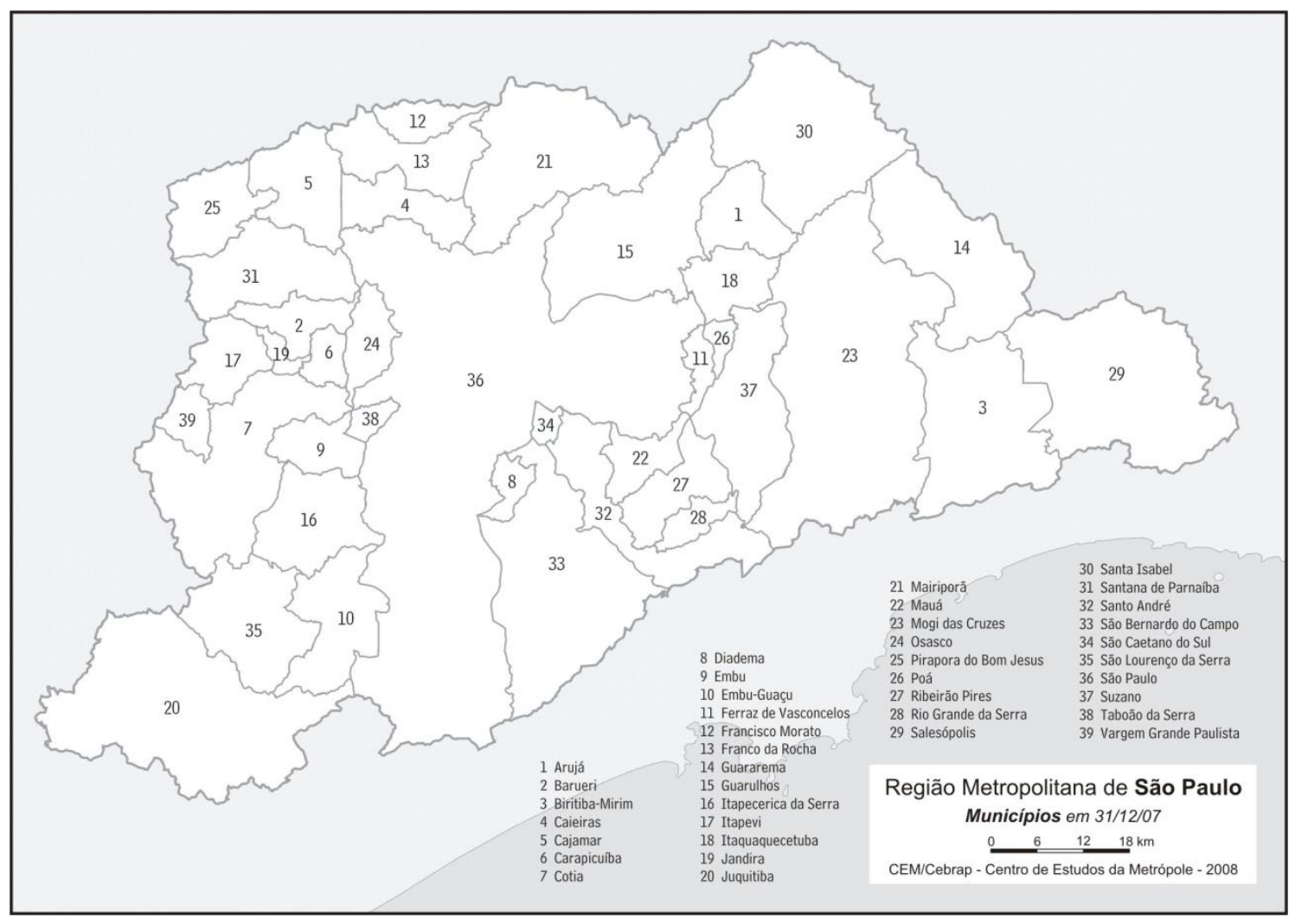

Figura 4 - Mapa da Divisão Político-administrativa dos municípios da Região Metropolitana de São Paulo, Fonte: CEM/Cebrap, 2006.

\subsubsection{Município de São Paulo (MSP)}

De acordo com o último Censo de 2010, o município de São Paulo apresenta uma população residente de 11.253 .503 pessoas. Para fins administrativos do poder público municipal, é divido em 96 distritos administrativos e 5 grandes regiões, conforme exposto na Figura 5. 


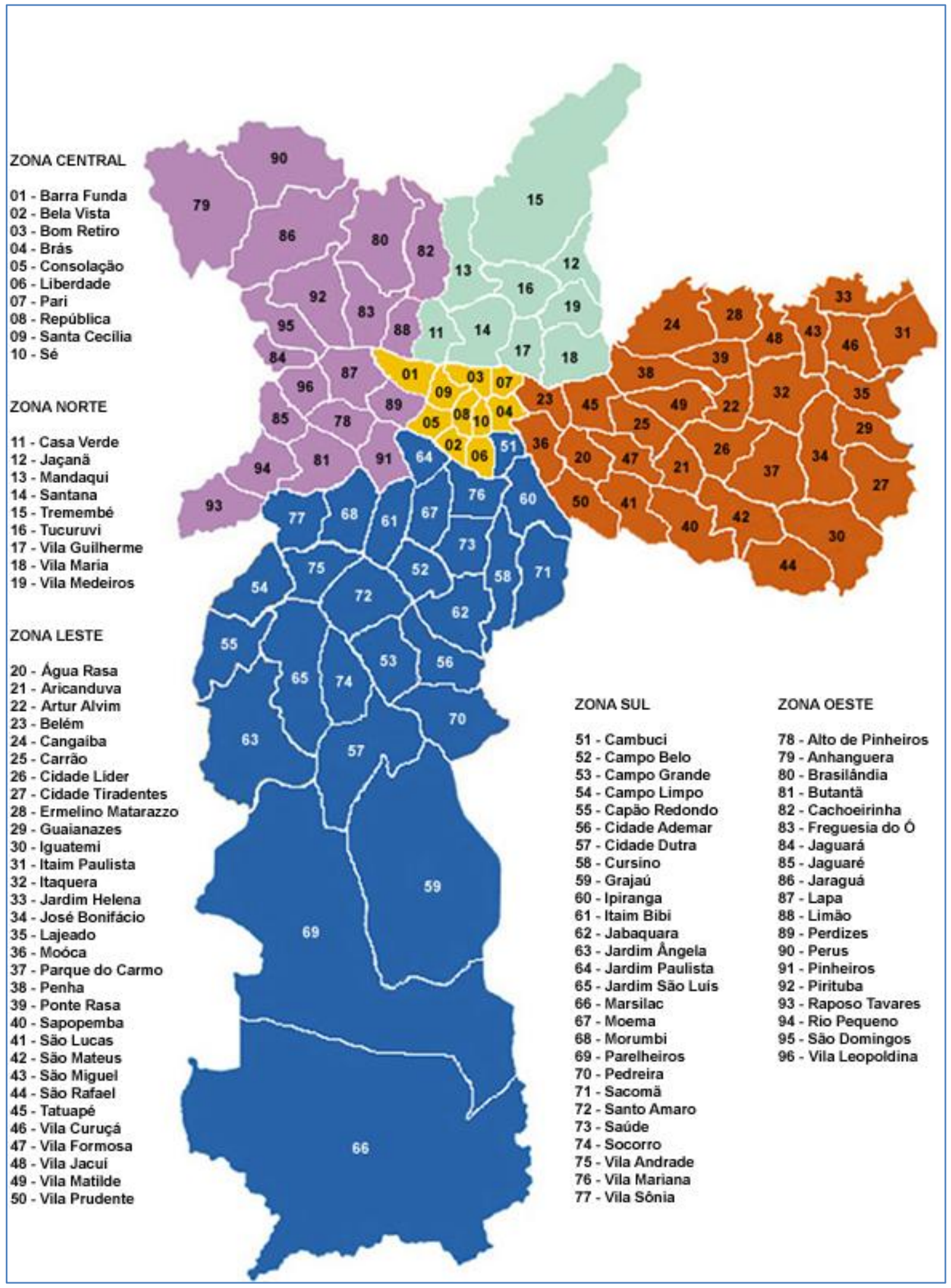

Figura 5 - Mapa da Divisão Administrativa dos 96 distritos do município de São Paulo. 


\subsection{MATERIAIS E PROCEDIMENTOS TÉCNICO-OPERACIONAIS}

\subsubsection{Base cartográfica}

Para o desenvolvimento dos Mapas Temáticos:

Utilizamos as Bases Cartográficas do Centro de Estudos da Metrópole (CEM): do Estado de São Paulo; da Região Metropolitana de São Paulo e do município de São Paulo;

\subsubsection{Dados epidemiológicos, demográficos e socioeconômicos}

Atualmente, com a implantação do Sistema de Informações sobre Nascidos Vivos (SINASC)3 no Brasil, coletamos os seguintes dados de importância epidemiológica, demográficas e socioeconômicas:

$\checkmark$ Número total de Nascidos Vivos;

$\checkmark$ Número total de mulheres em idade reprodutiva (entre 10 e 49 anos);

$\checkmark \quad$ Número total de mulheres grávidas entre 20 e 34 anos, gravidez precoce (10 a 19 anos) e gravidez tardia (acima de 35 anos);

$\checkmark$ Número total de nascidos vivos prematuros de mães entre 20 e 34 anos, entre 10 e 19 anos e acima de 35 anos

$\checkmark$ Número total de nascidos vivos de acordo com a instrução (escolaridade) das mães: nenhuma, 1 a 3 anos ou mais, de 4 a 7 anos, 8 a 11 anos e 12 anos ou mais;

3 O SINASC é um subsistema de informações de âmbito nacional, sob responsabilidade das Secretarias Estaduais e Municipais de Saúde, concebido para diminuir a subenumeração e melhorar a qualidade da informação sobre nascidos vivos. Este sistema é alimentado pelas declarações de nascido vivo (DN), documento oficial emitido pelo hospital onde ocorre o nascimento. Avaliação do Sinasc no Estado de São Paulo demonstrou uma excelente cobertura $(99,5 \%)$ e boa fidedignidade para quase todas as variáveis, exceto o índice de Apgar e o nível de instrução da mãe (MELLO JORGE et al., 1993). 
$\checkmark$ Número total de nascidos prematuros de acordo com a instrução (escolaridade) das mães: nenhuma, 1 a 3 anos ou mais, de 4 a 7 anos, 8 a 11 anos e 12 anos ou mais;

$\checkmark$ Número total de nascidos vivos de acordo com o tipo de parto natural e cesariana.

$\checkmark$ Número total de nascidos vivos prematuros em decorrência de acordo com o tipo de parto natural e cesariana.

\subsubsection{Dados de Atendimento destinados a Saúde Materna e Infantil}

Para avaliarmos as condições de atendimento dos serviços de saúde destinados às mães e aos recém-nascidos, coletamos junto à base do SINASC:

$\checkmark$ Número total de nascidos vivos de acordo com o número de consultas pré-natal: acima de 7 consultas e abaixo de 7 consultas;

$\checkmark$ Número total de nascidos prematuros de acordo com o número de consultas prénatal: acima de 7 consultas e abaixo de 7 consultas;

\subsubsection{Dados de equipamentos de saúde relacionados à Saúde Materna e Infantil}

A partir da base do sistema de Cadastro Nacional dos Estabelecimentos de Saúde (CNES) do Ministério da Saúde, levantamos o número absoluto de Unidades de Tratamento Intensivo neonatais e fizemos o cálculo do número de UTIs neonatais por 1000 nascidos, tendo como referência o ano de 2007. 


\subsection{FORMA DE ANÁLISE DOS DADOS}

\subsubsection{Análise dos dados epidemiológicos}

Geramos histogramas sobre a distribuição da prematuridade: prematuridade por ano e por faixa etária, escolaridade ou instrução das mães, tipo de parto (normal e cesariana), tipo de gestação (única, gemelar, tripla ou mais) e de acordo com estado civil das mães para o estado de São Paulo entre 2002 e 2007.

\subsubsection{Cálculo dos riscos relativos de prematuridade infantil}

Calculamos os riscos relativos de prematuridade por unidade de escala e ano.

Utilizamos o Programa SatScan v.8.0 (KULLDORFF, 2010) para calcularmos os riscos relativos de nascimentos pré-termo, tendo como co-variável a faixa-etária das mães. O Risco Relativo é o risco estimado dentro de um agrupamento dividido pelo risco estimado fora do agrupamento. Ele é calculado como os casos observados dividido pelos casos esperados dentro do agrupamento dividido pelos casos observados dividido pelos casos esperados fora do agrupamento. Em notação matemática:

$$
R R=\frac{c / E[c]}{(C-c) /(E[C]-E[c])}=\frac{c / E[c]}{(C-c) /(C-E[c])}
$$

$\mathrm{c}=$ é o número de casos observados dentro do agrupamento

$\mathrm{C}=$ é o total de número de casos no conjunto de dados $\mathrm{E}[\mathrm{C}]=\mathrm{C}$; sendo que a análise é condicionada a um número total de casos observados.

Empregamos o modelo discreto de Poisson para o cálculo do risco relativo de prematuridade, usando a co-variável idade da mãe.

O programa foi ajustado para encontrar janelas que incluíssem até 10 e até $50 \%$ da população em risco. A significância estatística foi testada para 999 interações, sendo 
considerados significativos os agrupamentos espaciais com valor de $\mathrm{p}<0,05$, para $\mathrm{o}$ agrupamento mais provável e de $\mathrm{p}<0,02$, para os agrupamentos secundários.

\subsubsection{Análise de varredura espacial para detecção de agrupamentos espaciais}

Aplicamos testes estatísticos para identificação de agrupamentos espaciais, por meio do programa SatScan versão 9.1 (KULLDORFF, INFORMATION MANEGEMENT SERVICES, 2010) para o cálculo dos riscos relativos de:

1) Prematuridade infantil, padronizada pela idade das mães = população de Nascidos Prematuros em relação aos Nascidos Vivos de mães (soma de todas as idades);

2) Prematuridade, padronizada pela escolaridade ou instrução das gestantes = população de Nascidos Vivos Prematuros em relação aos Nascidos Vivos das mães sem nenhuma instrução, 1 a 3 anos de instrução, 4 a 7 anos de instrução, 8 a 11 anos e 12 anos ou mais de instrução;

3) Prematuridade infantil, padronizada pelo número de consultas pré-natal realizadas pelas gestantes $=$ população de Nascidos Vivos Prematuros em relação aos Nascidos Vivos de gestantes que realizaram mais de sete consultas e menos de 7 consultas pré-natal;

4) Prematuridade infantil, padronizada pelo número de mães que realizaram partos cesáreos = população de Nascidos Prematuros em relação aos Nascidos Vivos de gestantes que realizaram partos cesáreos;

5) Prematuridade infantil, padronizada pelo número de mães que realizaram partos normais $=$ população de Nascidos Prematuros em relação aos Nascidos Vivos de gestantes que realizaram partos normais;

Utilizamos a técnica estatística de varredura espacial para identificar agrupamentos dos municípios que tiveram risco alto e baixo para cada um destes 
desfechos, por meio do programa SatScan versão 9.1 (KULLDORFF, INFORMATION MANEGEMENT SERVICES, 2010).

Este teste tem sido aplicado pelo Center for Disease Control (CDC) de Atlanta para identificar agrupamentos significativos de doenças. A estatística de varredura espacial coloca uma janela circular de tamanhos variáveis na superfície do mapa e permite que seu centro se mova de forma que, para uma dada posição e tamanho, a janela inclua um conjunto diferente de vizinhos próximos. Se a janela incluir o centróide de um vizinho, então, toda área do município é considerada inclusa. Como a janela se move passando por todos os centróides, seu raio varia continuamente de zero ao raio máximo, que nunca inclui mais do que $50 \%$ da população total (KULLDORFF, INFORMATION MANEGEMENT SERVICES, 2010).

Utilizamos o valor de $5 \%$ da população para permitir a identificação de agrupamentos pequenos e de $50 \%$ da população para detecção de agrupamentos maiores.

\subsubsection{Análise de associação espacial dos riscos relativos de nascimentos pré-termo com as variáveis socioeconômicas}

Em seguida, desenvolvemos uma análise de associação espacial dos riscos relativos de nascimentos pré-termo com as variáveis socioeconômicas.

Para isso, coletamos do site do DATASUS, no item informações demográficas e socioeconômicas as seguintes variáveis socioeconômicas:

- Taxa de Desemprego (TD): representa o percentual da população de 16 anos e mais, economicamente ativa, desocupada.

- Taxa de Analfabetismo (TA): consideram-se como analfabetas as pessoas maiores de 15 anos que declararam não serem capazes de ler e escrever ou que aprenderam a ler e escrever, mas esqueceram, e as que apenas assinavam o próprio 
nome. As pessoas capazes de ler e escrever um bilhete simples no idioma que conhecem são consideradas alfabetizadas.

- Porcentagem de Aglomerados Subnormais ou Assentamentos Precários (BA): são assentamentos irregulares conhecidos como favelas, invasões, grotas, baixadas, comunidades, vilas, ressacas, mocambos, palafitas, entre outros.

- O Índice de privação sócio-material (IP) a privação sociomaterial foi avaliada através de um indicador composto, que é resultado da soma da padronização de três indicadores socioeconômicos do Censo 2010 do IBGE: a) Taxa de desemprego, b) Taxa de analfabetismo e 3) Porcentagem de assentamentos precários). Ele pode variar entre < 0 >, quanto mais negativo, melhores são as condições socioeconômicas e quanto mais positivo, piores. Ou quanto mais próximo de zero, menos díspares, ou seja, traduz-se em valores positivos, representativos de áreas com privação alta, e negativos, representativos de áreas com privação baixa. (CARSTAIRS et al, 1991; SALCEDO, 2012; SANTANA et. al, 2014).

Utilizamos o programa GeoDa 1.0.1. (October 20, 2011) para os testes de padrão e associação espacial entre os riscos relativos e as variáveis socioeconômicas. Empregamos o Índice de Moran (I) e o Local Indicator for Spatial Autocorrelation (LISA) (CÂMARA, 2001). O Índice de Moran (I) mede a autocorrelação espacial a partir do produto dos desvios em relação à média e é calculado por:

$$
\mathrm{I}=\frac{n \sum w i j(z i-\bar{z})(z j-\bar{z})}{S 0 \sum i(z i-\bar{z}) 2} \quad \text { onde: } S 0=\Sigma i \neq j w i j
$$

$\mathrm{n}=\mathrm{n}^{\circ}$ de áreas;

$\mathrm{zi}=$ valor da variável considerada na área "ii";

$\mathrm{z}=$ valor médio da variável na região de estudo;

wij = elementos da matriz de vizinhança;

$\mathrm{zj}=$ valor da variável considerada na área “ $\mathrm{j}$ ”; 
O I de Moran avalia a autocorrelação espacial das variáveis " $z$ " de interesse para o estudo em diferentes áreas i e j, (zi, zj), ponderada pela proximidade geográfica medida por wij (Matriz de Vizinhança), onde o numerador evidencia a média dos produtos dos desvios das áreas i e j em relação à média global, e o denominador é uma medida de variabilidade dos desvios. Os valores de I de Moran correspondem ao declive da reta de regressão e, à semelhança de um coeficiente de correlação linear, normalmente variam entre 1 e -1 , ou seja:

O I é positivo quando existe dependência espacial, com os valores das áreas vizinhas evidenciando similaridade entre si. Sendo o valor 1 atribuído a uma autocorrelação positiva perfeita. O I é negativo quando existe dependência espacial, mas os valores das áreas vizinhas são dissemelhantes. Sendo o valor -1 atribuído a uma autocorrelação negativa perfeita;

Testamos o uso de uma matriz de vizinhança de primeira ordem com qualquer contiguidade (modo“queen”) (ANSELIN, 2005). Para análise dos resultados, comparamos os valores de I de Moran e a significância dos testes. Utilizamos a Base Cartográfica do Centro de Estudos da Metrópole (CEM): do Estado de São Paulo e o programa ArcGis 9.3 para a confecção dos mapas temáticos.

Usamos o método coroplético para representação cartográfica, na qual os valores abaixo de 1 estão em tons de azul (número de casos observados menor do que os esperados) e acima de 1, em tons de vermelho (número de casos observados maior do que o de casos esperados).

\subsubsection{Teste de regressão pelos métodos OLS e GWR}

Aplicamos o teste de regressão dos Mínimos Quadrados Ordinários (OLS) para verificar se a privação sociomateiral, a porcentagem de partos cesáreos, a porcentagem 
de consultas pré-natal acima de 7 e número de UTIs neonatais explicariam a distribuição geográfica dos riscos relativos de nascimentos pré-termo no estado de São Paulo no contex to global.

O teste Ordinary Least Squares (OLS) do Programa ArcGis 9.3 pode estimar os parâmetros desconhecidos de um modelo de regressão linear. Este método minimiza a soma dos quadrados das distâncias verticais entre valores observados e os previstos pelo modelo linear (HAYASHI, 2000).

A variável dependente foi o risco relativo de nascimento pré-termo no estado de São Paulo entre os anos 2002 a 2007, enquanto que as variáveis dependentes foram o Índice de Privação Sócio Material, Porcentagem de Partos Cesáreos e Porcentagem de Consultas pré-natal acima de 7, número de UTIs neonatais por 1000 nascidos vivos. Foi feito teste de correlação entre as variáveis independentes, verificando-se que não houve colinearidade entre elas.

O teste de normalidade mostrou ser necessária a transformação por log da variável dependente (risco relativo). Os resíduos da regressão foram testados para avaliar dependência espacial. Quando a dependência é significativa, é necessária a utilização de outro modelo para incluir o componente espacial. Nesse caso, aplicamos o Geographical Weighted Regression (GWR), que é um método de regressão espacial local. Este método assume que o espaço é heterogêneo e a relação entre as variáveis dependentes e independentes pode variar espacialmente, ou seja, assume padrões mais ou menos regionalizados. (Druck, 2002).

\subsubsection{Representação cartográfica}

Para análises de varredura espacial, elaboramos os mapas a partir do programa cartográfico ArcGis 9.3 e também utilizamos a técnica coroplética para a representação dos riscos relativos. Adotamos a técnica de discretização por quantis, definindo 
intervalos de 8 classes. Para a representação dos mapas da análise do GWR, também utilizamos a discretização por quantis, só que com intervalos de 5 classes.

Para os mapas da RMSP e do município de São Paulo, adotamos o intervalo de 5 classes.

Para a representação dos agrupamentos significativos, utilizamos a técnica corocromática. A cor vermelha indicou os agrupamentos altos e a azul, os baixos para todas as escalas.

\section{RESULTADOS}

7.1 Análise Epidemiológica descritiva das condições sócio-demográficas e de saúde das mães e dos nascidos prematuros do estado de São Paulo entre 2002 e 2007

Observamos um decréscimo do número total de nascidos vivos de 623.302 para 565.408. No entanto, houve um ligeiro aumento da porcentagem de nascimentos prematuros, que variou de $7,1 \%$ para $7,9 \%$ (Tabela 1 ).

Tabela 1 - Nascimentos por residência das mães por ano do nascimento segundo Unidade da Federação - estado de São Paulo.

\begin{tabular}{|c|c|c|c|c|c|c|}
\cline { 2 - 7 } \multicolumn{1}{c|}{} & $\mathbf{2 0 0 2}$ & $\mathbf{2 0 0 3}$ & $\mathbf{2 0 0 4}$ & $\mathbf{2 0 0 5}$ & $\mathbf{2 0 0 6}$ & $\mathbf{2 0 0 7}$ \\
\hline Prematuros & 44.177 & 44.744 & 46.852 & 48.004 & 47.234 & 47.026 \\
\hline $\begin{array}{c}\text { Total de Nascidos } \\
\text { Vivos }\end{array}$ & 623.302 & 610.555 & 618.080 & 618.880 & 603.368 & 595.408 \\
\hline \% de Prematuros & $\mathbf{7 , 1}$ & $\mathbf{7 , 3}$ & $\mathbf{7 , 6}$ & $\mathbf{7 , 8}$ & $\mathbf{7 , 8}$ & $\mathbf{7 , 9}$ \\
\hline
\end{tabular}

Fonte: MS/SVS/DASIS - Sistema de Informações sobre Nascidos Vivos - SINASC

Dentre os tipos de parto entre os nascimentos prematuros, houve uma queda da porcentagem de partos vaginais de $47,4 \%$ para $41 \%$. Em contrapartida, verificamos um aumento acentuado dos partos cesáreos de 52, 2\% para quase $60 \%$ (Tabela 2).

Tabela 2 - Número total e porcentagem de nascimentos prematuros por tipo de parto de 
2002 a 2007 no estado de São Paulo.

\begin{tabular}{|c|c|c|c|c|c|c|}
\cline { 2 - 7 } \multicolumn{1}{c|}{} & $\mathbf{2 0 0 2}$ & $\mathbf{2 0 0 3}$ & $\mathbf{2 0 0 4}$ & $\mathbf{2 0 0 5}$ & $\mathbf{2 0 0 6}$ & $\mathbf{2 0 0 7}$ \\
\hline TOTAL & 44.177 & 44.744 & 46.852 & 48.004 & 47.234 & 47.026 \\
\hline Vaginal & 20.919 & 20.410 & 20.894 & 20.538 & 19.874 & 19.287 \\
\hline Cesário & 23.077 & 24.094 & 25.921 & 27.380 & 27.265 & 27.671 \\
\hline Ignorado & 181 & 240 & 37 & 86 & 95 & 68 \\
\hline \% parto vaginal & $\mathbf{4 7 , 4}$ & $\mathbf{4 5 , 6}$ & $\mathbf{4 4 , 6}$ & $\mathbf{4 2 , 8}$ & $\mathbf{4 2 , 1}$ & $\mathbf{4 1 , 0}$ \\
\hline \% parto cesáreo & $\mathbf{5 2 , 2}$ & $\mathbf{5 3 , 8}$ & $\mathbf{5 5 , 3}$ & $\mathbf{5 7 , 0}$ & $\mathbf{5 7 , 7}$ & $\mathbf{5 8 , 8}$ \\
\hline
\end{tabular}

Fonte: MS/SVS/DASIS - Sistema de Informações sobre Nascidos Vivos - SINASC

Em relação ao total de nascidos vivos do estado de São Paulo de acordo com número de consultas pré-natal (Figura 6), notamos que a proporção de bebês prematuros decorrentes de mães que fizeram menos de 7 consultas pré-natal apresentou um aumento de $11 \%$ para $15 \%$ de 2002 para 2007. Ao mesmo tempo em que os nascidos prematuros de mães que realizaram mais de 7 consultas representaram apenas $5 \%$ dos casos, variando entre $4,9 \%$ a $5,6 \%$. Isso pode indicar que os bebês estão nascendo mais prematuros (com 6 meses de gestação, por exemplo, não dando tempo de fazerem as 7 consultas pré-natais). 


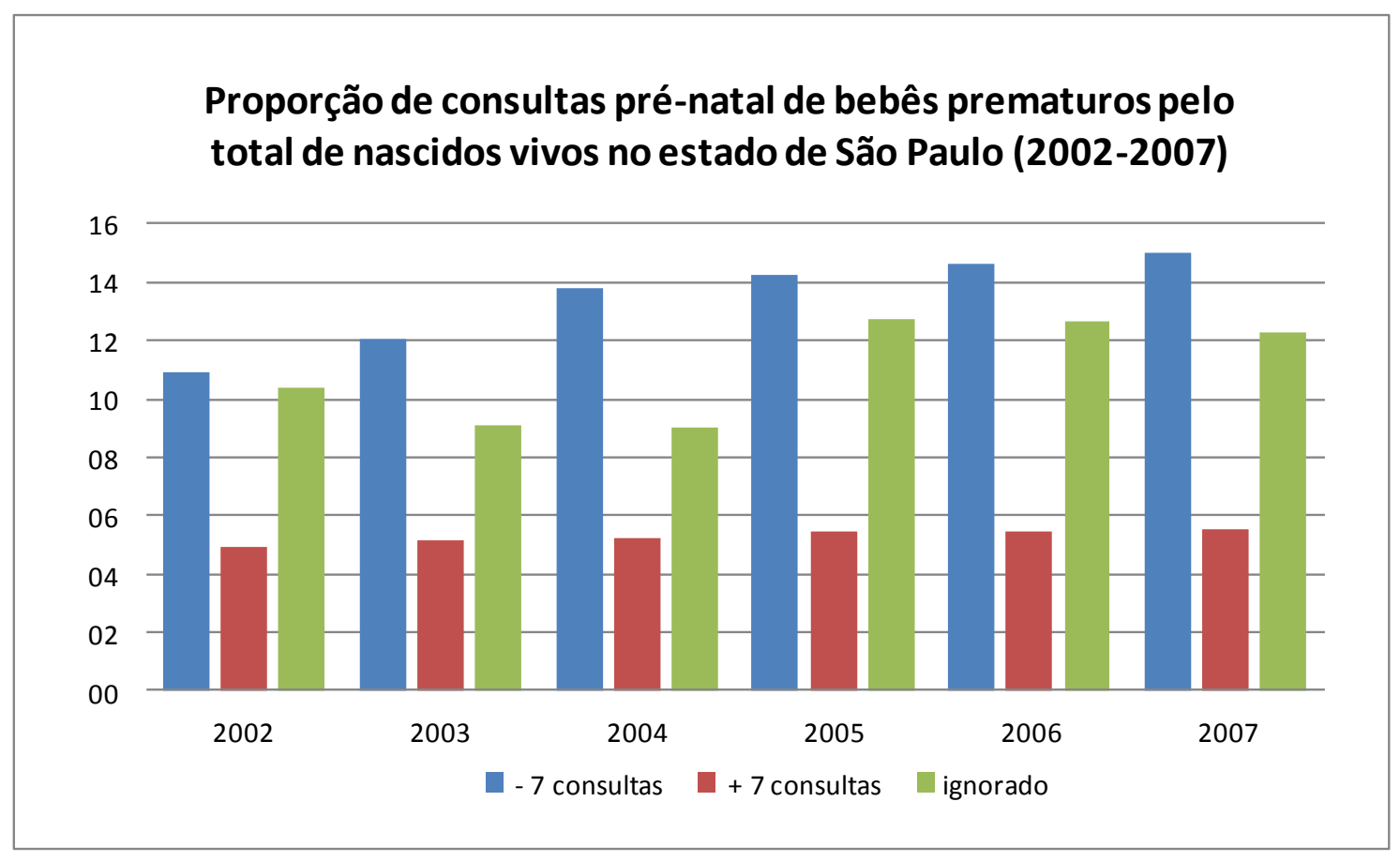

Figura 6 -Proporção de bebês prematuros pelo total de nascidos vivos no estado de São Paulo, de acordo com o número de consultas pré-natal durante os anos de 2002 a 2007.

(Fonte: MS/SVS/DASIS - Sistema de Informações sobre Nascidos Vivos - SINASC).

As informações ignoradas corresponderam entre $10,4 \%$ a $12,2 \%$ das informações sobre preenchimento de consultas pré-natal.

Em relação ao total de nascidos vivos do estado de São Paulo de acordo com a faixa-etária das mães (Figura 7), observamos que a proporção de bebês prematuros decorrentes de mães com mais de 35 anos (gravidez tardia) mostrou-se mais representativa durante o período estudado devido ao aumento de $10 \%(8,8 \%, 9,8)$. 


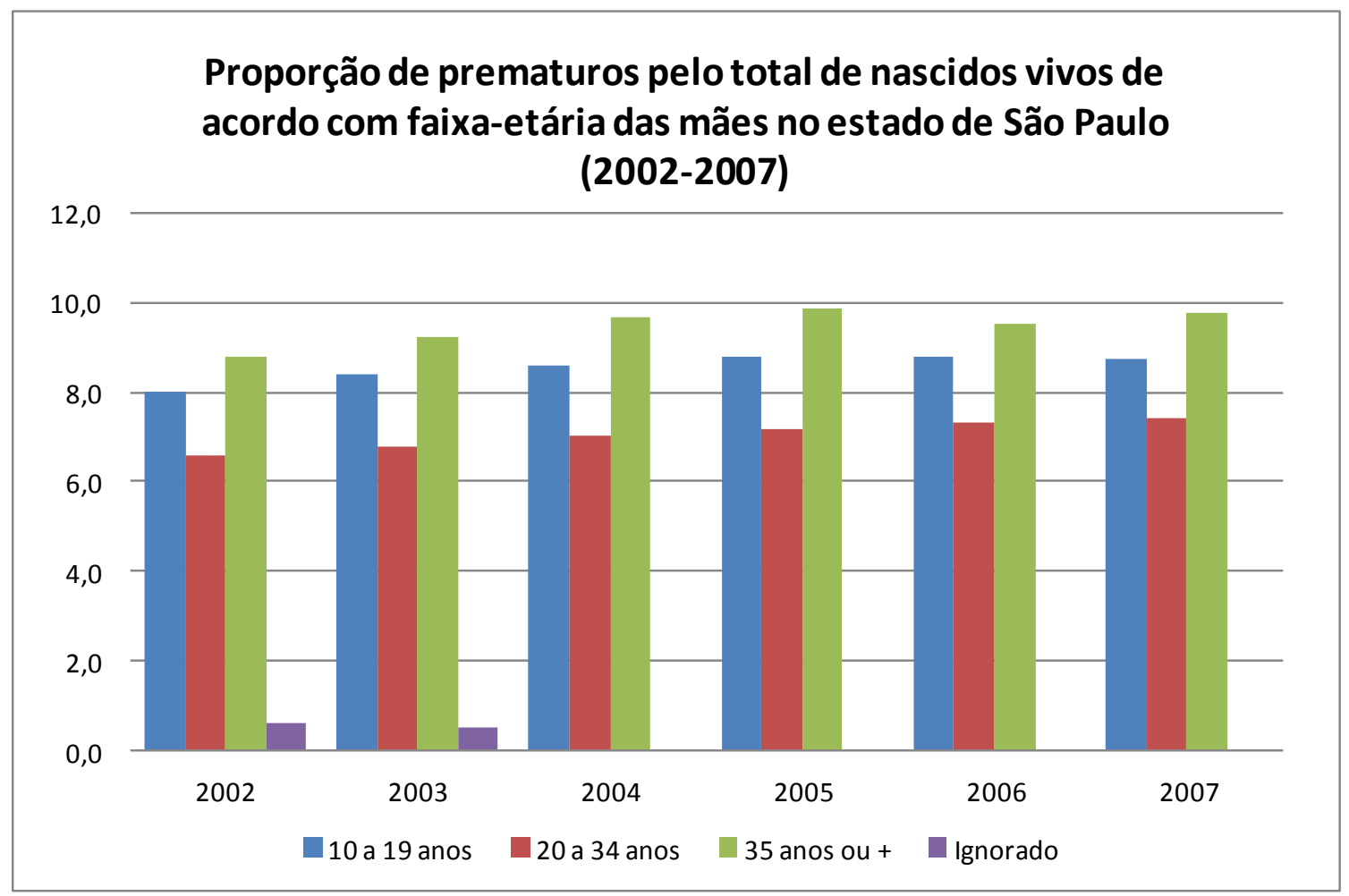

Figura 7- Proporção de bebês prematuros pelo total de nascidos vivos no estado de São Paulo, de acordo com a faixa-etária das mães durante os anos de 2002 a 2007.

(Fonte: MS/SVS/DASIS - Sistema de Informações sobre Nascidos Vivos - SINASC).

A faixa das mães entre 10 e 19 anos foi a segunda faixa etária mais importante, já que a porcentagem dos bebês prematuros oscilou de 8,0 para 8,8\%, entre 2002 e 2007. Já na faixa etária das mães entre 20 e 34 anos, a proporção de bebês prematuros variou entre $6,6 \%$ a 7,4\%, sendo a faixa-etária de menor risco individual das mães terem filhos prematuros.

As informações ignoradas corresponderam entre menos de $1 \%$ das informações sobre preenchimento da faixa etária das mães. As mães sem nenhuma instrução e as com 12 anos ou mais de instrução tiveram as maiores proporções de bebês prematuros, 6,9\% para 9\% e 7,3\% para 8,7\%, respectivamente entre 2002 e 2007 (Figura 8).

Já as mães entre 1 a 3 anos, de 4 a 7 anos e 8 a 11 anos de instrução apresentaram porcentagens semelhantes, oscilando entre 7 e $8 \%$ dos casos de bebês prematuros. 
As informações ignoradas apresentaram elevadas taxas entre 2002 e 2005 (8,8\%; 10,5), passando a decair substancialmente em 2006 e 2007 (2,9\%; 2\%).

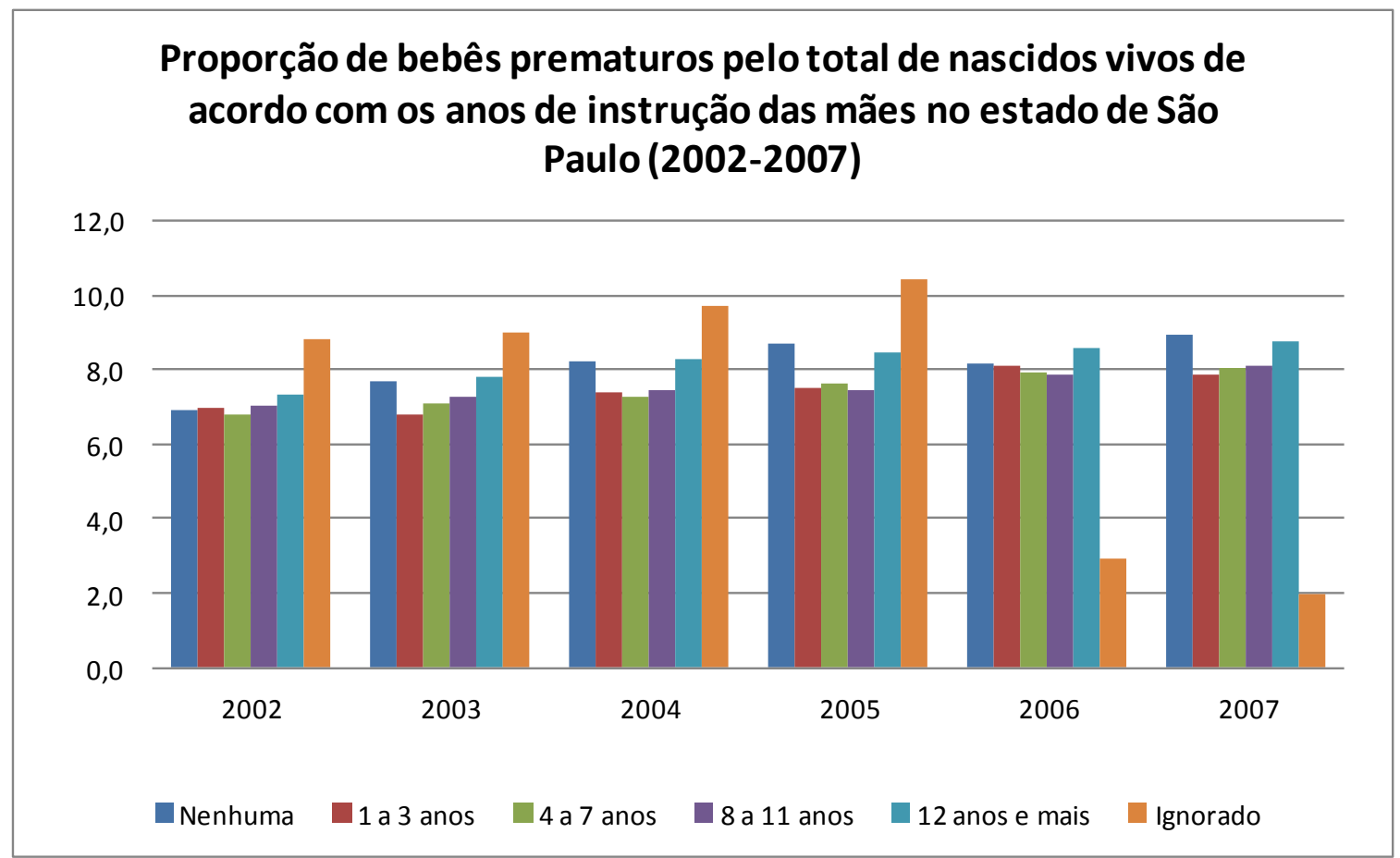

Figura 8- Proporção de bebês prematuros pelo total de nascidos vivos no estado de São Paulo, de acordo com os anos de instrução das mães durante os anos de 2002 a 2007. (Fonte: MS/SVS/DASIS - Sistema de Informações sobre Nascidos Vivos - SINASC).

A partir do ano de 2005 observamos que a proporção de nascidos prematuros em relação ao total de nascidos vivos de acordo com o estado civil das mães apresentou uma distinção maior entre as categorias (Figura 9). Entre as mães consideradas viúvas e separadas judicialmente, as incidências de prematuridade infantil mais elevadas do que nas outras categorias, apresentando $10,9 \%$ e 9,8\%, respectivamente em 2007. Já entre as mães solteiras os casos de prematuridade representam 8,3\% dos nascidos vivos, enquanto que entre as mães casadas $8,1 \%$. A incidência de prematuros entre as mães com união consensual chegaram a apenas $5,8 \%$ do total de nascidos vivos. 


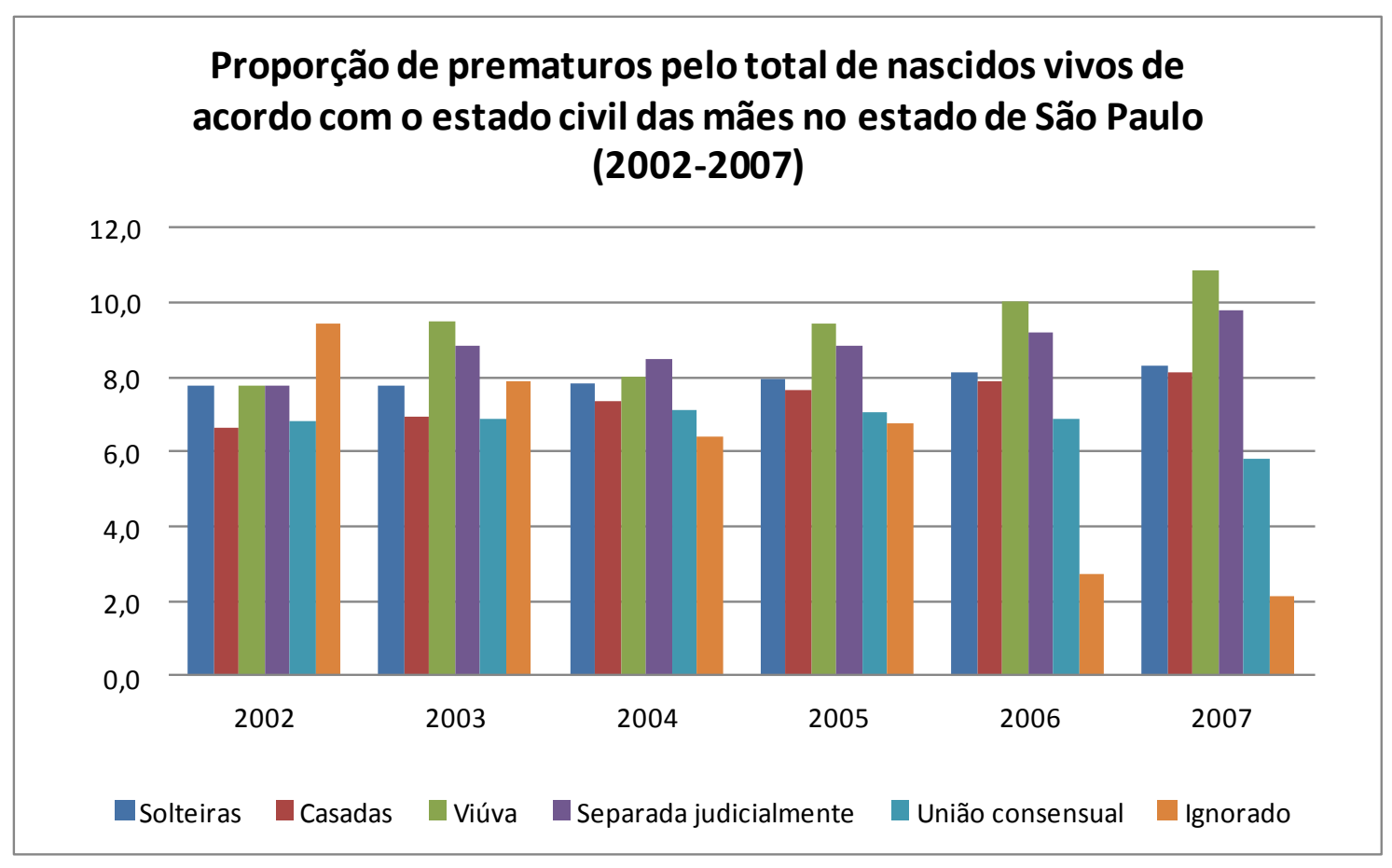

Figura 9 - Proporção de bebês prematuros pelo total de nascidos vivos no estado de São Paulo, de acordo com o estado civil das mães durante os anos de 2002 a 2007.

(Fonte: MS/SVS/DASIS - Sistema de Informações sobre Nascidos Vivos - SINASC).

A partir do total de nascidos vivos, a proporção de bebês prematuros em decorrência de gravidez do tipo tripla é a mais representativa, variando entre $87 \%$ e 90\% (Figura 10). A prematuridade em decorrência de gravidez do tipo dupla indicou entre $44 \%$ e $50 \%$ dos casos, enquanto que o tipo de gravidez única apenas entre $6 \%$ e $8 \%$ dos casos. Logo, as gestações do tipo dupla e tripla são comumente fatores de risco individual para prematuridade infantil.

As informações ignoradas apresentaram somente $2,7 \%$ do total. 


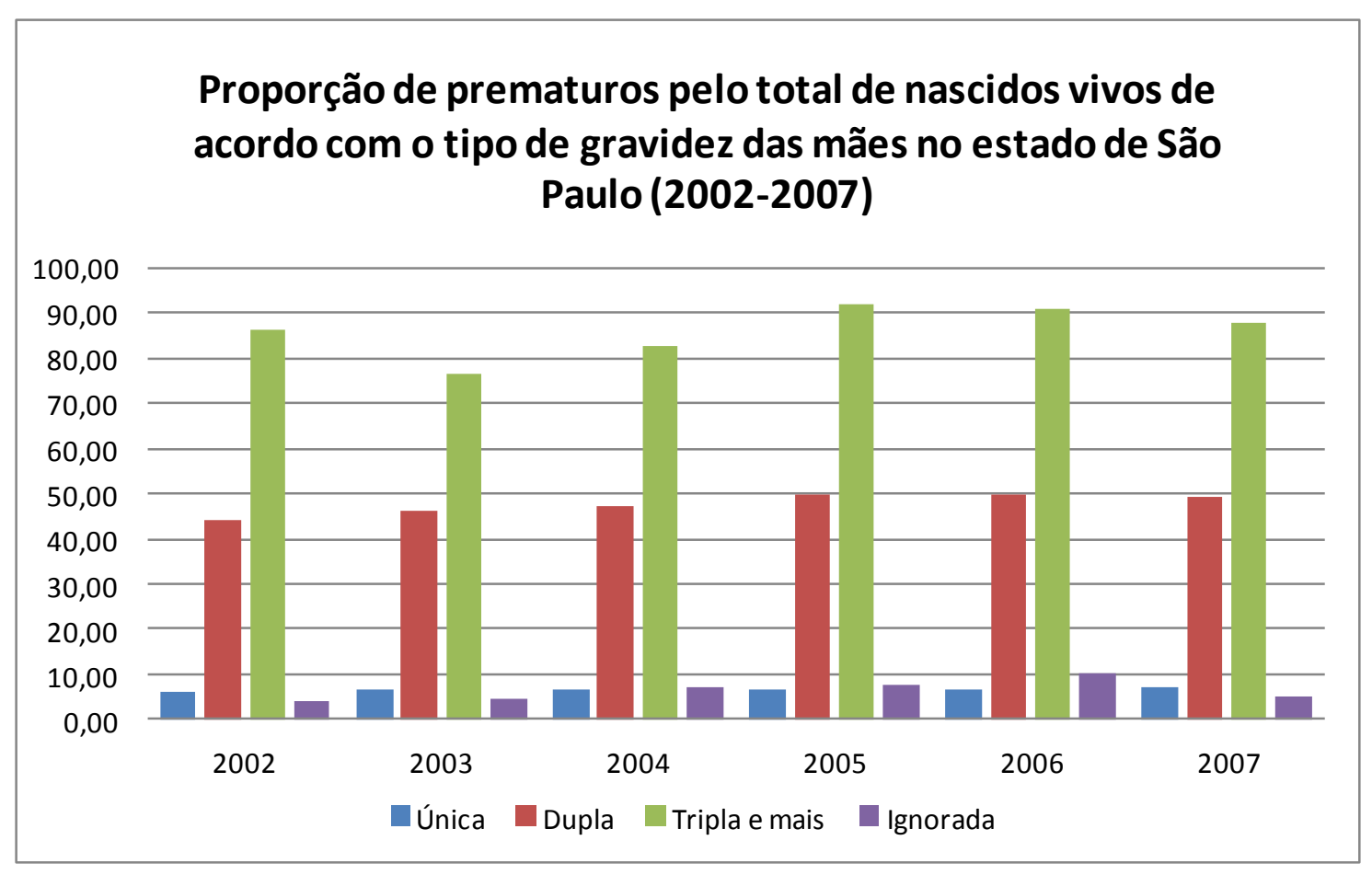

Figura 10- Proporção de bebês prematuros pelo total de nascidos vivos no estado de São Paulo, de acordo com o tipo de gravidez das mães durante os anos de 2002 a 2007.

(Fonte: MS/SVS/DASIS - Sistema de Informações sobre Nascidos Vivos - SINASC).

7.2 Análise espacial exploratória dos riscos relativos da prematuridade infantil em relação à idade e escolaridade das mães, ao atendimento pré-natal e ao tipo de parto (normal e cesarianas) no estado de São Paulo entre 2002 e 2007

Quando a idade das mães entrou como co-variável da prematuridade infantil, percebemos que o risco relativo variou entre 0,24 e 1,75 em todo o estado de São Paulo (Figura 11 - Mapa da esquerda). O município de Ribeirão dos Índios, próximo a Presidente Prudente (noroeste do estado), apresentou o menor risco de 0,24, enquanto que o município de Guaraçaí (também no noroeste do estado) apresentou o maior risco de 1,75 . 


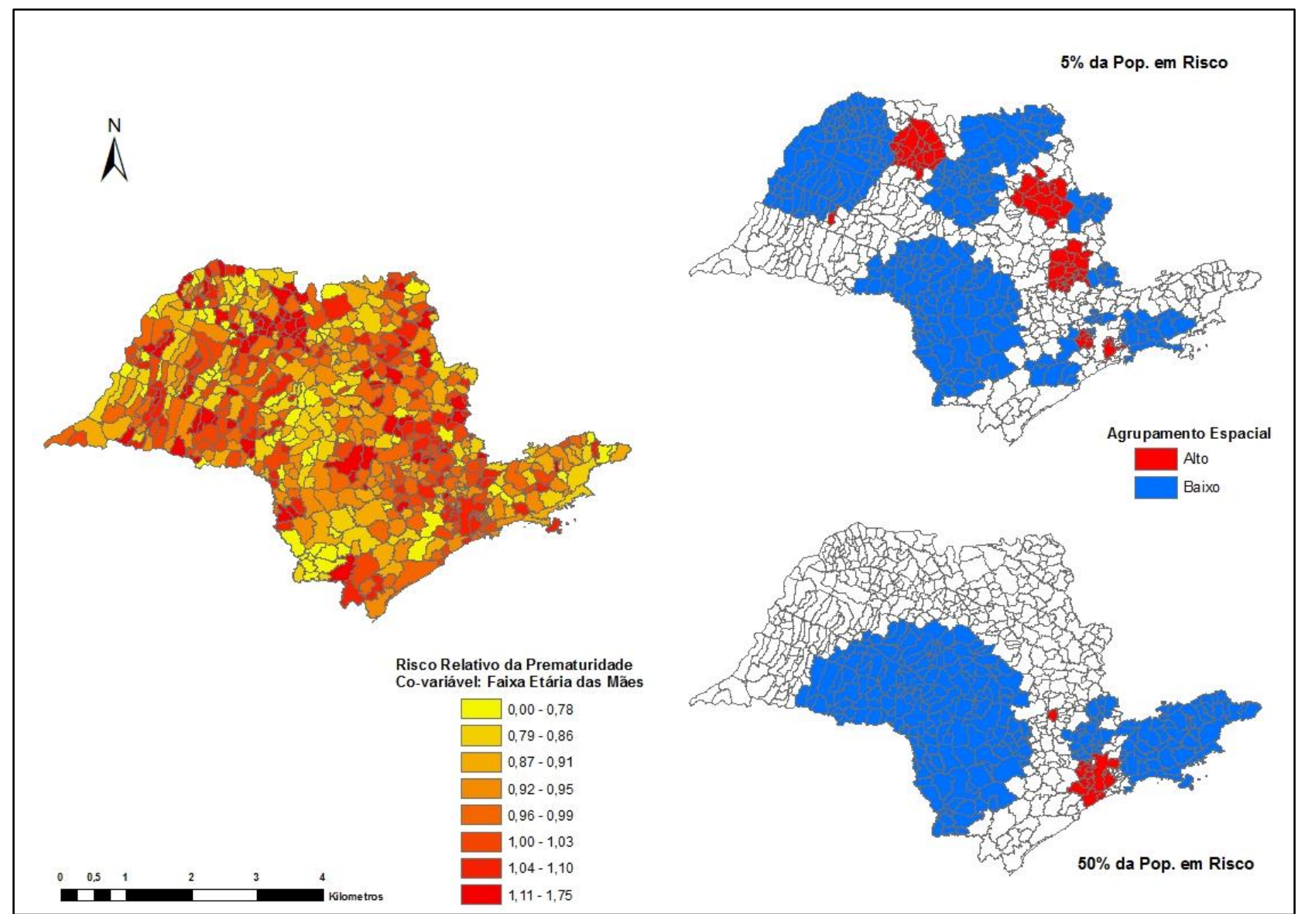

Figura 11 - Riscos Relativos da prematuridade infantil padronizado pela idade das mães no estado de São Paulo, entre 2002 e 2007 (Mapa da esquerda); e Agrupamentos significativos - 5\% da População em Risco (Mapa superior do canto direito) e 50\% da População em Risco (Mapa do canto inferior direito). 
Pela análise de 5\% da população em risco (Figura 11 - Mapa Superior direito), observamos dois grandes clusters de alto risco (representados em vermelho): um no município de São José do Rio Preto e nos seus municípios do entorno (mesorregião de São José do Rio Preto - no norte do estado), outro no município de Ribeirão Preto e adjacências (mesorregião de Ribeirão Preto - no nordeste do estado).

Também houve presença de cluster de alto risco entre os municípios da mesorregião de Campinas e Piracicaba (no sudeste do estado).

Na área metropolitana de São Paulo, os municípios de São Bernardo do Campo, Diadema, Arujá, Guarulhos, Vargem Grande Paulista, Cotia, Embu, Embu-Guaçu e Juquitiba formaram cluster de alto risco.

Já em relação à varredura espacial de $50 \%$ da população em risco (Figura 8 Mapa Inferior direito), notamos que os clusters alto apenas na Área Metropolitana de São Paulo, com a inclusão do município de São Paulo, além da presença dos municípios do ABDC e da Baixada Santista.

Em relação aos clusters de baixo risco (representados em azul), verificamos que, na varredura espacial de 5\%, eles aparecem mais dispersos pelo estado de São Paulo. No entanto, pela varredura espacial de $50 \%$, notamos que houve a formação de dois grandes clusters que abrangeram inúmeros municípios do centro, centro-sul, extremoleste do estado.

Quando a escolaridade das mães entrou como co-variável da prematuridade infantil, percebemos que o risco relativo variou entre 0,22 e 2 em todo o estado de São Paulo (Figura 12 - Mapa da esquerda). O município de Ribeirão dos Índios, próximo a Presidente Prudente (noroeste do estado), apresentou o menor risco de 0,22, enquanto que o município de Guaraçaí (também no noroeste do estado) apresentou o maior risco de 2. 


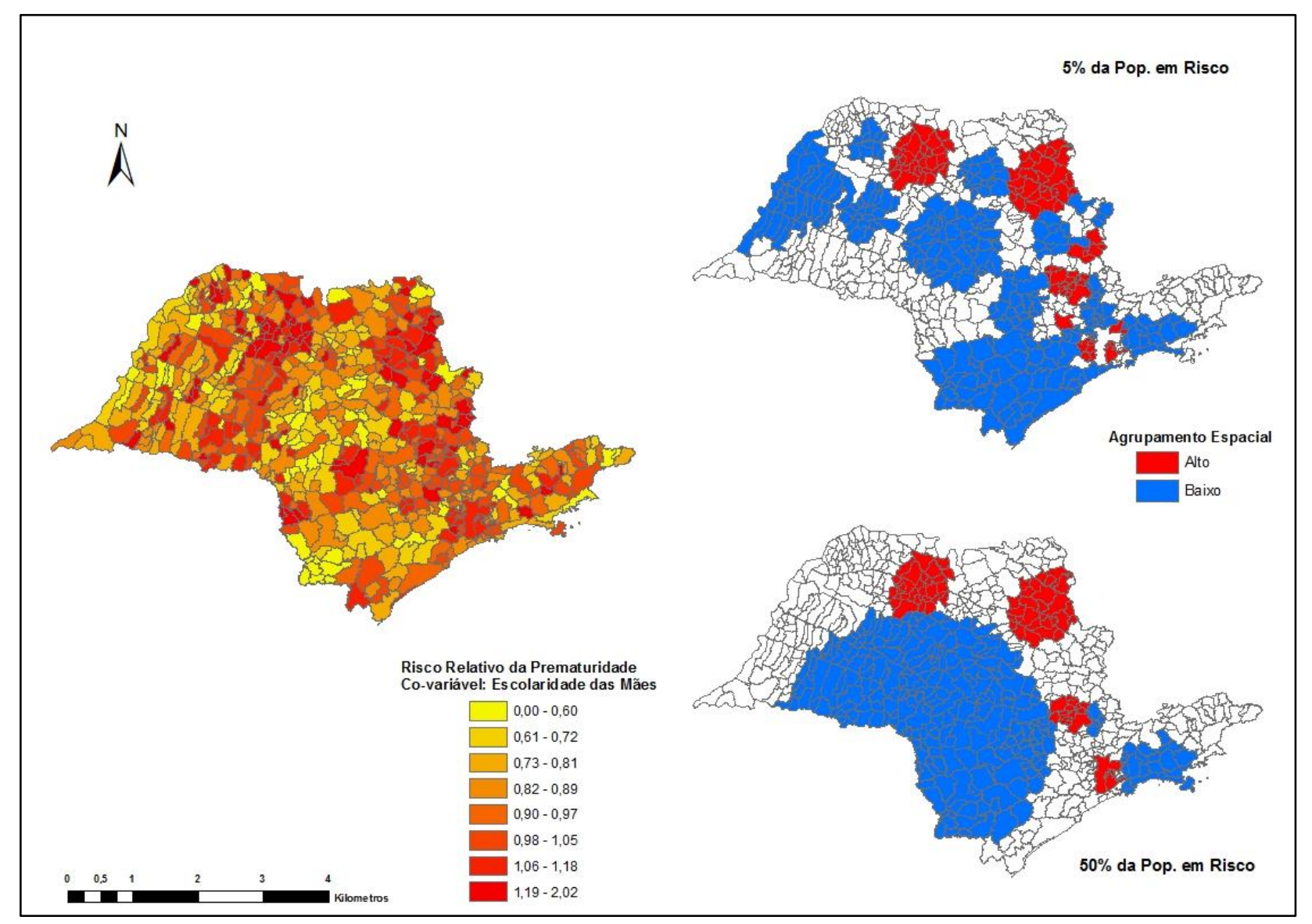

Figura 12 - Riscos Relativos da prematuridade infantil padronizada pela escolaridade das mães no estado de São Paulo, entre 2002 e 2007 (Mapa da esquerda); e Agrupamentos significativos - 5\% da População em Risco (Mapa superior do canto direito) e 50\% da População em Risco (Mapa do canto inferior direito). 
Pela análise de varredura espacial de 5\% (Figura 12 - Mapa Superior direito), observamos dois grandes clusters de alto risco (representados em vermelho): um no município de São José do Rio Preto e nos seus municípios do entorno (mesorregião de São José do Rio Preto - no norte do estado) e outro no município de Ribeirão Preto e adjacências (mesorregião de Ribeirão Preto - no nordeste do estado).

Também houve presença de clusters menores de alto risco: nos municípios de Mogi-Guaçu, Mogi-mirim, Espírito Santo do Pinhal, Santo Antônio do Jardim e São João da Boa Vista (no centro-leste do estado). Entre os municípios de Campinas e Limeira (no sudeste do estado), notamos outro cluster de alto risco. Um pouco ao sul de Campinas, aparece o município de Itu, enquanto que na Baixada Santista, o município de Cubatão.

Na área metropolitana de São Paulo, os municípios de São Bernardo do Campo, Diadema, Arujá, Guarulhos, Vargem Grande Paulista, Cotia, Embu, Embu-Guaçu e Juquitiba formaram cluster de alto risco.

Já em relação à varredura espacial de 50\% (Figura 12 - Mapa Inferior direito), notamos que os clusters de alto risco dos municípios de São José do Rio Preto, Ribeirão Preto, Campinas e Limeira se mantiveram. Contudo, na Área Metropolitana de São Paulo, surgiu um novo cluster de alto risco com a inclusão do município de São Paulo, além da presença dos municípios de São Bernardo do Campo, Diadema e Mauá.

Dentre os municípios da Baixada Santista, apenas Cubatão permaneceu com alto risco de incidência de prematuridade em função da escolaridade das mães.

Em relação aos clusters de baixo risco (representados em azul), verificamos que, na varredura espacial de 5\%, eles aparecem mais dispersos pelo estado de São Paulo. No entanto, pela varredura espacial de $50 \%$, notamos que houve a formação de um único grande cluster que abarcou inúmeros municípios do centro, centro-sul e centro- 
oeste do estado.

Os riscos relativos da prematuridade infantil em função das consultas pré-natal realizadas nas mães registraram entre 0,20 e 2,19 em todo o estado de São Paulo entre 2002 e 2007. O município de Borebi, próximo a Bauru (região central do estado), apresentou o menor risco de 0,20, enquanto que o município de Sagres, localizado na mesorregião de Presidente Prudente (no noroeste do estado) apresentou o maior risco de 2, 19 (Figura 13 - Mapa da esquerda). 


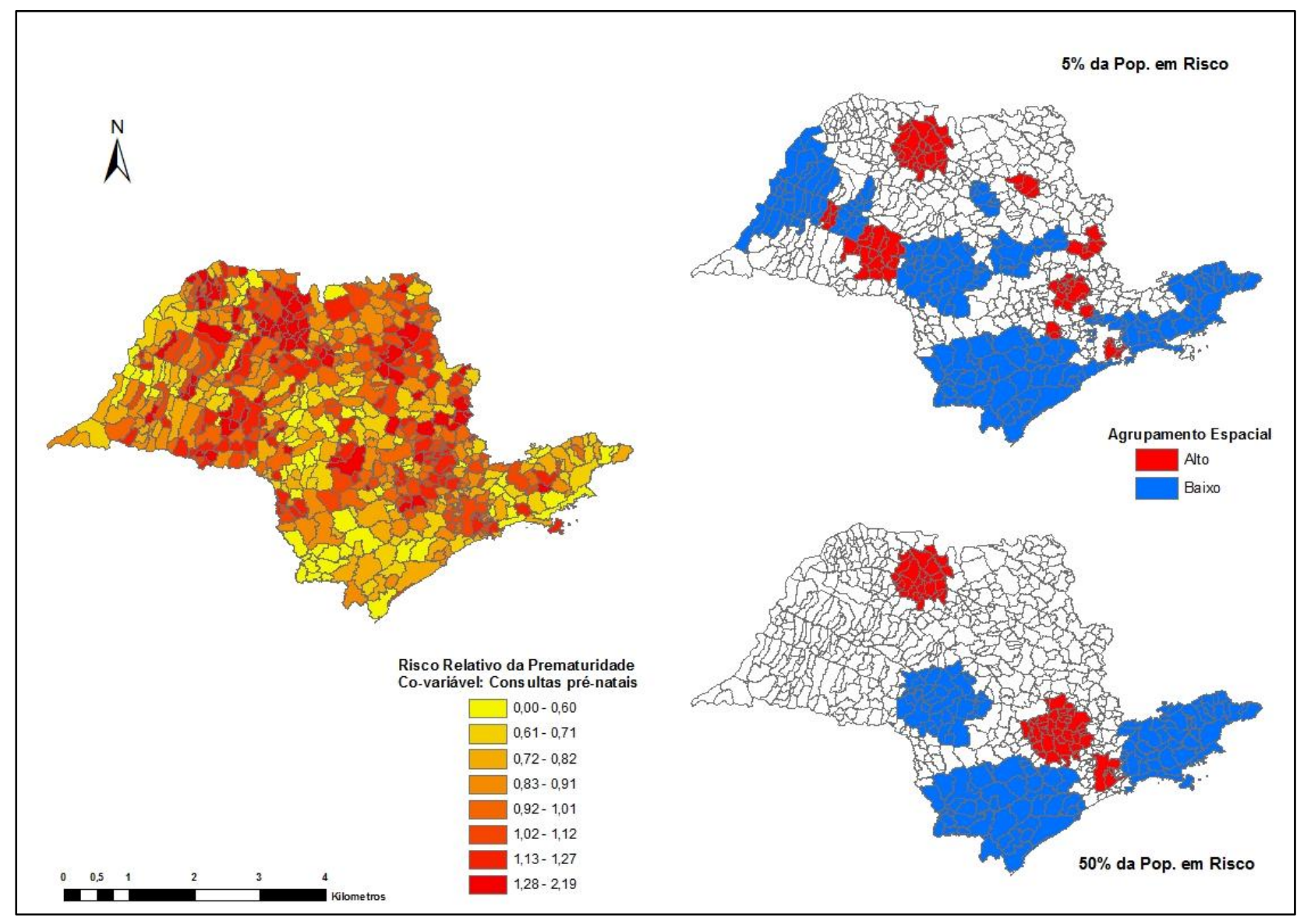

Figura 13 - Riscos Relativos da prematuridade infantil padronizada pelo número de consultas pré-natais realizadas pelas mães no estado de São Paulo, entre 2002 e 2007 (Mapa da esquerda); e Agrupamentos significativos - 5\% da População em Risco (Mapa superior do canto direito) e $50 \%$ da População em Risco (Mapa do canto inferior direito). 
A partir da análise para detecção dos agrupamentos espaciais significativos (ou clusters), identificamos com mais propriedade os padrões da distribuição geográfica da prematuridade infantil em função das consultas pré-natais realizadas pelas mães.

Pela varredura espacial de 5\% (Figura 13 - ver Mapa superior direito), notamos clusters de alto risco (representados em vermelho): um na cidade de São José do Rio Preto e nos seus municípios do entorno (mesorregião de São José do Rio Preto - no norte do estado); no município de Ribeirão Preto e adjacências (mesorregião de Ribeirão Preto - no nordeste do estado).

Na região do noroeste do estado, também ocorreu a presença de clusters de alto risco: nos municípios de Lucélia, Inúbia Paulista, Salmourão, Osvaldo Cruz e Sagres (mesorregião de Presidente Prudente). Da mesma maneira, formou-se outro grande cluster de alto risco no entorno do município de Marília (mesorregião de Marília).

No centro-leste do estado, também se formou um cluster de alto risco, abarcando os municípios de Mogi-Guaçu, Estiva-Gerbi, Espírito Santo do Pinhal, Santo Antônio do Jardim e São João da Boa Vista.

No sudeste do estado, sobretudo nos municípios de Campinas e sua Região Metropolitana, notamos outro cluster de alto risco. E outro, nas proximidades da grande São Paulo, representado por apenas dois municípios de Jundiaí e Várzea Paulista.

Na área metropolitana de São Paulo, os municípios do ABCD: São Caetano do Sul, Bernardo do Campo, Diadema e Santo André constituíram um cluster de alto risco. Somente o município de Cubatão indicou alto risco na Baixada Santista. Os municípios de Sorocaba e Votorantim também formaram um cluster de alto risco.

Em relação à varredura espacial de 50\% (Figura 13 - Mapa inferior direito), verificamos que os clusters de alto risco do município de São José do Rio Preto e entorno se manteve e outro grande cluster se formou, abrangendo os municípios como: 
Sorocaba, Piracicaba, Campinas, Limeira, Jundiaí e Itu. Ao mesmo tempo, na Área Metropolitana de São Paulo, apareceu um novo cluster de alto risco com a inserção da cidade de São Paulo, além da permanência dos municípios da região do ABCD.

Ao visualizarmos os clusters de baixo risco (representados em azul), verificamos que na varredura espacial de 5\% eles se destacaram na mesorregião do Vale do Paraíba, do Litoral Sul Paulista, de Itapetininga (no sul do estado), de Piracicaba (sudeste), de Bauru (central), Araraquara (noroeste) e Presidente Prudente (noroeste), Araçatuba e Marília. Alguns municípios (Caieiras, Cajamar, Franco da Rocha, Guarulhos, Mogi das Cruzes, Mairiporã, Poá, Suzano etc.) da RMSP ao norte da cidade de São Paulo também apresentaram clusters de baixo risco.

Pela varredura espacial de 50\%, identificamos três grandes clusters de baixo risco: um na região centro-oeste do estado (com municípios pertencentes às mesorregiões de Bauru, Assis e Marília); um segundo, incluindo municípios do Vale do Paraíba e parte da RMSP; e um terceiro no centro-sul e litoral sul paulistas. 


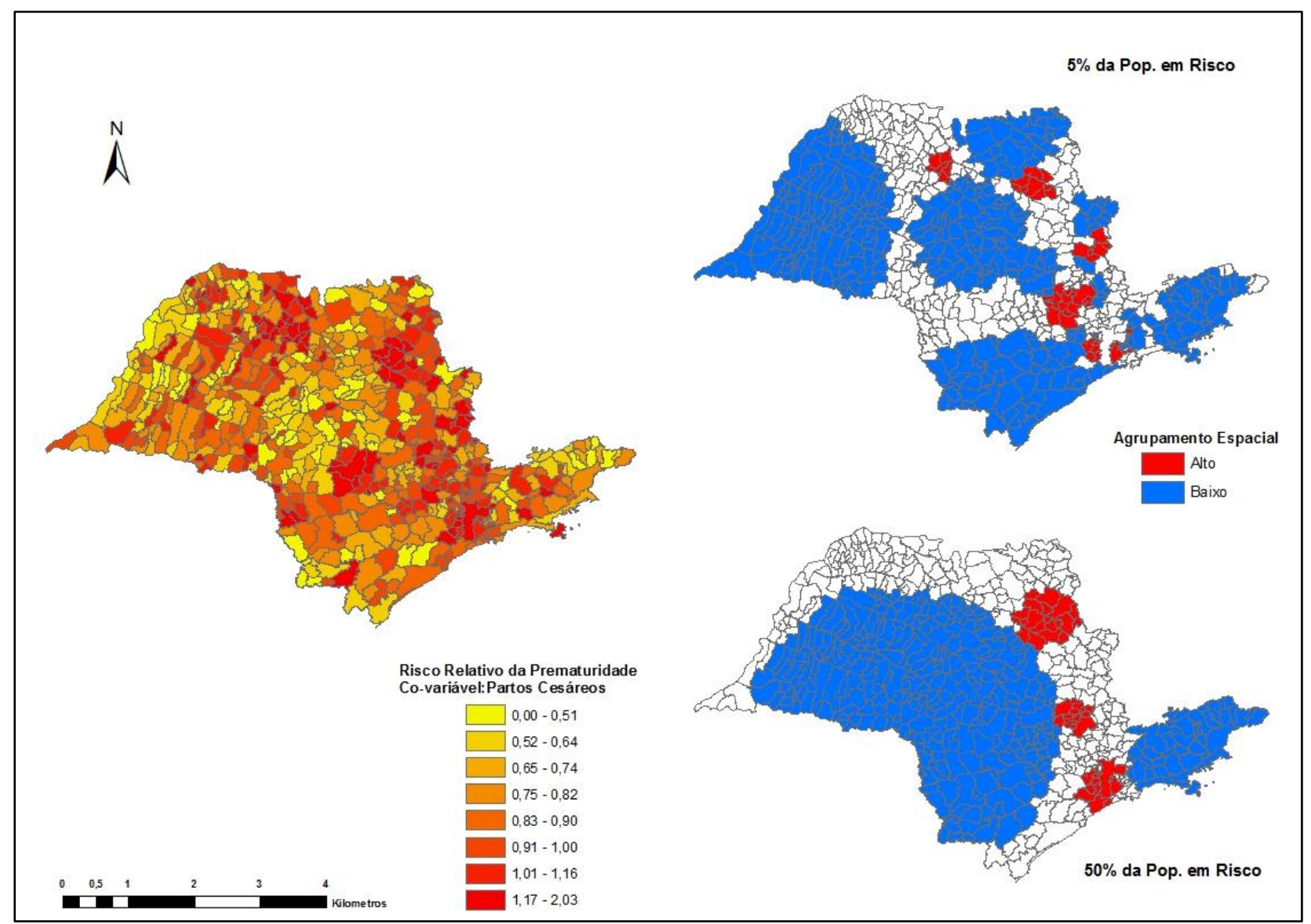

Figura 14 - Riscos Relativos da prematuridade infantil em função dos partos cesáreos realizados nas mães no estado de São Paulo, entre 2002 e 2007 (Mapa da esquerda); e Agrupamentos significativos - 5\% da População em Risco (Mapa superior do canto direito) e 50\% da População em Risco (Mapa do canto inferior direito). 
Os riscos relativos da prematuridade infantil em função dos partos cesáreos realizados nas mães variaram entre 0,10 e 2,03 em todo o estado de São Paulo, entre 2002 e 2007 (Figura 14 - Mapa da esquerda). O município de Borebi, próximo a Bauru (região central do estado), apresentou o menor risco de 0,10 , enquanto que o município de Redenção da Serra, situado no Vale do Paraíba (no sudeste do estado) apresentou o maior risco de 2,03 .

Pela varredura espacial de 5\% (Figura 14 - Mapa inferior direito), identificamos agrupamentos significativos de alto risco (que estão representados em vermelho): em São José do Rio Preto, Badid Bassit, Cedral, Uchoa, Guapiacu e Ibira (mesorregião de São José do Rio Preto - no norte do estado); no município de Ribeirão Preto, Cravinhos, Sertãozinho, Dumont, Barrinha, Brodósqui, Jardinópolis, Serra Azul, Serrana (mesorregião de Ribeirão Preto - no nordeste do estado).

No centro-leste do estado, também se desenvolveu um cluster de alto risco, envolvendo os municípios de Mogi-Guaçu, Estiva-Gerbi, Espírito Santo do Pinhal, Santo Antônio do Jardim e São João da Boa Vista.

No sudeste do estado, os municípios de Campinas, Sorocaba, Itu e imediações compuseram outro cluster de alto risco. $\mathrm{Na}$ área metropolitana de São Paulo, os municípios do ABCD (São Caetano do Sul, Bernardo do Campo, Diadema e Santo André) constituíram um cluster de alto risco. Somente o município de Itaquaquecetuba apontou alto risco a leste do município de São Paulo. A leste da capital, outros municípios da RMSP também formaram um cluster de alto risco.

Pela varredura espacial de 50\% (Figura 14 - Mapa inferior direito), detectamos um novo agrupamento significativo de alto risco do município de Ribeirão Preto e sua vizinhança. Outro grande cluster se formou na porção sudeste do estado, compreendendo os municípios que interligam os municípios de Campinas e Limeira. 
Na Área Metropolitana de São Paulo, surgiu um novo e grande agrupamento de alto risco com a inclusão do município de São Paulo e de dois municípios do litoral sul paulista (Itanhaém e Mongaguá), além da permanência dos demais municípios da RMSP.

$\mathrm{Na}$ varredura espacial de 5\% (Figura 14 - Mapa superior direito), os clusters de baixo risco, destacaram-se em grande parte do território paulista, do mesmo modo que na varredura espacial de 50\% (Figura 14 - Mapa inferior direito). 


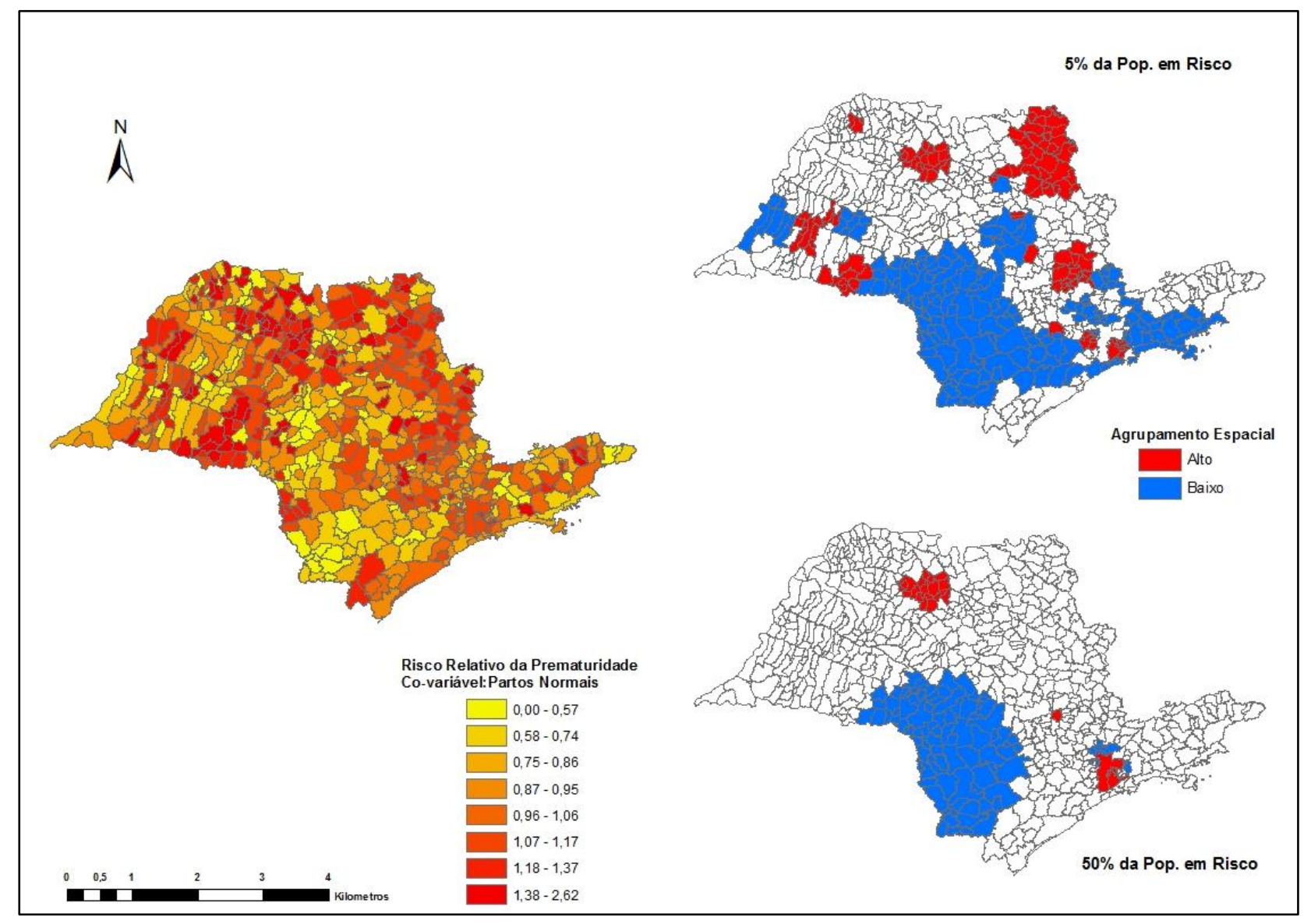

Figura 15 - Riscos Relativos da prematuridade infantil em função dos partos normais realizados nas mães no estado de São Paulo, entre 2002 e 2007 (Mapa da esquerda); e Agrupamentos significativos - 5\% da População em Risco (Mapa superior do canto direito) e 50\% 5\% da População em Risco (Mapa do canto inferior direito). 
Os riscos relativos da prematuridade infantil em função dos partos normais realizados nas mães variaram entre 0,13 e 2,62 em todo o estado de São Paulo, entre 20022007 (Figura 15 - Mapa da esquerda). O município de Cabrália Paulista, próximo a Bauru (região central do estado), apresentou o menor risco de 0,13 , enquanto que o município de Ariranha, localizado na mesorregião de São José do Rio Preto (no norte do estado) obteve o maior risco de 2,62.

Pela varredura espacial de 5\% (Figura 15 - Mapa superior direito), detectamos clusters significativos de alto risco (representados em vermelho): em São José do Rio Preto e municípios do entorno (Mirassol, Onda Verde, Ipiguá, Mirassolândia, Badid Bassit, Cedral, Uchoa, Guapiacu, Ibira, Monte Aprazível etc; todos pertencentes à mesorregião de São José do Rio Preto - no norte do estado).

Na mesorregião de Ribeirão Preto (no nordeste do estado), houve a formação de um grande agrupamento significativo de alto risco, composto pelo município de Ribeirão Preto e vizinhanças. Este cluster começa no entorno de Cajurú e se estende até Igarapava (na divisa com Minas Gerais).

No extremo norte do estado, também se desenvolveu um pequeno cluster de alto risco, abarcando os municípios de Jales, Urânia e Vitória Brasil. Da mesma maneira, no noroeste do estado, em Presidente Prudente e entorno formou-se um agrupamento significativo de alto. Um pouco mais ao sul de Presidente Prudente, na região de Assis, ocorreu outro cluster de alto risco.

No sudeste do estado, os municípios de Mogi-Guaçu, Mogi-Mirim, Limeira, Araras, Sumaré e imediações compuseram outro cluster de alto risco. $\mathrm{Na}$ área metropolitana de São Paulo, os municípios do ABCD (São Caetano do Sul, Bernardo do Campo, Diadema e Santo André) e demais municípios da RMSP constituíram um outro cluster de alto risco. 
Pela varredura espacial de 50\% (Figura 15 - Mapa inferior direito), identificamos um novo agrupamento significativo de alto risco na Área Metropolitana de São Paulo, com a inserção da cidade de São Paulo, além dos municípios do ABCD. Em São José do Rio Preto e municípios vizinhos também constituíram outro. Apenas o município de Santa Bárbara d'Oeste formou um cluster de alto risco na mesorregião de Campinas (sudeste do estado).

Na varredura espacial de 5\% (Figura 15 - Mapa superior direito), os clusters de baixo risco (representados em azul), estão distribuídos de modo mais disperso pelo território paulista. Houve a presença de dois clusters na porção nordeste: um no entorno de Presidente Venceslau e outro nas adjacências de Iacri (região de Marília).

Na região central do estado, formaram-se outros nos entornos do município de Ribeirão Bonito (mesorregião de Araraquara), de Monte Alegre do Sul (sudeste) e Jundiaí (sudeste). Outros dois grandes clusters se conectam na porção centro-sul do estado, e outro entre o Vale do Paraíba e os de Piracáia.

Por fim, pela varredura espacial de 50\% (Figura 15 - Mapa inferior direito), detectamos apenas um grande cluster de baixo risco na porção centro-sul do estado. Outros três se formaram no entorno da cidade de São Paulo: um a oeste (composto pelos municípios de Barueri e Osasco); outro a leste (composto pelos municípios de Ferraz de Vasconcelos, Poá e Suzano), e mais a norte (composto pelos municípios de Campo Limpo Paulista, Mairiporã, Francisco Morato, Franco da Rocha, Caieiras e Cajamar). 


\subsection{Análise espacial exploratória de associação entre os riscos relativos e as variáveis socioeconômicas.}

Tabela 3 - Correlação simples entre o risco relativo e as variáveis socioeconômicas no estado de São Paulo entre 2002 e 2007.

\begin{tabular}{|c|c|}
\hline ESTADO_SP & Valor de $r$ \\
\hline RR $\times$ TD & 0,0132 \\
\hline RR X TA & $-0,1340$ \\
\hline RR X BAR & 0,0467 \\
\hline RR X IP & $-0,0442$ \\
\hline
\end{tabular}

As correlações simples entre o risco relativo e as variáveis socioeconômicas não foram significativas como um todo (Tabela 3). Somente entre o risco e porcentagem de assentamentos precários ou favelas que ela foi um pouco superior a 10\% $(-0,1340)$.

Tabela 4- Autocorrelação espacial global das variáveis no estado de São Paulo entre 2002 e 2007.

\begin{tabular}{|c|c|c|}
\hline ESTADO_SP & $\begin{array}{c}\text { I Moran Global - } \\
\text { Univariado }\end{array}$ & Valor de $\mathrm{p}$ \\
\hline Risco Relativo (RR) & 0,1482 & $0,001^{* \star}$ \\
\hline Taxa de Desemprego (TD) & 0,3384 & $0,001^{* *}$ \\
\hline Taxa de Analfabetismo (TA) & 0,3879 & $0,001^{* *}$ \\
\hline Porcent. de assentamentos precários (BAR) & 0,4789 & $0,001^{* *}$ \\
\hline Índice de Privação (IP) & 0,3282 & $0,001^{* *}$ \\
\hline${ }^{*} \mathrm{p}<0,05,{ }^{* *} \mathrm{p}<0,01$ &
\end{tabular}

O risco relativo, assim como todas as variáveis socioeconômicas apresentaram um padrão espacial não aleatório (Tabela 4), ou seja, existem autocorrelações significativas demonstradas pelos o valores de $\mathrm{p}<0,01$.

Tabela 5 - Correlação espacial global entre o risco relativo e as variáveis socioeconômicas no estado de São Paulo entre 2002 e 2007.

\begin{tabular}{|c|c|c|}
\hline ESTADO_SP & I Moran Global - Bivariado & Valor de $p$ \\
\hline RR X TD & 0,0053 & 0,384 \\
\hline RR X TA & $-0,0658$ & $0,002^{*}$ \\
\hline RR X BA & 0,0480 & $0,030^{*}$ \\
\hline RR X IP & $-0,0074$ & 0,415 \\
\hline
\end{tabular}

${ }^{*} p<0,05,{ }^{* *} p<0,01$ 
Ocorreu uma associação espacial global significativa entre o risco relativo (RR) e taxa de analfabetismo (TA), só que ela é inversa (I Moran - Bivariado $=-0,0658$ e o valor de $\mathrm{p}<0,05$ ), ou seja, apesar do Moran's I estar próximo de zero (Tabela 3) o risco a nascimento pré-termo diminuiu, ao mesmo tempo em que aumenta a taxa de analfabetismo. Também houve associação espacial global significativa entre o risco relativo (RR) e o percentual de assentamentos precários: I Moran - Bivariado $=0,0480$ e o valor de $\mathrm{p}<0,05$ (Tabela 5). Dessa maneira, podemos inferir que o risco a nascimentos pré-termo é maior, conforme aumenta o percentual de assentamentos precários.

Para as análises dos padrões espaciais locais (LISA), também aplicamos o módulo bivariado para identificar os agrupamentos de municípios mais vulneráveis em relação aos riscos de nascimentos pré-termo quando associados às variáveis socioeconômicas.

Na Figura 16, os municípios (Ribeirão Preto, Tanabi e Hortolândia) representados em vermelho intenso correspondem a categoria 1 (Alto-Alto), que se refere a valores de alto risco de nascimentos pré-termo com alta porcentagem de assentamentos precários. Os municípios (representados em azul forte pertencem a categoria 2 (Baixo-Baixo), que se refere a baixo risco de nascimentos pré-termo com baixa porcentagem de assentamentos precários.

A categoria 3 (Baixo-Alto) são dos municípios representados em azul claro, onde coincidem valores de baixo risco de nascimentos pré-termo, mas com alta porcentagem de assentamentos precários. A categoria 4 (Alto-Baixo), representada pela cor rosa, corresponde ao município de Bauru - com alto risco de nascidos pré-termo e baixa porcentagem de assentamentos precários. A categoria 5, representada em cinza, refere-se a Ilhabela, único município do estado de São Paulo que não apresenta 
vizinhos. A categoria 0 indica que os municípios, representados pela cor branca, não apresentaram clusters significativos, ou seja, o valor de $\mathrm{p}>0,05$.

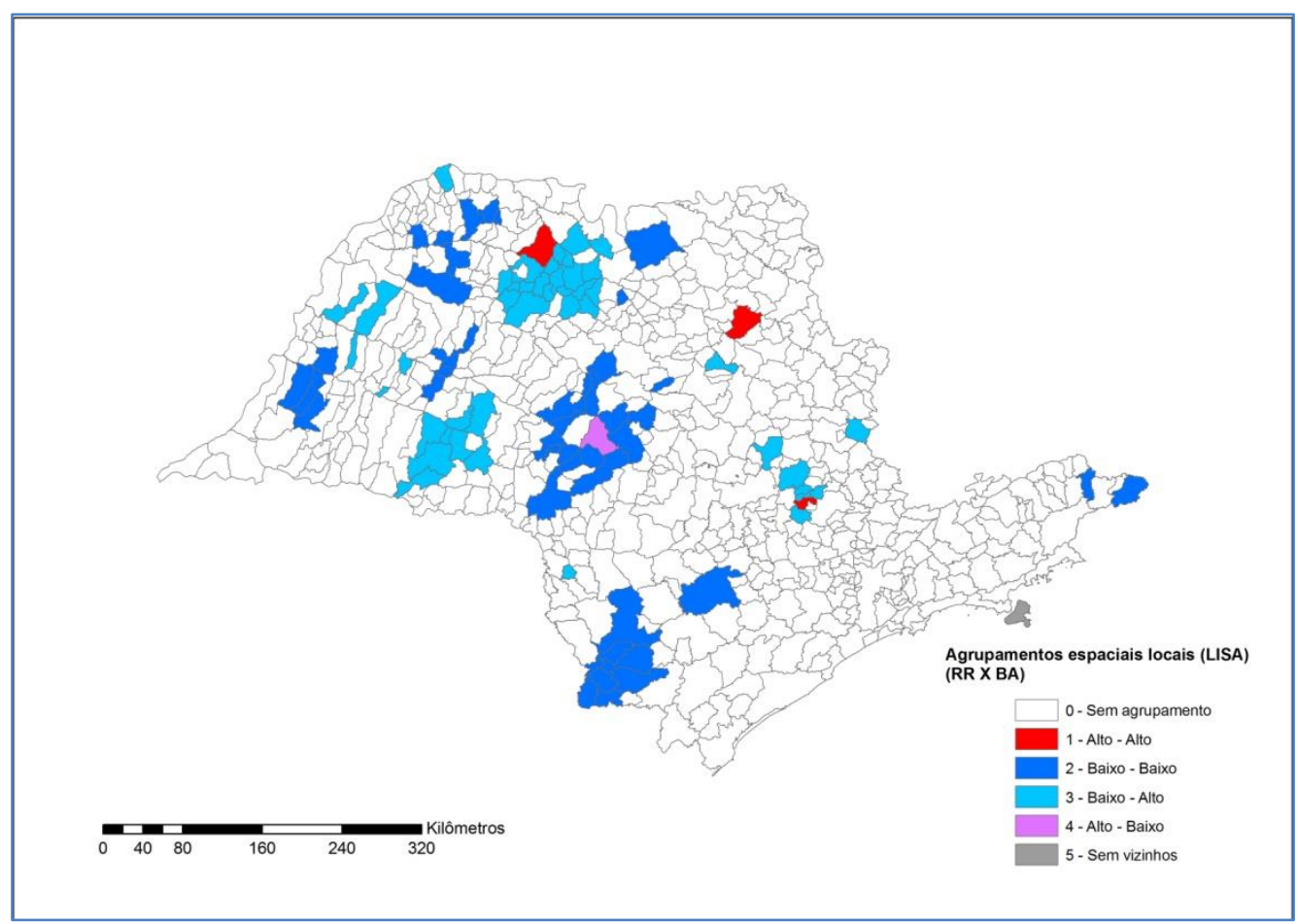

Figura 16 - Mapa dos Agrupamentos espaciais locais (LISA) da associação entre Risco relativo e porcentagem de assentamentos precários.

Na Figura 17, os municípios representados em vermelho intenso correspondem a categoria 1 (Alto - Alto), que se refere a valores de alto risco de nascimentos prétermo com alta taxa de desemprego. Os municípios representados em azul forte pertencem a categoria 2 (Baixo-Baixo), que se refere a baixo risco de nascimentos prétermo com baixa taxa de desemprego.

A categoria 3 (Baixo-Alto) são dos municípios representados em azul claro, onde coincidem valores de baixo risco de nascimentos pré-termo, mas com alta taxa de desemprego. A categoria 4 (Baixo-Baixo), representada pela cor rosa, corresponde a municípios com baixo risco de nascidos pré-termo e baixa taxa de desemprego. 


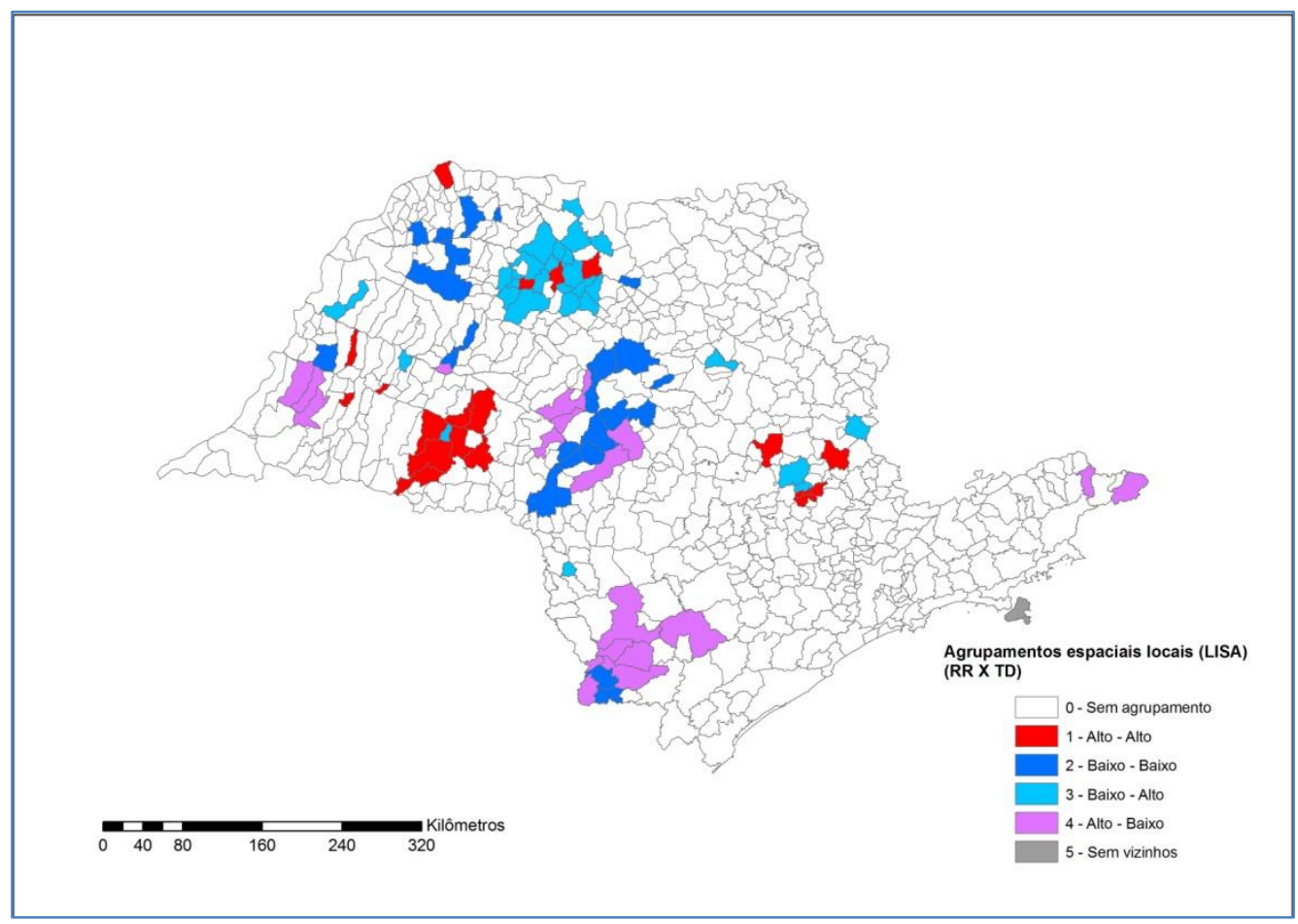

Figura 17- Mapa dos Agrupamentos espaciais locais (LISA) da associação entre Risco relativo e taxa de desemprego.

Na Figura 18, os municípios representados em vermelho intenso correspondem a categoria 1 (Alto - Alto), que se refere a valores de alto risco de nascimentos pré-termo com alta taxa de analfabetismo. Os municípios representados em azul forte pertencem a categoria 2 (Baixo-Baixo), que se refere a baixo risco de nascimentos pré-termo com baixa taxa de analfabetismo.

A categoria 3 (Baixo-Alto) é a dos municípios representados em azul claro, onde coincidem valores de baixo risco de nascimentos pré-termo, mas com alta taxa de analfabetismo. A categoria 4 (Baixo-Baixo), representada pela cor rosa, corresponde a municípios com baixo risco de nascidos pré-termo e baixa taxa de analfabetismo. 


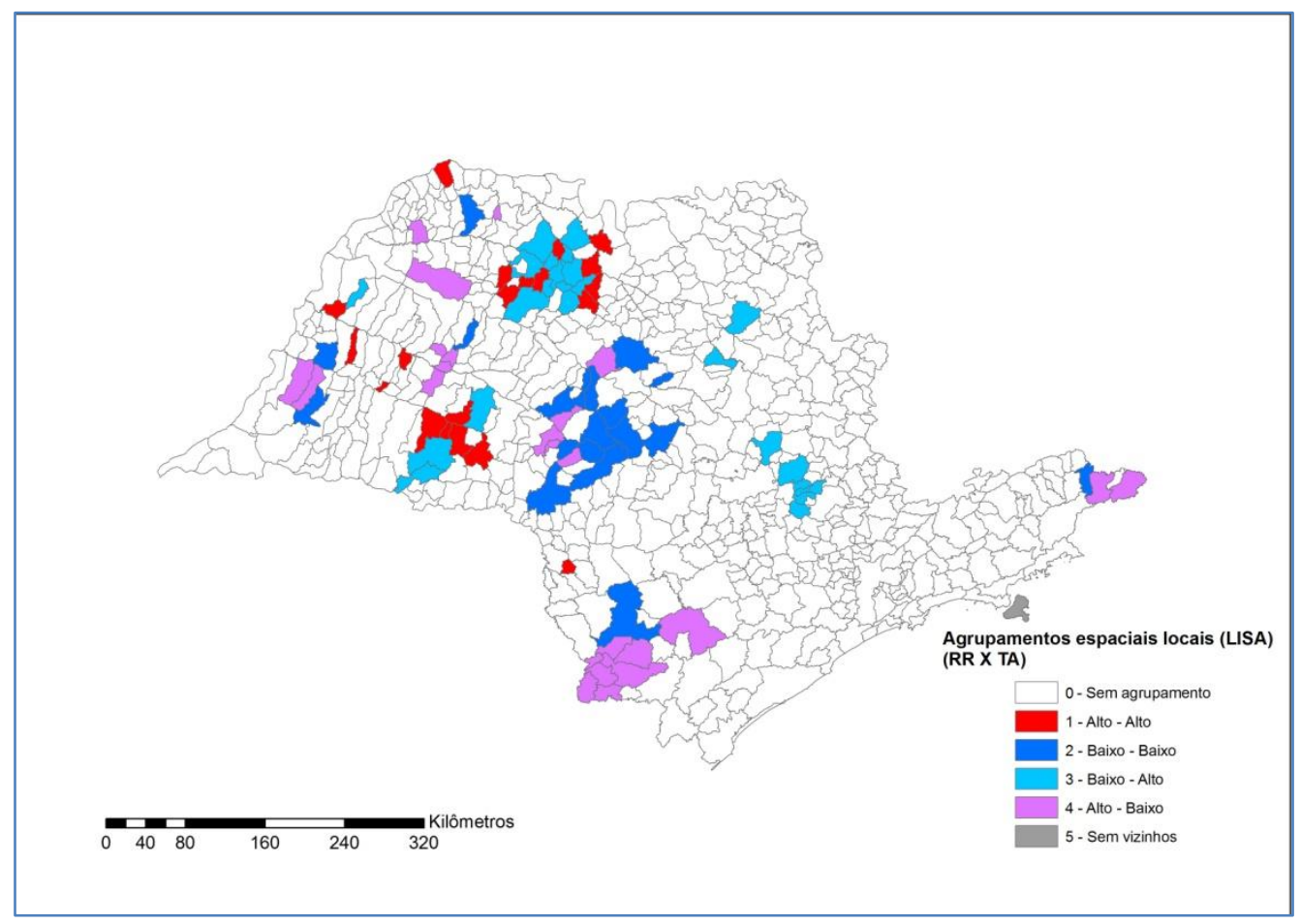

Figura 18 - Agrupamentos espaciais locais (LISA) da associação entre Risco relativo e taxa de analfabetismo.

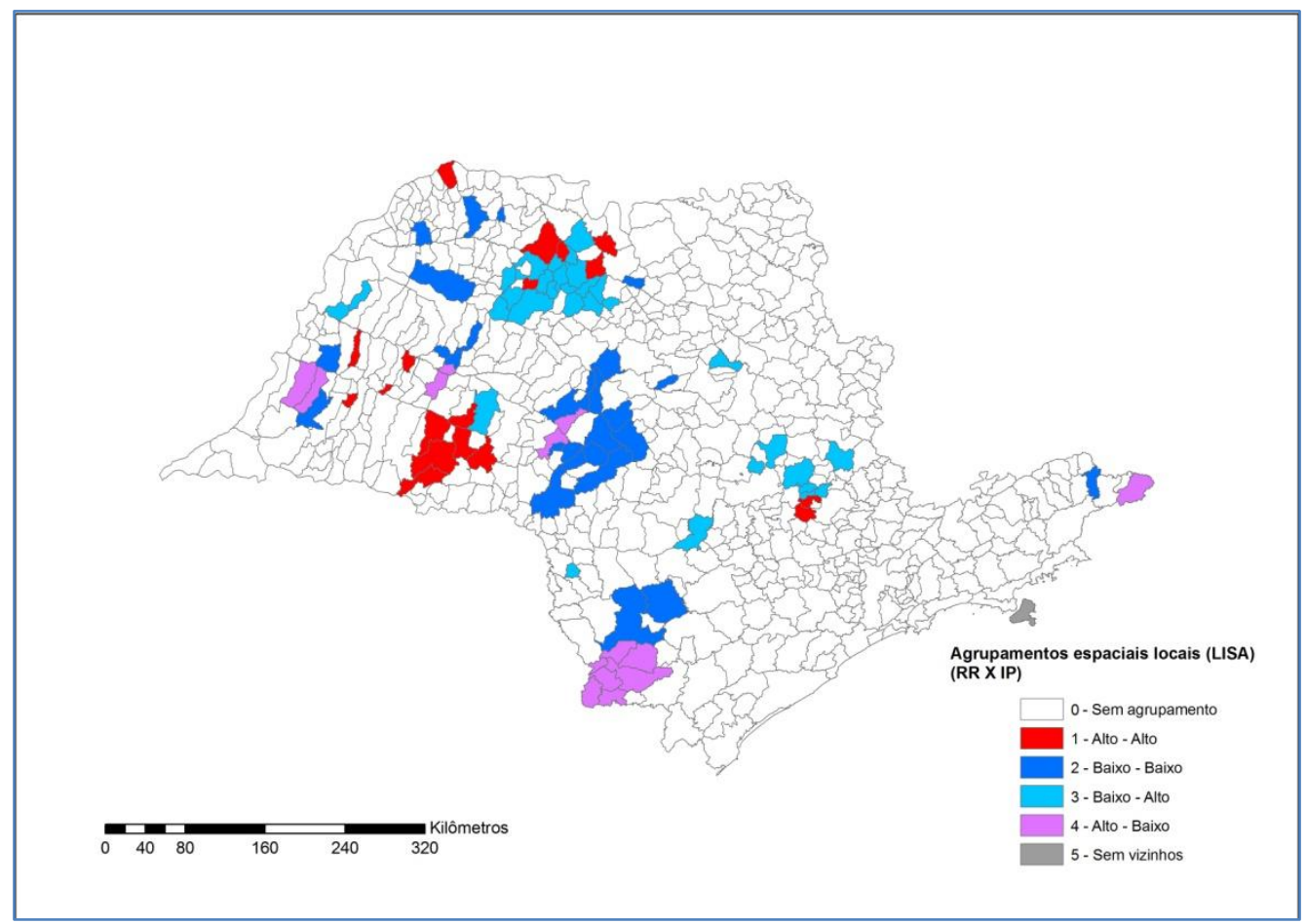

Figura 19 - Agrupamentos espaciais locais (LISA) da associação entre Risco relativo e índice de privação sócio-material.

Na Figura 19, os municípios representados em vermelho intenso correspondem a categoria 1 (Alto - Alto), que se refere a valores de alto risco de nascimentos pré- 
termo com alto índice de privação sócio-material. Os municípios representados em azul forte pertencem a categoria 2 (Baixo-Baixo), que se refere a baixo risco de nascimentos pré-termo com baixo índice de privação sócio-material.

A categoria 3 (Baixo-Alto) são dos municípios representados em azul claro, onde coincidem valores de baixo risco de nascimentos pré-termo, porém com alto índice de privação sócio-material. A categoria 4 (Baixo-Baixo), representada pela cor rosa, corresponde a municípios com alto risco de nascidos pré-termo e baixo índice de privação sócio-material.

\subsection{Aplicação dos Testes de Regressão OLS e GWR}

Tabela 6 - Teste de Regressão da OLS - Regressão dos Mínimos Quadrados Ordinários OLS - RR prematurida (dependente); IP2010; \% CESAREA; \% CONSULTA; UTI

\begin{tabular}{|c|c|c|c|c|c|c|c|c|}
\hline Variable & Coefficient & StdError & t-Statistic & Probability & Robust_SE & Robust_t & Robust_Pr & VIF [1] \\
\hline Intercept & -0.126666 & 0.252897 & -0.500861 & 0.616653 & 0.268636 & -0.471517 & 0.637445 & ------- \\
\hline IP_20_2011 & -0.020088 & 0.024064 & -0.834767 & 0.404147 & 0.021507 & -0.934024 & 0.350630 & 1.054 .795 \\
\hline P_CESARE_1 & 0.005058 & 0.002771 & 1.825 .379 & 0.068412 & 0.003115 & 1.623 .833 & 0.104916 & 1.163 .802 \\
\hline P_CONSUL_1 & -0.002507 & 0.003192 & -0.785335 & 0.432537 & 0.003551 & -0.705896 & 0.480504 & 1.145 .298 \\
\hline UTI_1 & 0.042172 & 0.021270 & 1.982 .742 & $0.047817 *$ & 0.013262 & 3.180 .052 & $0.001557 *$ & 1.006 .124 \\
\hline
\end{tabular}

OLS - Regressão dos Mínimos Quadrados Ordinários RR - Risco relativo de nascimentos pré-termo normalizado (variável dependente) IP2010 - Índice de Privação sócio material (variável independente)

\% Cesáreas - Porcentagem de cesáreas (variável independente) $\%$ Consultas - Porcentagem de consultas pré-natal acima de 7 (variável independente) UTI - Número de Unidades de Terapia Intensiva neonatais por 1000 nascidos vivos

Tabela 7 - Diagnóstico da OLS

\begin{tabular}{lcll} 
Number of Observations: & 645 & \multicolumn{2}{c}{ Number of Variables: 5 } \\
Degrees of Freedom: & 640 & Akaike's Information Criterion (AIC) [2]: 1830.944263 \\
Multiple R-Squared [2]: & 0.013070 & Adjusted R-Squared [2]: 0.006902 & \\
Joint F-Statistic [3]: & 2.118886 & Prob(>F), (4,640) degrees of freedom: & 0.076943 \\
Joint Wald Statistic [4]: & 14.370698 & Prob(>chi-squared), (4) degrees of freedom: $0.006201^{*}$ \\
Koenker (BP) Statistic [5]: & $\mathbf{1 2 . 6 4 1 0 1 2}$ & Prob(>chi-squared), (4) degrees of freedom: $0.013170^{*}$ \\
Jarque-Bera Statistic [6]: & $\mathbf{1 3 7 . 8 7 8 9 0 7}$ & Prob(>chi-squared), (2) degrees of freedom: $0.000000^{*}$
\end{tabular}

Notes on Interpretation

Statistically significant at the 0.05 level.

[1] Large VIF (> 7.5, for example) indicates explanatory variable redundancy. 
[2] Measure of model fit/performance.

[3] Significant p-value indicates overall model significance.

[4] Significant $p$-value indicates robust overall model significance.

[5] Significant p-value indicates biased standard errors; use robust estimates.

[6] Significant p-value indicates residuals deviate from a normal distribution.

Para este modelo (Tabela 6), apenas a variável número de UTIs neonatais por 1000 nascidos vivos que apresentou a probabilidade significativa de $0.047817 *$ (valor de $\mathrm{p}<0,05)$. Isto significa que esta variável é o único preditor estatisticamente significativo para explicar a variância dos riscos relativos de nascimentos pré-termo em alguns municípios do estado, mas também um preditor fraco em outros.

O teste de koenker (BP) da OLS é estatisticamente significativo $\mathrm{p}=0.013170^{*}$, indicando que as relações entre a variável dependente e todas as variáveis explanatórias são não-estacionária, o que sugere que a aplicação do GWR melhoraria os resultados do modelo (Tabela 7).

Verificou-se que os residuos do modelo testado não apresentaram uma distribuição normal (o resultado do teste Jarque-Bera foi de 137.88 com $p<0,05$ ) (Tabela 7).

Tabela 8 - Teste de autocorrelação espacial dos resíduos da OLS

$\begin{array}{cc}\text { Global Moran's I Summary } \\ \text { Moran's Index: } & \mathbf{0 . 1 4 6 9 6 2} \\ \text { Expected Index: } & -0.001553 \\ \text { Variance: } & 0.000553 \\ \text { Z Score: } & 6.316670 \\ \text { p-value: } & \mathbf{0 . 0 0 0 0 0 0}\end{array}$

O teste de autocorrelação espacial dos resíduos da regressão global da OLS (Tabela 8) apresentou clusterização, com I Moran de 0.147 e o valor de p<0,05 $(0,000)$, portanto foi significativo. Desta forma, o modelo testado não conseguiu explicar uniformemente os riscos relativos de nascimentos pré-termo no estado de São Paulo em função das variáveis explanatórias: Índice de Privação-sóciomaterial (IP 2010), 
Porcentagem de Partos Cesáreos (\%Ces), Porcentagem de consultas pré-natal acima de 7 (\%Cons) e número de UTIs neonatais por 1000 nascidos vivos.

Tabela 9 - GWR - Regressão Geograficamente ponderada

\begin{tabular}{l} 
Messages \\
\multicolumn{3}{c}{ Start Time: Thu Jul 03 21:51:33 2014 } \\
Bandwidth $\quad: 0.9108197446316735$ \\
ResidualSquares $: 536.9839353121529$ \\
EffectiveNumber $: 69.89010296109176$ \\
Sigma $\quad: 0.9662849734633517$ \\
AICc $\quad:$ 1823.2855885817041 \\
R2 0.16617404407661296 \\
R2Adjusted $\quad: 0.06629338430889087$ \\
Thu Jul 03 21:51:34 2014 (Elapsed Time: 1.00 seconds)
\end{tabular}

O valor de Akaike (AIC) da OLS foi de 1830.94 (Tabela 7), enquanto que o valor de Akaike pelo da teste de regressão espacial local geograficamente ponderada (GWS) caiu para 1823.3 (Tabela 9). Percebe-se que houve uma melhora real no desempenho do modelo pela análise GWR (Tabela W), uma vez que o descréscimo do valor de akaike foi maior do que 3 pontos (MATTHEWS et. al , 2012).

Os valores observados do risco relativo de nascimento pré-termo normalizados e os valores preditos do risco relativo de nascimentos apresentam distribuições espaciais diferenciadas (Figura 20), o que explica que as variações espaciais locais do risco de nascimento não foram bem explicadas pelo modelo GWS para todos os municípios do estado, já que em apenas alguns áreas a configuração espacial dos valores observados e preditos se assemelham.

Os resíduos padronizados resultam da diferença entre os valores observados e esperados. Verificamos que o mapa dos resíduos não apresenta padrão espacial definido. Nos municípios do noroeste e do extremo sul do estado que o risco de nascimentos prétermo é menos explicado pelo modelo, como se pode verificar pelos valores dos resíduos estarem distantes de zero (Figura 21). 
Observamos que o coeficiente do Índice de Privação sociomaterial apresentou maior poder explicativo em alguns municípios das regiões centro-oeste, do extremooeste e no litoral norte do estado (Figura 22).

O coeficiente da porcentagem de partos cesáreos indicou maior capacidade explicativa em alguns municípios do extremo-leste e centro-oeste e noroeste (Figura 23).

Verificamos que a capacidade explicativa dos parâmetros do modelo variam entre os municípios. A porcentagem de consultas pré-natal acima de 7 tem um maior peso no modelo nos municípios representados em laranja e vermelho (localizados nas porções sudeste e centro-oeste do território paulista)(Figura 24).

A contribuição do coeficiente do número de UTIs neonatais por 1000 nascidos vivos para o modelo é superior em alguns municípios do centro-sul, extremo-oeste e nordeste (Figura 25). 


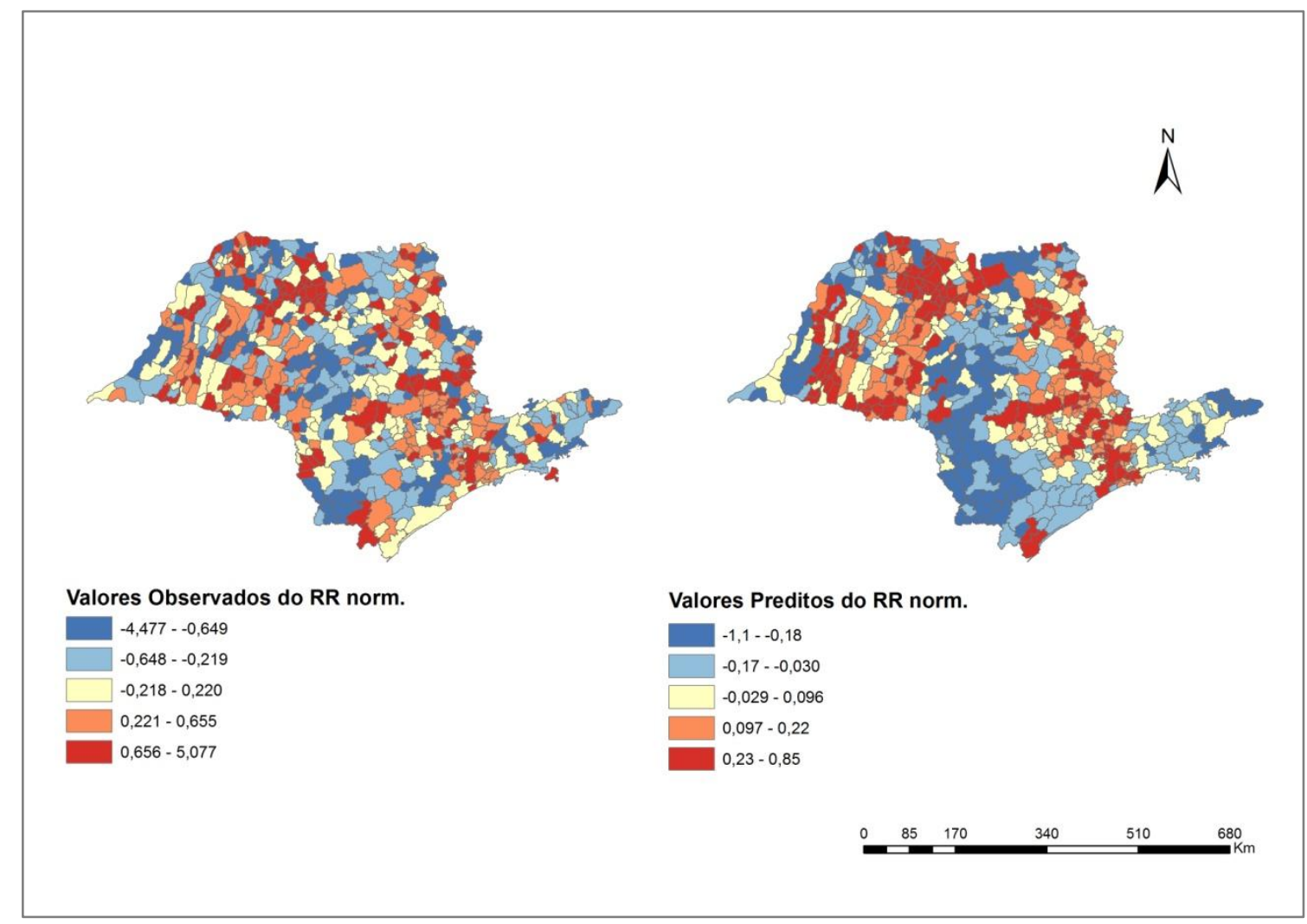

Figura 20 - Mapa dos valores observados normalizados e preditos do risco relativo de nascimentos pré-termo.

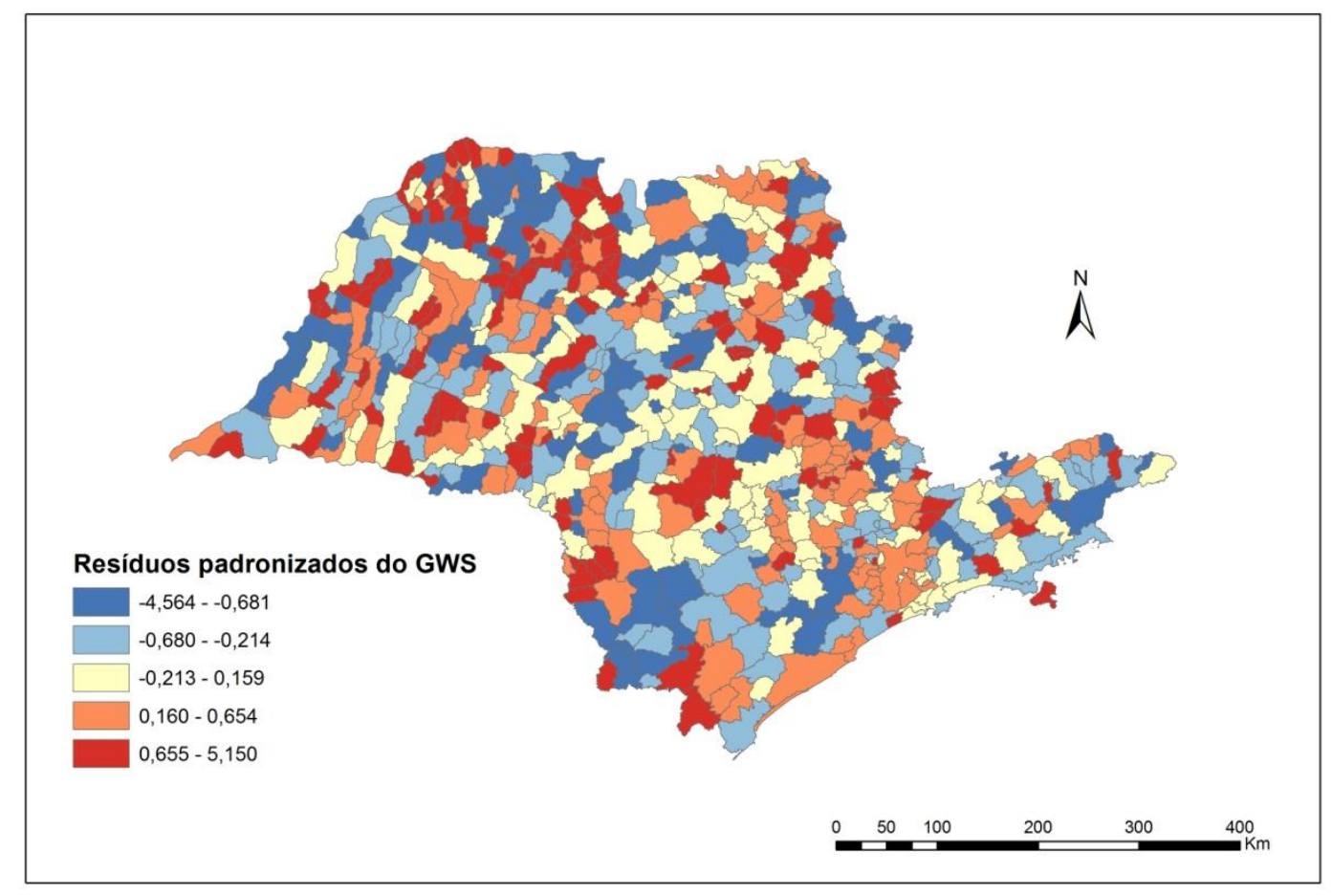

Figura 21 - Mapa dos Resíduos padronizados do GWS 


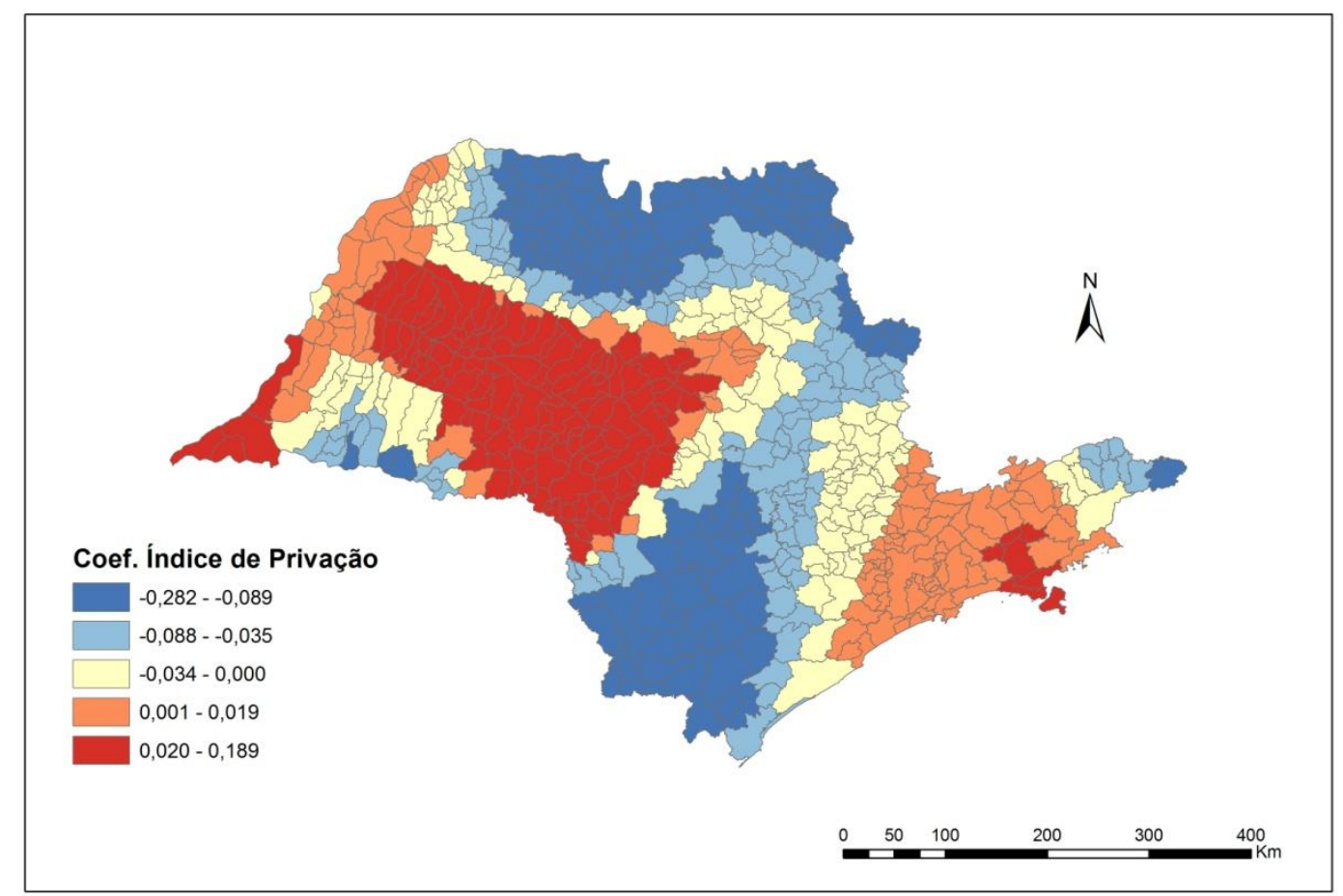

Figura 22 - Mapa do coeficiente do Índice de Privação-sociomaterial

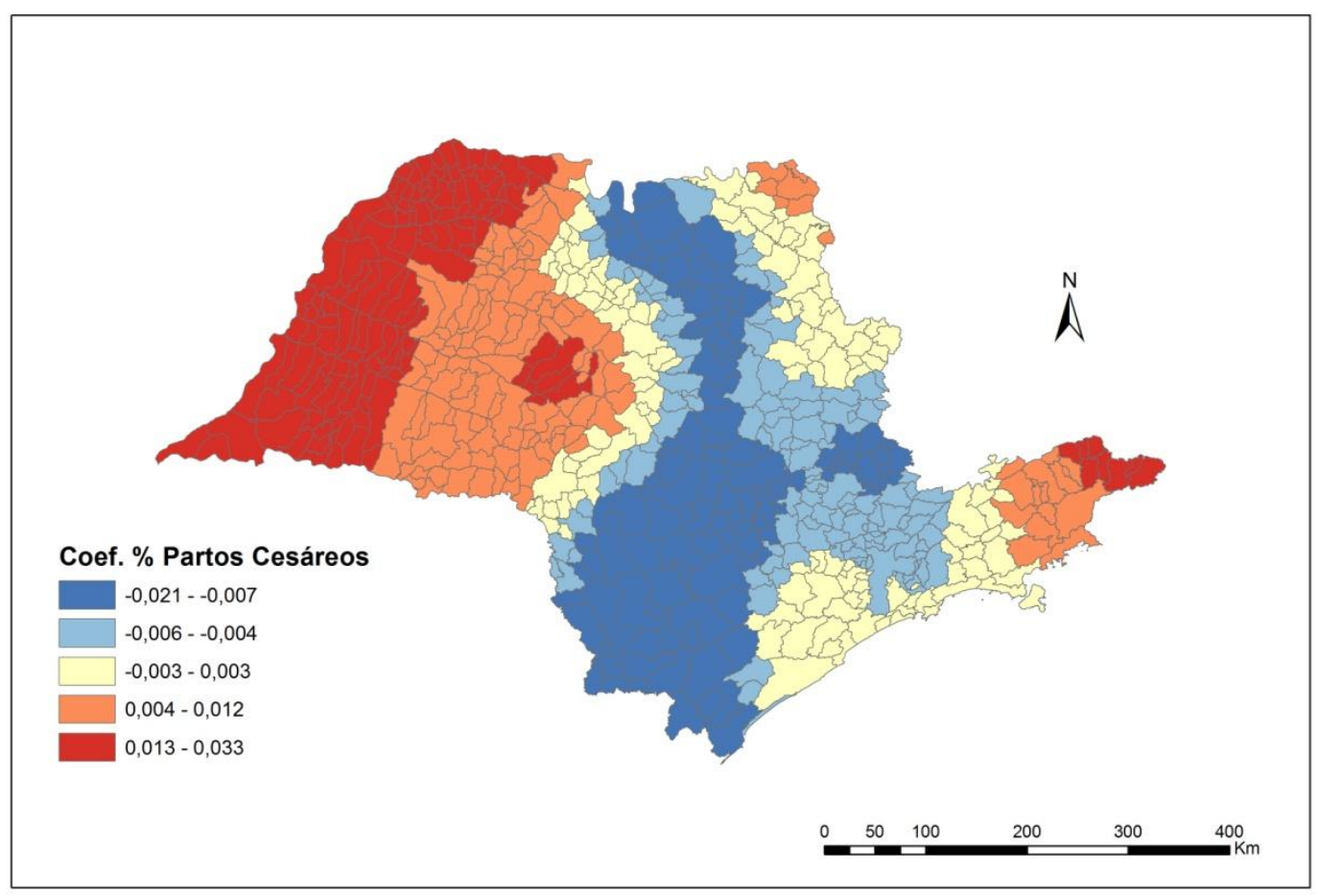

Figura 23- Mapa do coeficiente da porcentagem de partos cesáreos. 


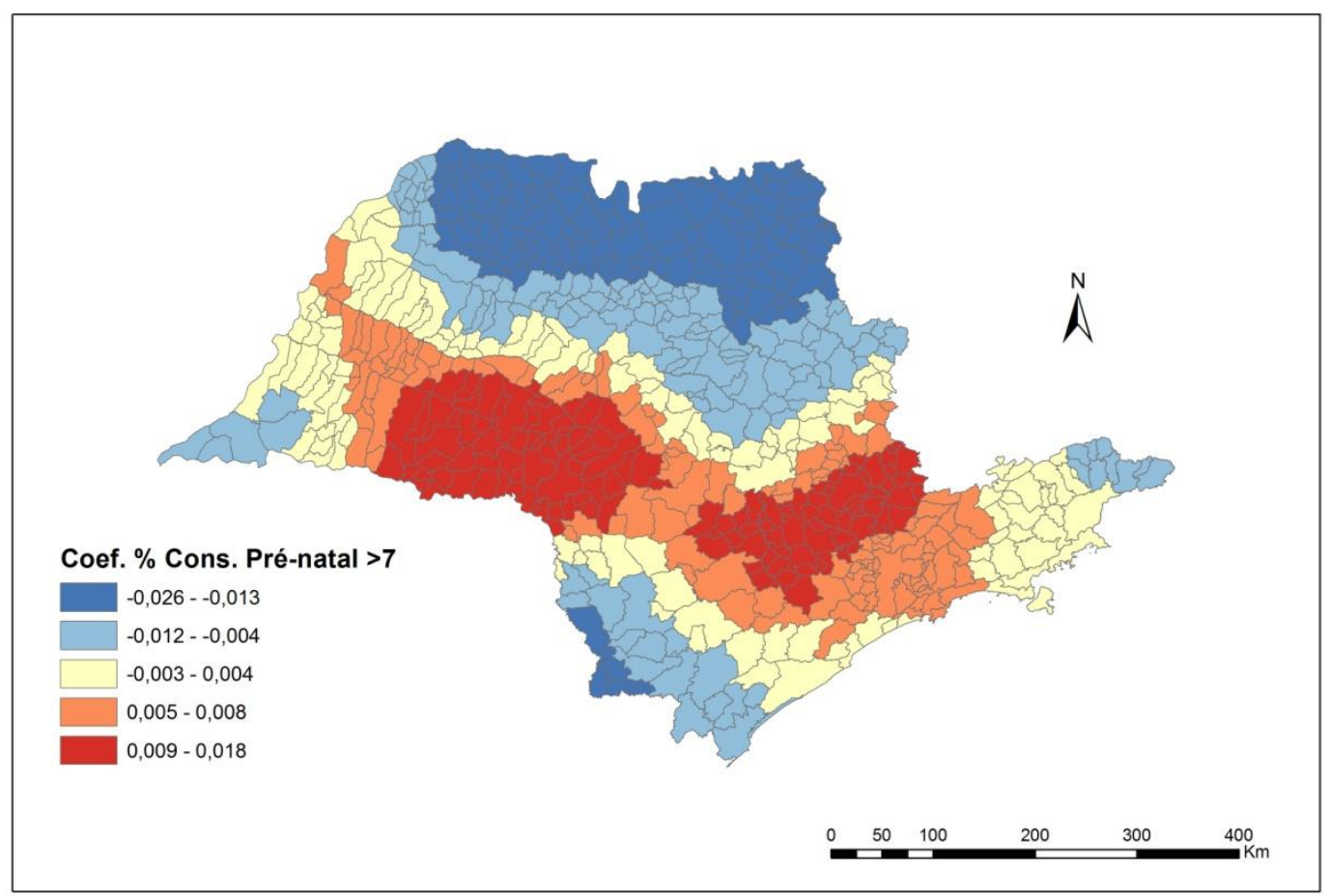

Figura 24 - Mapa do coeficiente da porcentagem de consultas pré-natais acima de 7.

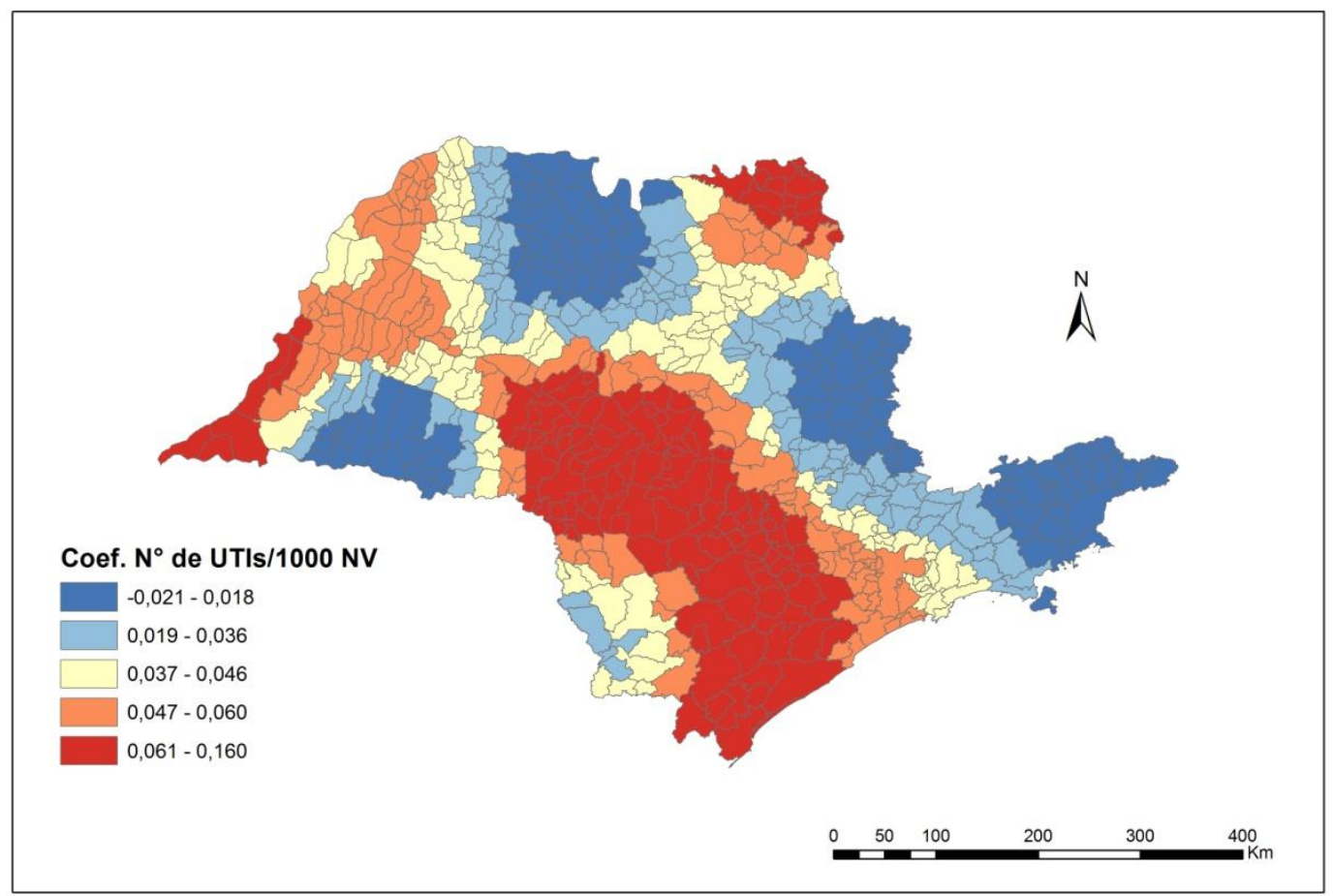

Figura 25 - Mapa do coeficiente do número de UTIs neonatais por 1000 nascidos vivos. 
7.5 Análise espacial exploratória retrospectiva do padrão espacial dos riscos relativos de nascimentos pré-termo para Região Metropolitana de São Paulo

No período de 2000 a 2010, do total de 3.524.138 nascidos vivos, 286.035 foram prematuros, representando $8,1 \%$ de nascimentos pré-termo nesta última década. No ano de 2000 , a Taxa era de $7,5 \%$ e chegou a $8,8 \%$ em 2010, isto é, houve um progressivo aumento de mais de $1 \%$ na última década (Figura 26).

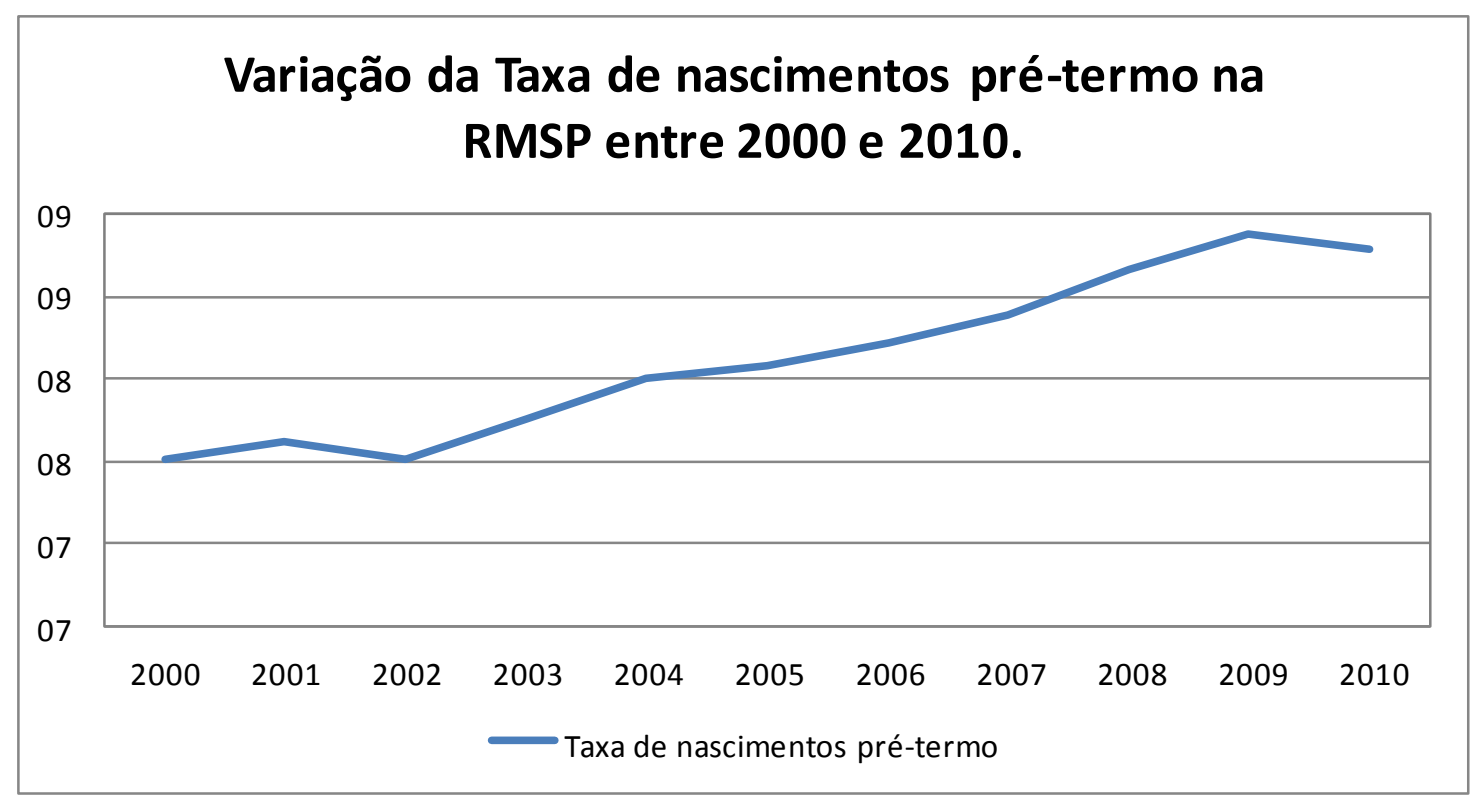

Figura 26- Variação da Taxa de nascimentos pré-termo na RMSP entre 2000 e 2010.

O risco relativo de nascimentos pré-termo variou de 0,58 a 1,47 , sendo que o município de Salesópolis, São Paulo, Guarulhos, Cajamar, Santana de Parnaíba e Cotia apresentaram os riscos mais elevados na faixa de 1,05 a 1,47 (Figura 27)

Já pelo Mapa de Agrupamentos espaciais para 5\% da população em risco (Figura 8), verificamos que apenas os municípios de Cotia, São Bernardo do Campo e São Caetano do Sul tiveram alto risco de nascimentos pré-termo (representados em vermelho).

Ao mesmo tempo, os municípios de Taboão da Serra, Osasco, Santana de Parnaíba, Barueri (a oeste de São Paulo) formaram um agrupamento de baixo risco a 
nascimentos pré-termo. Ao norte de São Paulo, os municípios de Mairiporã, Franco da Rocha, Caieiras e Francisco Morato constituíram outro agrupamento de baixo risco. Por fim, a leste de São Paulo, Biritiba-Mirim, Guarema, Arujá, Mogi das Cruzes, Santa Isabel, Suzano, Poá, Ferraz de Vasconcelos, Mauá, Ribeirão Pires e Rio Grande da Serra formaram um grande agrupamento de baixo risco a nascimentos pré-termo (Figura 28).

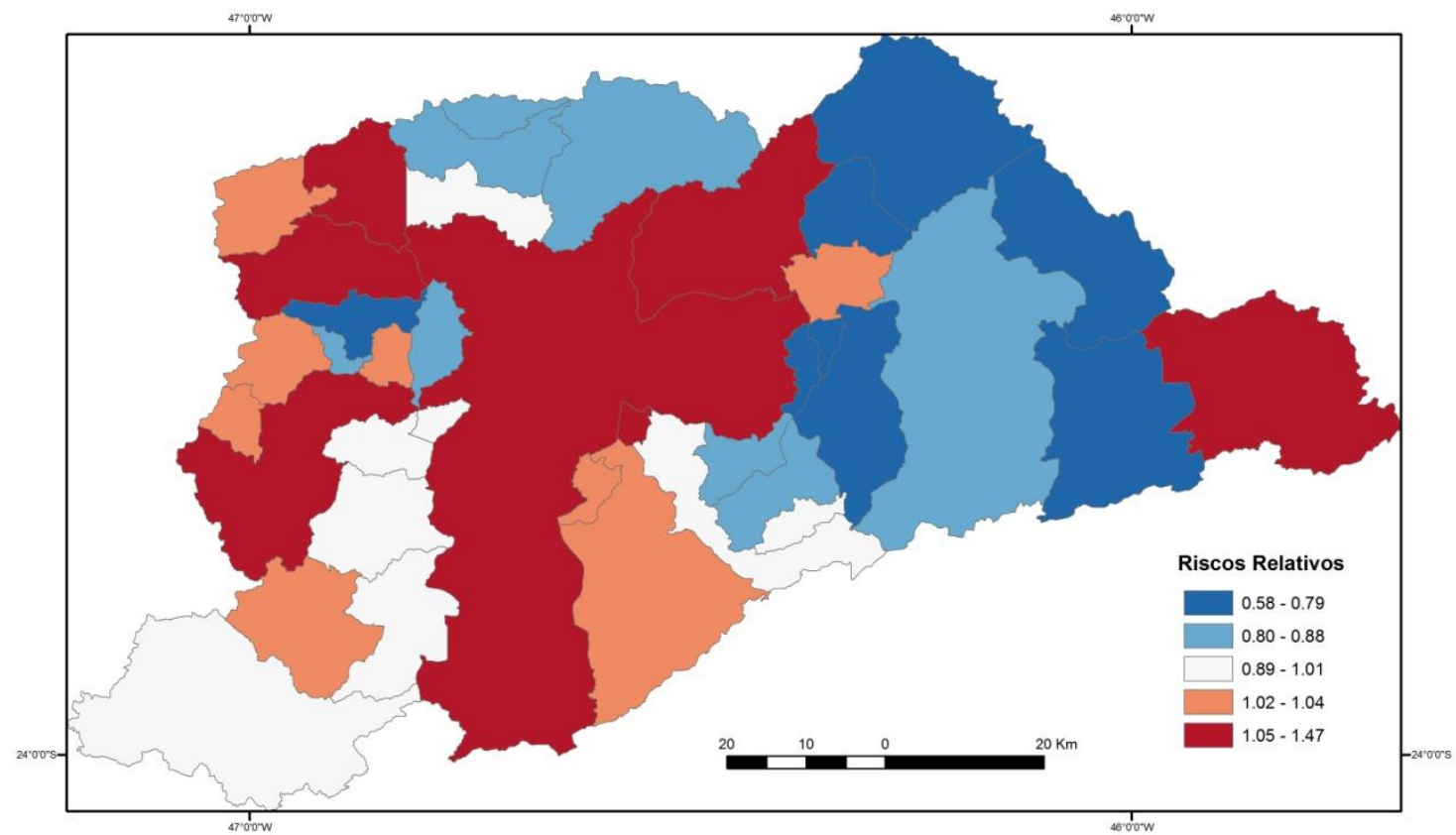

Figura 27 - Mapa dos Riscos Relativos de nascimentos pré-termo na RMSP, entre 2000 e 2010, tendo como co-variável a faixa-etária das mães. 


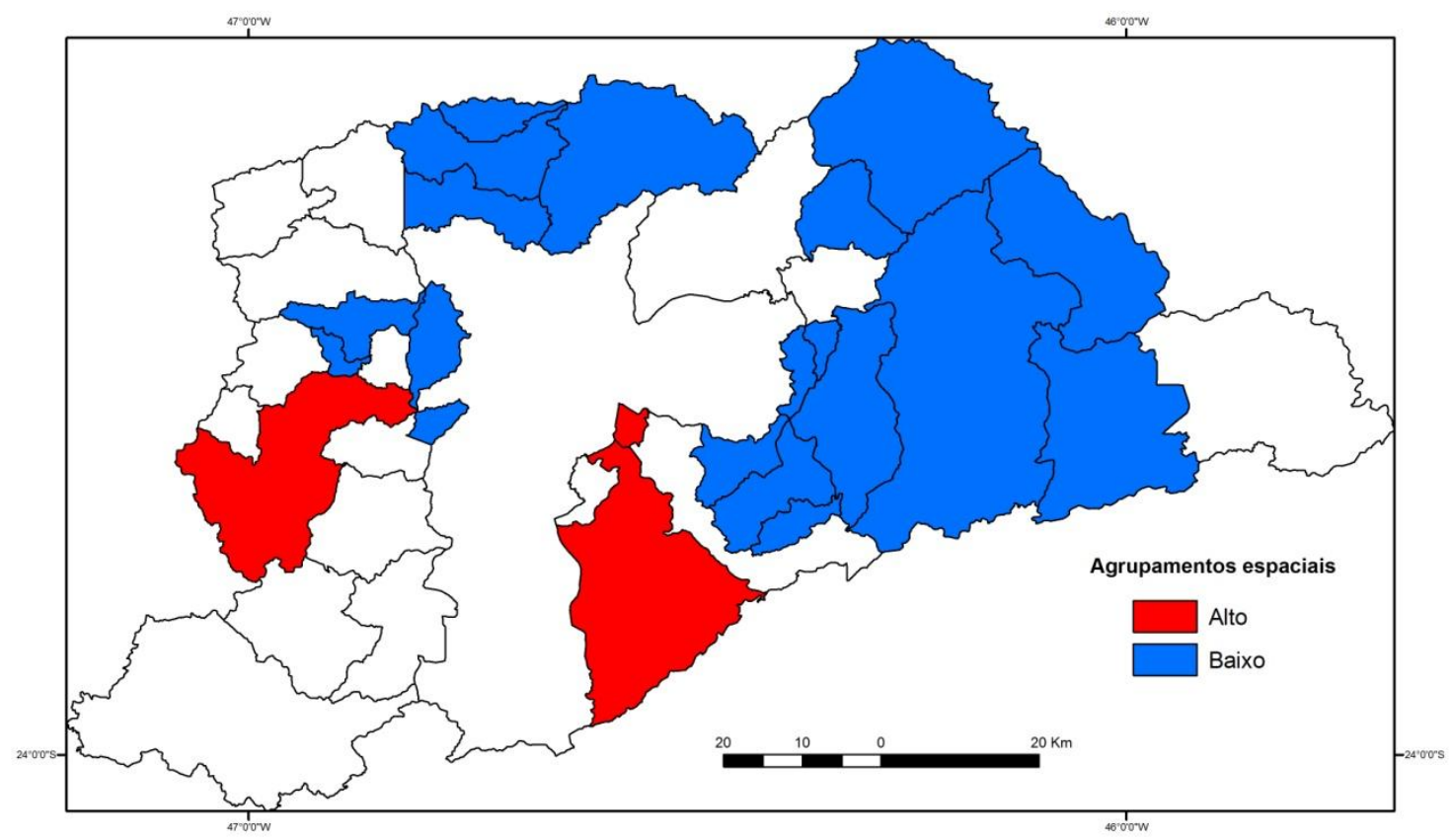

Figura 28- Mapa dos Agrupamentos espaciais dos nascimentos pré-termo na RMSP entre 2000 e 2010.

Tabela 10 - Autocorrelação espacial global das variáveis na RMSP entre 2000 e 2010

\begin{tabular}{|l|c|c|}
\hline RMSP & $\begin{array}{l}\text { I Moran Global - } \\
\text { Univariado }\end{array}$ & Valor de p \\
\hline Risco Relativo (RR) & 0,0413 & 0,259 \\
\hline Índice de Gini (IG) & 0,0340 & 0,246 \\
\hline Índice de Privação (IP) & 0,0446 & 0,429 \\
\hline Taxa de Desemprego (TD) & $-0,2261^{*}$ & $0,018^{*}$ \\
\hline Taxa de Analfabetismo (TA) & $0,4445^{* *}$ & $0,001^{* *}$ \\
\hline Porc. de Aglomerados Subnormais (TAG) & $0,2422^{*}$ & $0,013^{*}$ \\
\hline
\end{tabular}

${ }^{*} \mathrm{p}<0,05,{ }^{* *} \mathrm{p}<0,01$

Observamos que as variáveis de: Taxa de Desemprego, a Taxa de Analfabetismo e a Porcentagem de Aglomerados Subnormais apresentaram autorrelação espacial global signigicativas, oui seja, com valor de $\mathrm{p}<0,05$ (Tabela 10). 
Tabela 11- Correlação espacial global entre o risco relativo e as variáveis socioeconômicas na RMSP entre 2000 e 2010.

\begin{tabular}{|l|c|c|}
\hline RMSP & $\begin{array}{l}\text { I Moran Global - } \\
\text { Bivariado }\end{array}$ & Valor de $\mathrm{p}$ \\
\hline RR X IG & $0,2003^{*}$ & $0,026^{*}$ \\
\hline RR x IP & 0,1462 & 0,108 \\
\hline RR X TD & $0,2261^{*}$ & $0,018^{*}$ \\
\hline RR X TA & 0,0779 & $0,318^{*}$ \\
\hline RR X TAG & 0,0679 & 0,180 \\
\hline
\end{tabular}

$* \mathrm{p}<0,05, * * \mathrm{p}<0,01$

Verificamos que na RMSP houve apenas associação espacial global significativa entre Risco Relativo e Taxa de Desemprego, e entre Risco Relativo e Índice de Gini (Tabela 11). A associação entre as condições socioeconômicas e o risco a nascimentos pré-termo é mais complexa na RMSP devido à maior heterogeneidade espacial dos indicadores.

\subsection{Análise espacial exploratória retrospectiva do padrão espacial dos riscos relativos de nascimentos pré-termo para o município de São Paulo}

Pela Fígura 29, verificamos que ocorrência de nascimentos pré-termo também aumentou no município de São Paulo na última década. Do total de 1.693 .074 nascidos vivos entre 2003 e 2012, 155.353 nasceram prematuros, ou seja, nascidos decorrentes de gestações inferiores a 37 semanas completas. Dessa maneira, a porcentagem de nascimentos pré-termo variou de 8,4\% em 2003 para 12,3\% em 2012. O ano de 2012, especificamente, obteve a maior porcentagem de $12,3 \%$ no período todo aqui analisado. 


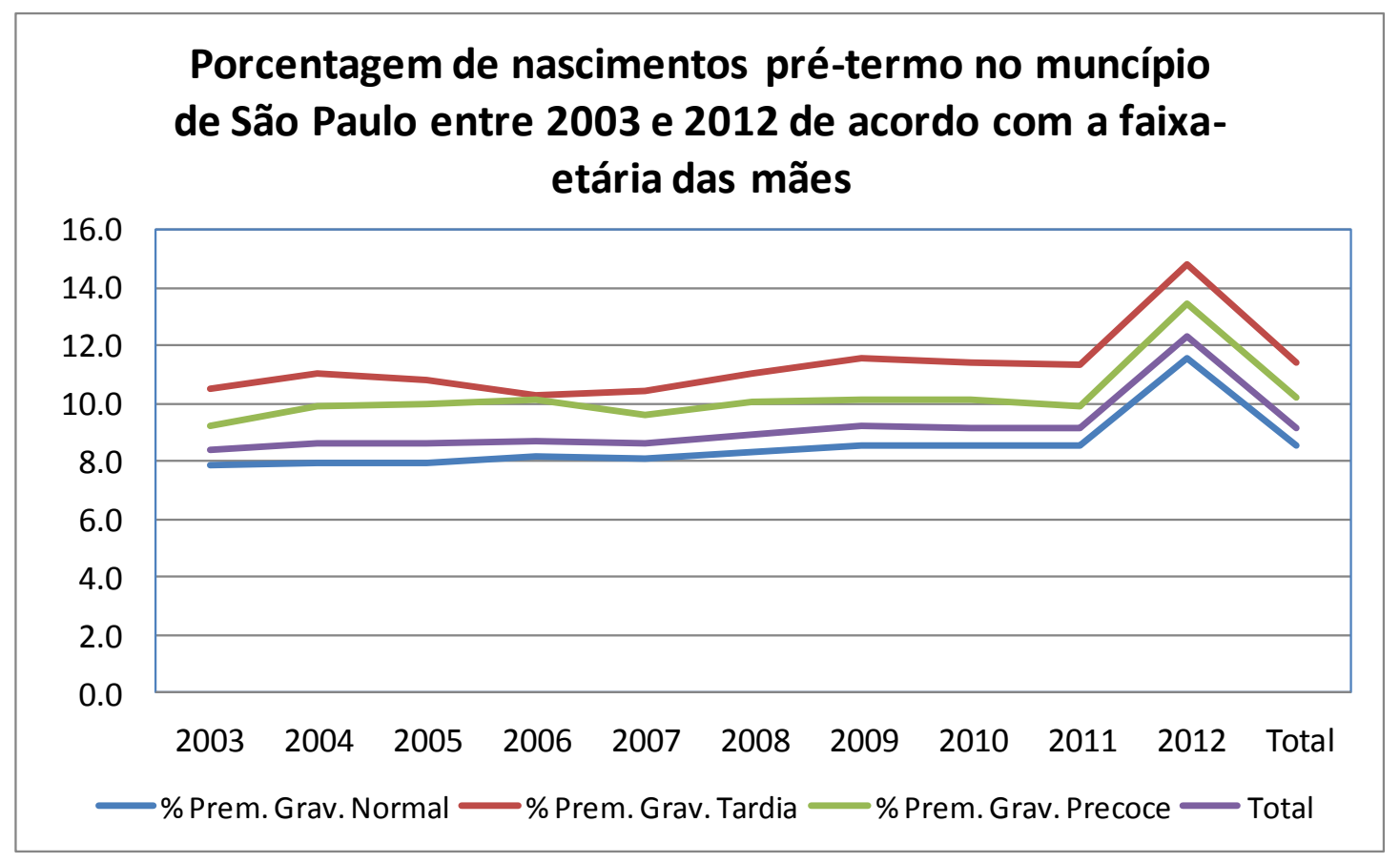

Figura 29 - Porcentagem de nascimentos pré-termo no município de São Paulo entre 2003 e 2012 de acordo com a faixa-etária das mães.

Entre 2003 e 2012, a prematuridade em decorrência da gravidez tardia (mães com mais de 35 anos) é um pouco mais representativa, variando entre $10,5 \%$ a $14,8 \%$ dos casos. A prematuridade em função da gravidez na adolescência (mães entre 10 e 19 anos) ficou entre $9,2 \%$ e $13,4 \%$. Já os nascimentos pré-termo consequentes de gestações com as mães em idade reprodutiva entre 20 e 34 anos (consideradas com menor risco) oscilaram entre $7,8 \%$ e $11,6 \%$ entre 2003 e 2012.

Do total de 155.353 nascimentos pré-termo, apenas 271 não tiveram a identificação de distrito por residência das mães, isto é, apenas $0,17 \%$ do total da amostra.

Observamos que o risco relativo de nascimentos pré-termo, tendo como covariável a faixa-etária das mães, variou entre 0,75 a 1,27 entre os anos de 2003 a 2007 no município de São Paulo (Figura 30). O distrito Anhanguera (zona norte) obteve o menor, enquanto o maior pertenceu ao distrito de Moema na (zona sul). 
$\mathrm{Na}$ análise de varredura espacial para 5\% da população em risco (Figura 31), verificamos que os distritos Vila Leopoldina, Parque do Carmo, Bela Vista, Campo Belo, Itaim Bibi, Jardim Paulista, Moema, Saúde, Vila Mariana, Barra Funda, Bom Retiro, Casa Verde, Consolação, Lapa, Limão, Perdizes, Santa Cecília, Campo Grande, Cidade Ademar, Água Rasa, Belém, Carrão, Tatuapé, Brasilândia, Cachoeirinha, São Lucas, Vila Prudente, Cidade Tiradentes e Guaianases apresentaram agrupamentos de alto risco (representados em vermelho), com valores acima de 1.

Os distritos de Ermelino Matarazzo, São Miguel, Vila Jacuí, Iguatemi, São Mateus, São Rafael, Sacomã, Campo Limpo, Capão Redondo, Jaçanã, Tremembé, Jardim São Luis, Jardim Ângela e Anhanguera tiveram agrupamentos de baixo risco (representado em azul), com valores abaixo de 1.

Enquanto que os distritos Alto de Pinheiros, Aricanduva, Artur Alvim, Brás, Butantã, Cambuci, Cangaíba, Cidade Dutra, Cidade Líder, Cursino, Freguesia do Ó, Grajaú, Ipiranga, Itaim Paulista, Itaquera, Jabaquara, Jaguara, Jaguaré, Jaraguá, Jardim Helena, José Bonifacio, Lajeado, Liberdade, Mandaquí, Marsilac, Mooca, Morumbi, Parelheiros, Pari, Pedreira, Penha, Perus, Pinheiros, Pirituba, Ponte Rasa, Raposo Tavares, República, Rio Pequeno, Santana, Santo Amaro, São Domingos, Sapopemba, Sé, Socorro, Tucuruvi, Vila Andrade, Vila Curuçá, Vila Formosa, Vila Guilherme, Vila Maria, Vila Matilde, Vila Medeiros e Vila Sônia não apresentaram agrupamentos significativos (representados em branco). 


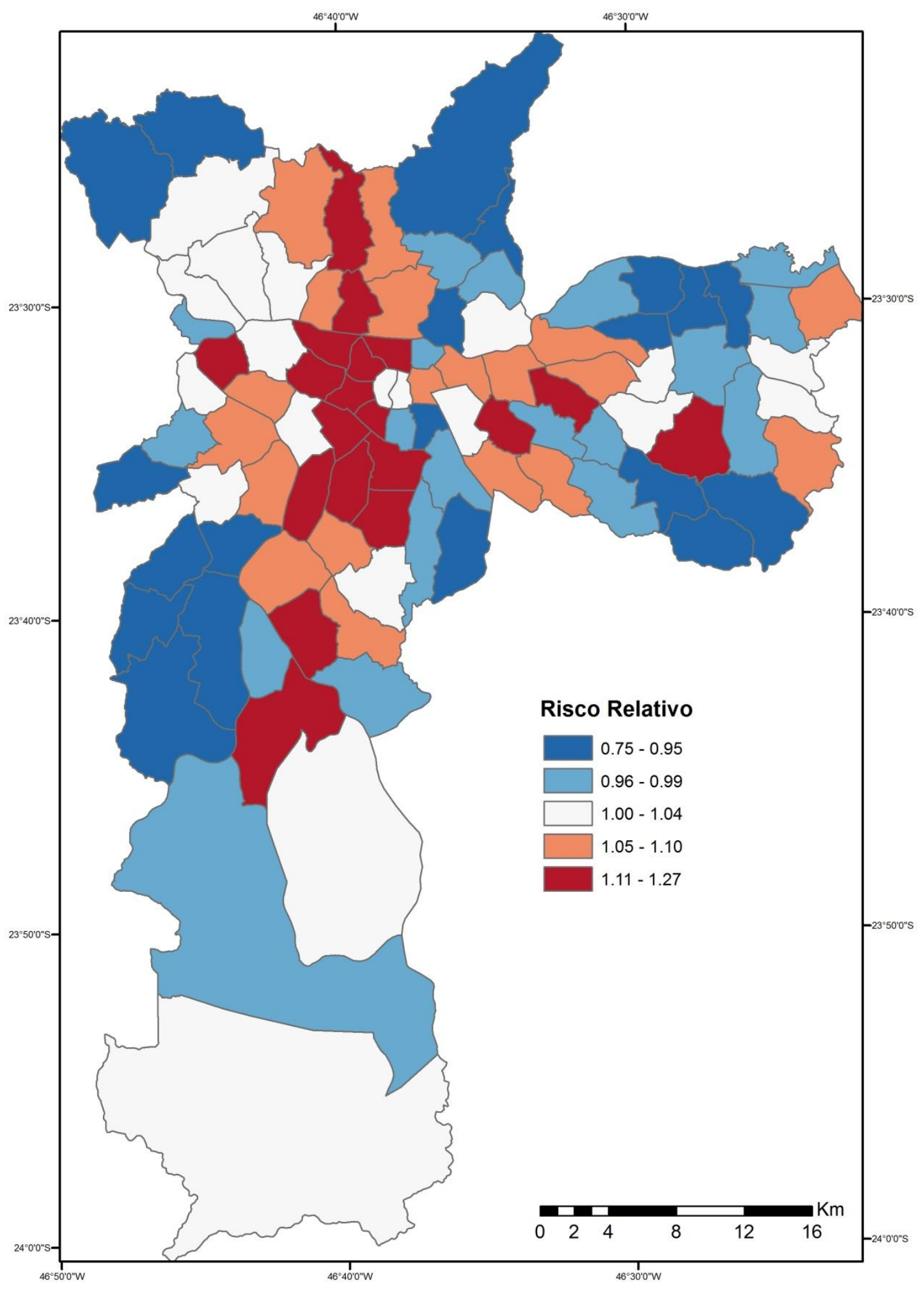

Figura 30 - Mapa dos Riscos Relativos de nascimentos pré-termo no município de São Paulo entre 2003 e 2007, co-variável: faixa-etária das mães. 


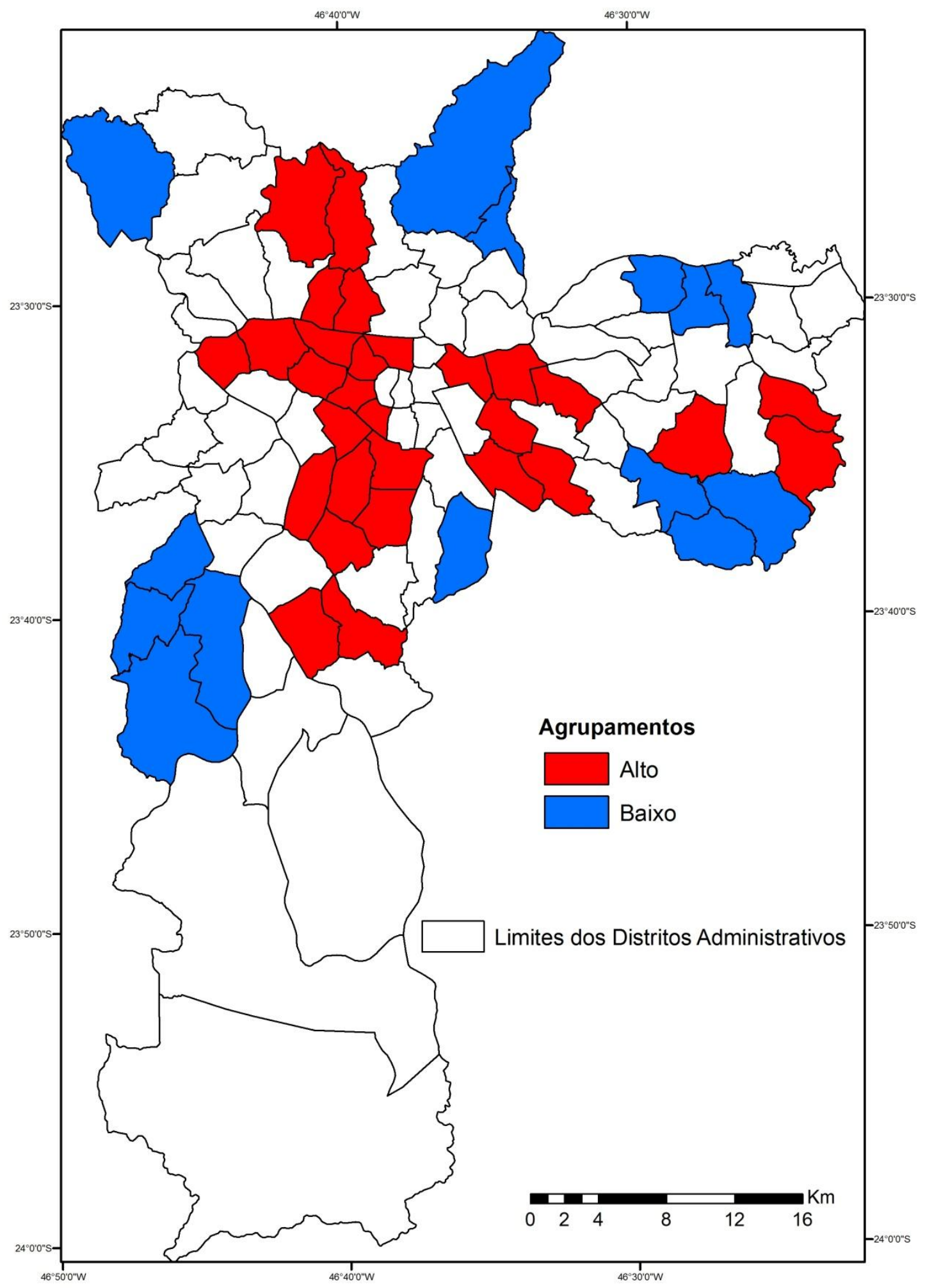

Figura 31- Mapa dos Agrupamentos Espaciais para 5\% da População em Risco, entre 2003 e 2007, no município de São Paulo. 
Notamos que o risco relativo de nascimentos pré-termo, tendo como co-variável a faixa-etária das mães, variou entre 0,84 a 1,24 entre os anos de 2008 e 2012 no município de São Paulo (Figura 32). O distrito Anhanguera (zona norte) obteve o menor, enquanto o maior referiu-se ao distrito de Marsilac (zona sul).

$\mathrm{Na}$ análise de varredura espacial para $5 \%$ da população em risco (Figura 33), verificamos que os distritos Parque do Carmo, Campo Belo, Campo Grande, Itaim Bibi, Morumbi, Santo Amaro, Socorro, Vila Andrade, Cidade Ademar, Água Rasa, Aricanduva, Carrão, São Lucas, Tatuapé, Vila Formosa, Vila Prudente, Barra Funda, Limão, Perdizes, Santa Cecília, Bela Vista, Cambuci, Ipiranga, Jardim Paulista, Liberdade, Moema, Saúde, Vila Mariana, Sapopemba, Jaçanã, Tremembé, Tucuruvi e Vila Medeiros apresentaram agrupamentos de alto risco (representados em vermelho), com valores acima de 1.

Os distritos Jardim São Luís, Cangaíba, Ermelino Matarazzo, Ponte Rasa, Vila Jacuí, Lajeado, São Miguel, Vila Curuçá, Casa Verde, Iguatemi, São Mateus, São Rafael, Jardim Ângela, Anhanguera, Jaraguá, Perus e São Domingos tiveram agrupamentos de baixo risco (representado em azul), com valores abaixo de 1 - (Figura 13).

Ao mesmo tempo, os distritos de Alto de Pinheiros, Artur Alvim, Belém, Bom Retiro, Brás, Brasilândia, Butantã, Cachoeirinha, Campo Limpo, Capão Redondo, Cidade Dutra, Cidade Líder, Cidade Tiradentes, Consolação, Cursino, Freguesia do Ó Grajaú, Guaianases, Itaim Paulista, Itaquera, Jabaquara, Jaguara, Jaguaré, Jardim Helena, José Bonifácio, Lapa, Mandaqui, Marsilác, Mooca, Parelheiros, Pari, Pedreira, Penha, Pinheiros, Pirituba, Raposo Tavares, República, Rio Pequeno, Sacomã, Santana, Sé, Vila Guilherme, Vila Leopoldina, Vila Maria, Vila Matilde e Vila Sônia não apresentaram agrupamentos significativos (representados em branco) - (Figura 13). 


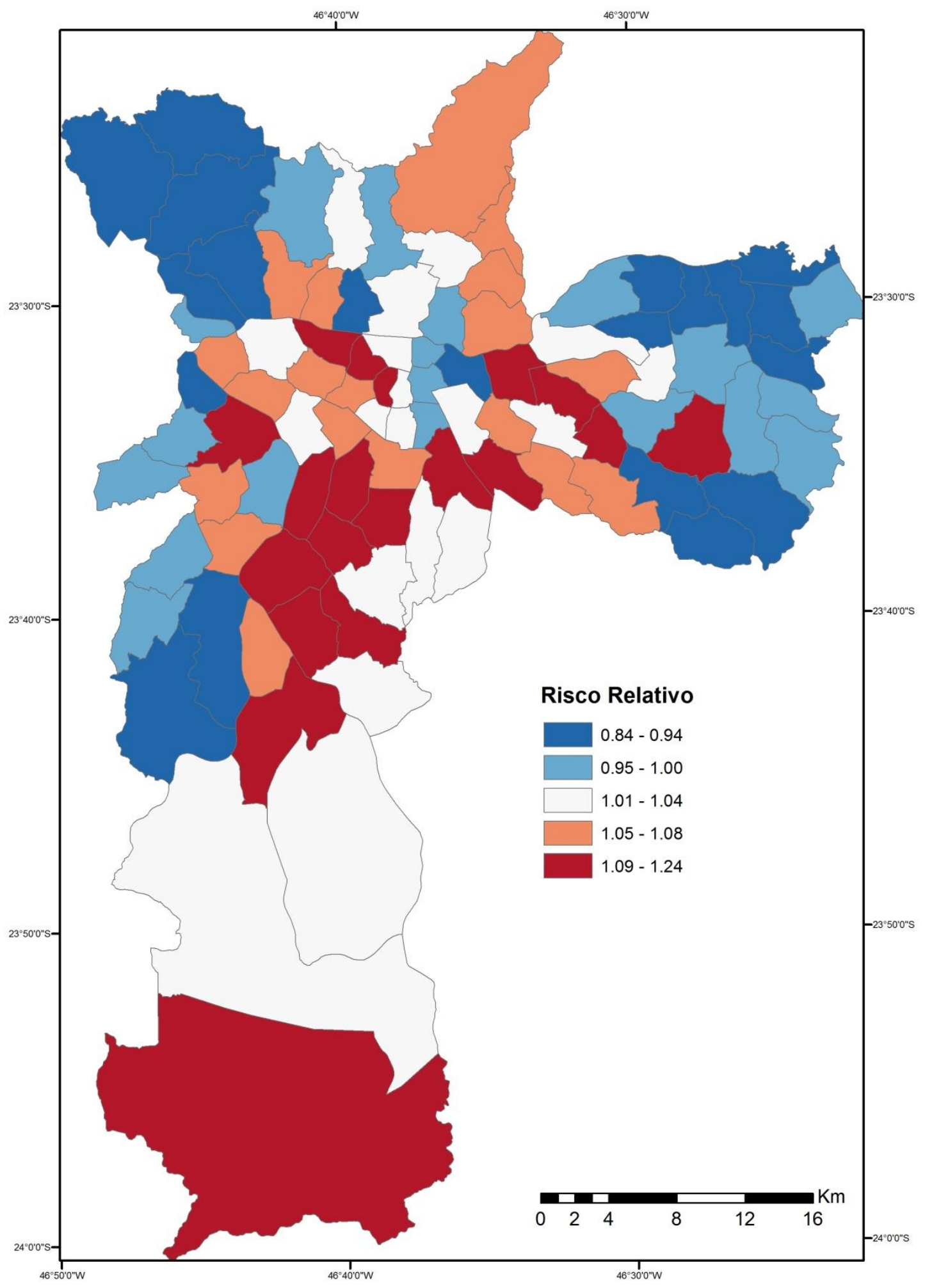

Figura 32 - Mapa dos Riscos Relativos de nascimentos pré-termo no município de São Paulo entre 2008 e 2012, co-variável: faixa-etária das mães. 


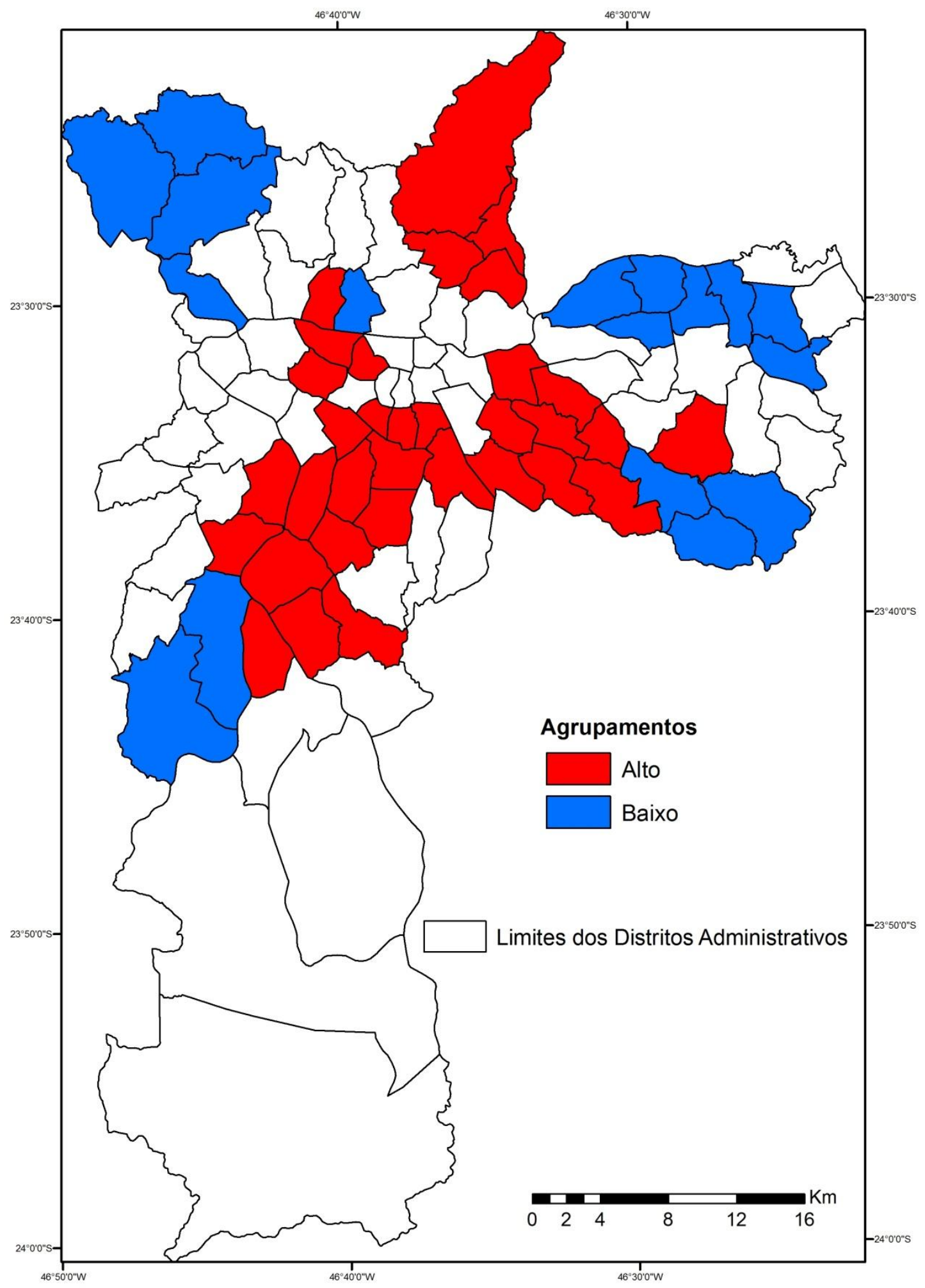

Figura 33 - Mapa dos Agrupamentos Espaciais para 5\% da População em Risco, entre 2008 e 2012, no município de São Paulo. 
Verificamos que o risco relativo de nascimentos pré-termo, tendo como covariável a faixa-etária das mães, variou entre 0,80 a 1,20 entre os anos de 2003 e 2012 no município de São Paulo (Figura 34). O distrito Anhanguera (zona norte) obteve o menor, enquanto o maior referiu-se ao distrito de Marsilác (zona sul).

$\mathrm{Na}$ análise de varredura espacial para $5 \%$ da população em risco (Figura 35), observamos que os distritos Vila Leopoldina, Parque do Carmo, Campo Belo, Itaim Bibi, Jardim Paulista, Moema, Saúde, Vila Mariana, Campo Grande, Cidade Ademar Barra Funda, Bela Vista, Bom Retiro, Consolação, Perdizes, República, Santa Cecília, Sé, Água Rasa, Aricanduva, Carrão, São Lucas, Tatuapé, Vila Formosa, Vila Prudente, Freguesia do Ó, Limão, Cachoeirinha, Mandaqui, Morumbi, Santo Amaro, Vila Andrade, Vila Sônia e Grajaú apresentaram agrupamentos de alto risco (representados em vermelho), com valores acima de 1.

Os distritos Campo Limpo, Capão Redondo, Jardim Helena, Vila Curuça, Ermelino Matarazzo, São Miguel, Vila Jacuí, Anhanguera, Jaraguá, Perus, Iguatemi, São Mateus, São Rafael, Jardim São Luís e Jardim Ângela tiveram agrupamentos de baixo risco (representado em azul), com valores abaixo de 1 (Figura 35).

Já os distritos de Alto de Pinheiros, Artur Alvim, Belém, Bom Retiro, Brás, Brasilândia, Butantã, Cambuci, Cangaíba, Casa Verde, Cidade Dutra, Cidade Líder, Cidade Tiradentes, Cursino, Guaianases, Ipiranga, Itaim Paulista, Itaquera, Jabaquara, Jaçanã, Jaguara, Jaguaré, José Bonifácio, Lajeado, Lapa, Liberdade, Marsilác, Mooca, Parelheiros, Pari, Pedreira, Penha, Pinheiros, Pirituba, Ponte Rasa, Raposo Tavares, Rio Pequeno, Sacomã, Santana, São Domingos, Sapopemba, Socorro, Tremembé, Tucuruvi, Vila Guilherme, Vila Maria, Vila Matilde e Vila Medeiros não apresentaram agrupamentos significativos (representados em branco) - (Figura 35). 


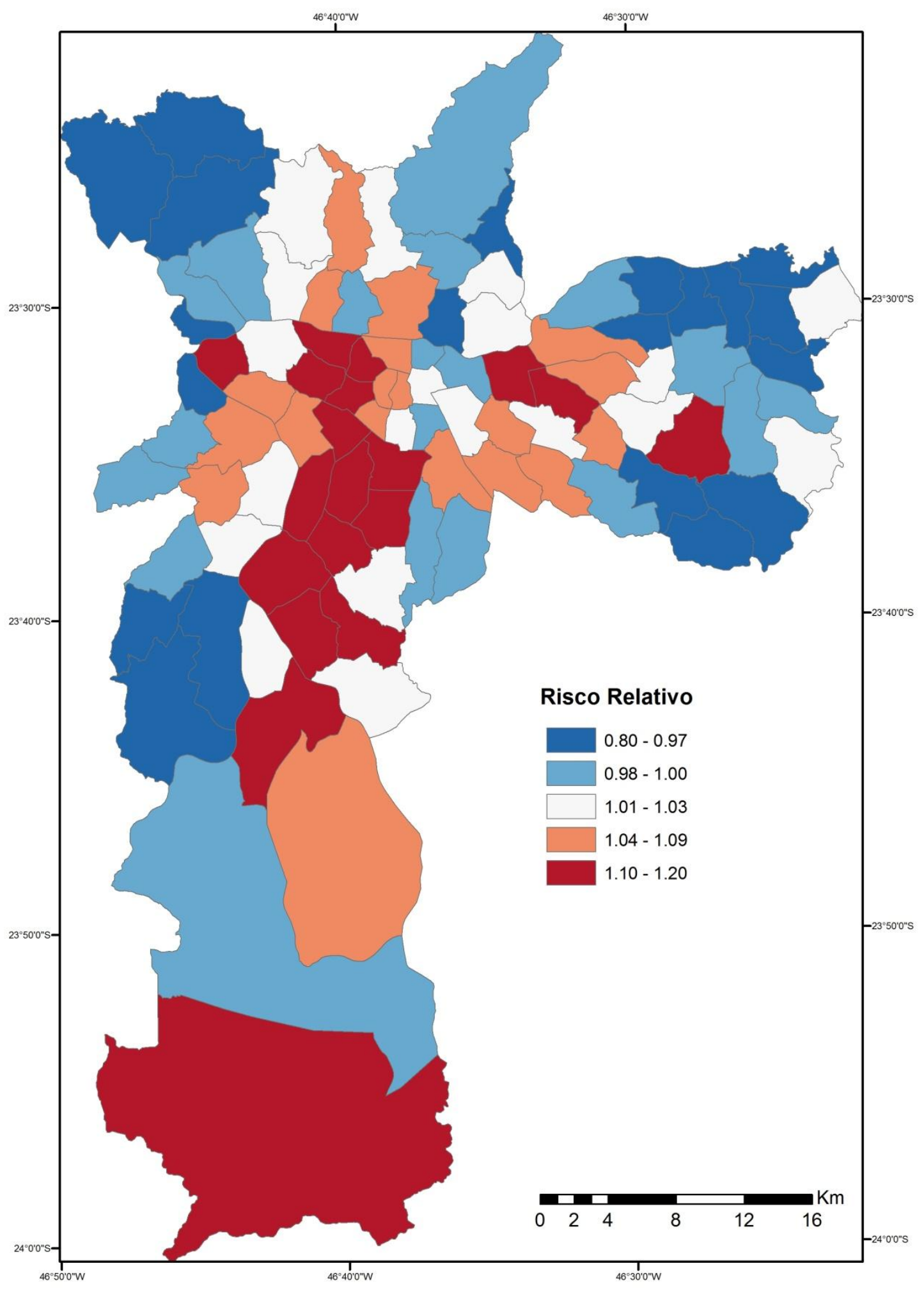

Figura 34 - Mapa dos Riscos Relativos de nascimentos pré-termo no município de São Paulo entre 2003 e 2012, co-variável: faixa-etária das mães. 


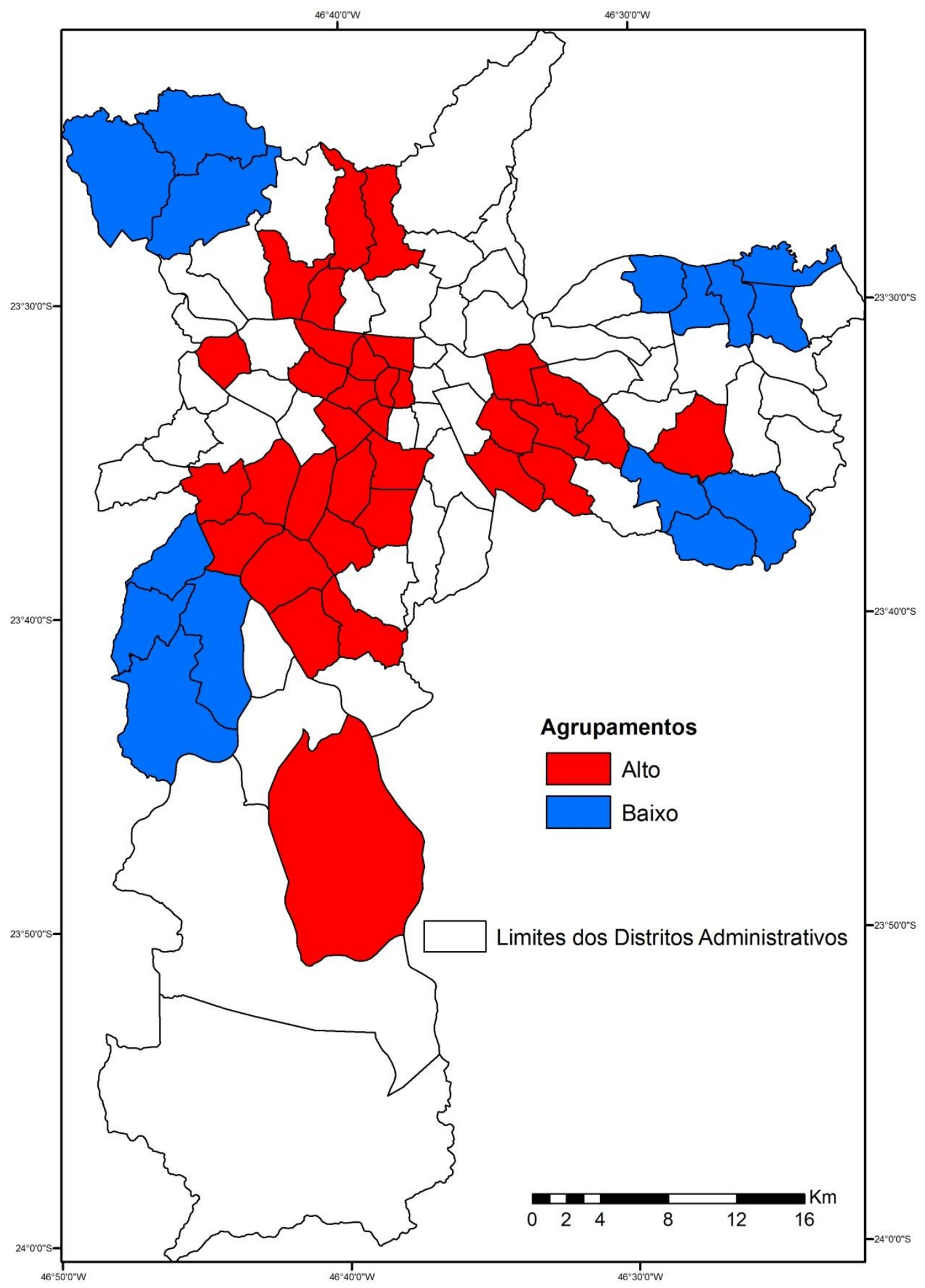

Figura 35- Mapa dos Agrupamentos Espaciais para 5\% da População em Risco, entre 2002 e 2013, no município de São Paulo. 


\section{DISCUSSÕES}

Para o estado de São Paulo, percebemos que há um padrão espacial dos riscos relativos de nascimentos pré-termo, que não há aleatoriedade na sua distribuição geográfica, com todas as co-variáveis testadas: a idade e a escolaridade das mães, tipo de parto (cesárea e normal) e número de consultas pré-natal.

Constatamos que os padrões espaciais dos aglomerados de alto risco, tanto na análise de varredura espacial de 5 quanto de 50\%, mantiveram-se semelhantes tanto nos municípios de Ribeirão Preto, São José do Rio Preto, para todas as co-variáveis analisadas. Isto sugere que o alto risco de nascimento pré-termo não se explica espacialmente pela idade, nem pela escolaridade da mães, nem pelo tipo de parto, nem pelo número de consultas pré-natal nessas localidades, demonstrando que outros fatores como compreender podem contribuir para a melhor compreensão espacial do risco alto de nascimentos pré-termo nesses municípios como modelo de atenção à saúde materna e infantil, por exemplo.

Tanto os riscos relativos dos nascimentos pré-termo como as variáveis socioeconômicas apresentaram autocorrelação espacial global significativa. No entanto, apenas as variáveis: porcentagem de assentamentos precários e taxa de analfabetismo, que tiveram associação espacial global significativa com os riscos relativos de nascidos prematuros.

Houve associação espacial local significativa entre os riscos relativos de nascidos prematuros com todas as variáveis socioeconômicas testadas (porcentagem de assentamentos precários, taxa de analfabetismo, taxa de desemprego e índice de privação socio-material). As distribuições geográficas destas associações ocorreram de maneira não aleatória e heterogênea pelo território paulista, demonstrando a relação complexa entre a saúde materna e dos recém-nascidos com as condições socioeconômicas em que eles estão inseridos. 
Estudo semelhante foi desenvolvido por Friche (2006) no município de Belo Horizonte, onde foi analisada a presença de aglomerados espaciais de indicadores de saúde para recém-nascidos e de suas mães por área de abrangência das Unidades Básicas de Saúde.

Da mesma maneira, aplicou-se o teste de regressão a partir do índice global de Moran (I) e Indicadores Locais de Associação Espacial (LISA) para o município de Belo Horizonte. Os resultados mostraram a presença de aglomerados espaciais relevantes para mães adolescentes e com baixa escolaridade, natimortos em gestações anteriores, cesárea e baixa participação em pré-natal, especialmente em áreas com características sócio-demográficas baixas (Fisher, 2006).

Em outro estudo feito num concelho do sul da Califórnia nos EUA, investigouas mudanças no padrão espacial de baixo peso ao nascer, assim como avalia-use o papel do indivíduo e dos fatores de vizinhança neste desfecho. Também foram usados modelos de regressão multivariada para identificar variáveis no nível individual e do bairro entre os anos 80 e 90 (Neutra et al. 2003).

Enquanto as variáveis individuais e de nível de vizinhança explicou sobre uma quantidade igual de variação no BPN, só variáveis de nível de bairro foram preditores significativos ao nascimento prematuro de baixo peso. As medidas de riqueza foram relacionados fortemente com o nascimento prematuro de baixo peso, destacando a importância importância das mudanças socioeconômicas e demográficas na saúde reprodutiva das mães no bairro (Neutra et al. 2003).

Williamson et al (2013) verificou se existe associal espacial entre mulheres com e nascimentos prematuros na Geórgia EUA entre 2002 e 2006, através do modelo espacial bayesiano multivariado. Os indicadores I Moran Global e-indicadores locais de associação estatística espacial sugerem significativa correlação espacial de doenças 
cardiovasculares e nascimentos prematuros.

Na análise de regressão dos Mínimos Quadrados Ordinários (OLS), apenas o número de UTIs foi a única variável estatisticamente significativa do modelo global que melhor explicar a distribuição geográfica dos riscos relativos de nascimentos pré-termo no estado de São Paulo.

Notando que o teste Koenker foi estatisticamente significativo, o que indica não estacionaridade entre as variáveis, que se aplicou o GWR para verificar uma possível melhorara no desempenho do modelo de regressão. Portanto, OLS ajudou a identificar os principais fatores que contribuem para a distribuição geográfica dos riscos de nascimentos pré-termo no estado.

O GWR ajudou a identificar separadamente e localmente quais os munícipios do território paulista apresentaram riscos mais altos de nascimentos pré-termo devido a privação sócio-material, a porcentagem de cesáreas, a porcentagem de consultas prénatal acima de 7 e número de UTIs neonatais por 1000 nascidos vivos.

Para a Região Metropolitana de São Paulo, pela análise de varredura espacial de 5\%, também compreendemos que há um padrão espacial dos riscos relativos de nascimentos pré-termo, que não há aleatoriedade na sua distribuição geográfica, tendo como co-variável a idades das mães. No entanto, por se tratarem de apenas 39 municípios também bastantes heterogêneos, a detecção de agrupamentos de alto risco foi identificada em apenas 3 deles.

Observamos que as variáveis de: Taxa de Desemprego, a Taxa de Analfabetismo e a Porcentagem de Aglomerados Subnormais apresentaram autorrelação espacial global significativas. houve apenas associação espacial global significativa entre Risco Relativo e Taxa de Desemprego, e entre Risco Relativo e Índice de Gini. A associação entre as condições socioeconômicas e o risco a nascimentos pré-termo é mais complexa 
na RMSP devido à maior heterogeneidade espacial dos indicadores.

Podemos inferir, portanto, que os riscos de nascimentos pré-termo apresentaram um padrão espacial não aleatório no município de São Paulo, quando padronizados pela idade das mães. Portanto, estes padrões espaciais de alto e baixo risco de nascimentos pré-termo não podem ser explicados apenas pela idade das mães.

Montero (2004) também desenvolveu um estudo ecológico para região Sul do município de São Paulo, onde verificou que distribuição espacial dos nascidos vivos e da mortalidade neonatal não apresentou padrão aleatório e regular, havendo formação de clusters inter-distritos, assim como apresentado aqui para os riscos de nascimentos pré-termo.

Santos (2014) também realizou um estudo, utilizando análise espacial de aglomerados de nascimentos ocorridos em hospitais SUS e não SUS do município de São Paulo em 2008, sendo que os resultados mostraram existir diferenciais significativos no perfil dos aglomerados de nascidos vivos, o que são refletem as desigualdades das condições de vida do MSP. Ambos trabalhos convergem em termos de metodologia e objetivo como este aqui proposto. Todos se complementam e podem colaborar para ações de vigilância e de medidas preventivas dentro das políticas de saúde materna e do recém-nascido no município de São Paulo. 


\section{CONSIDERAÇÕES FINAIS}

A metodologia de analise espacial exploratória aqui adotada teve a preocupação de analisar espacialmente um mesmo desfecho de saúde (nascimentos pré-termo) em diferentes escalas geográficas, o que foi bastante desafiador. O período das bases de dados epidemiológicos, demográficos e de saúde utilizadas não foi o mesmo, já que dao longo da pesquisa a disponibilidade dos dados secundários foi diferente.

Ao mesmo tempo esta metodologia revelou ser um instrumento fundamental para a detecção de áreas de risco para nascimentos pré-termo nas diferentes escalas. Ela pode ser facilmente incorporado em sistemas de vigilância da saúde como um mecanismo para controlar os eventos relacionados aos nascimentos em determinadas áreas, já que vem sendo aplicado tanto nos estudos de análise espacial de dados de saúde tantos nas pesquisas desenvolvidas no Brasil como no exterior.

A estrutura espacial da correlação entre nascimentos prematuros e as variavéis do contexto geográfico, assim como os métodos de regressão da OLS e GWS podem demostrar perspectivas consistentes a longo prazo sobre os determinantes sociais de saúde materna e do do recém-nascido no estado de São Paulo e na RMSP.

Desse modo, corroboramos as duas hípoteses da tese:

1. A de que a distribuição espacial dos riscos de nascimentos pré-termo não é aleatória nas três escalas propostas.

2. As variáveis de contexto geográfico estão associadas localmente e espacialmente aos nascimentos pré-termo no estado de São Paulo e na RMSP. 


\section{REFERÊNCIAS BIBLIOGRÁFICAS}

ALMEIDA, M. F. et al. Sobrevida e fatores de risco para mortalidade neonatal em uma coorte de nascidos vivos de muito baixo peso ao nascer, na Região Sul do Município de São Paulo, Brasil. Cad. Saúde Pública, Rio de Janeiro, 27(6):1088-1098, jun, 2011.

ALMEIDA, Wanessa da Silva de. Mortalidade Infantil e Acesso ao Parto Hospitalar nos Municípios Brasileiros. 2011. 85f. Dissertação (Mestrado), Escola Nacional de Saúde Pública Sérgio Arouca, Rio de Janeiro, 2011.

ANSELIN, L. \& BAO, S. Exploratory Spatial Data Analysis Linking SpaceStat and ArcView. In: Fischer, M. M. \& Getis, A. Recent developments in spatial analysis. New York: Springer, 1997, p. 35-59.

ANSELIN, L. Exploring Spatial Data with GeoDa TM: a Workbook. University of Illinois, Urbana-Champaign, 2005

ARAÚJO, D. M. R. et al. Ansiedade na gestação, prematuridade e baixo peso ao nascer: uma revisão sistemática da literatura. Cad. Saúde Pública, Rio de Janeiro, 23(4):747756, abr, 2007.

ASSUNÇÃO, P. L. et al. Fatores associados ao nascimento pré-termo em Campina Grande, Paraíba, Brasil: um estudo caso-controle. Cad. Saúde Pública, Rio de Janeiro, 28(6):1078-1090, jun, 2012.

AUGER, N. et al. Social Science \& Medicine, 75 (2012), 1032 e 1037.

BARCELOS, C. (Org). Território, Ambiente e Saúde. Editora FIOCRUZ, Rio de Janeiro, 2008.

BARRETO JUNIOR, I. F. ; FERREIRA, M. P. ; SILVA, Z. P. . Pesquisa de Condições de Vida 2006: acesso aos serviços de saúde. São Paulo em Perspectiva, v. 22, p. 5-18, 2008.

BARROS, F. C. et al. Preterm births, low birth weight, and intrauterine growth restriction in three birth cohorts in Southern Brazil: 1982, 1993 and 2004. Cad Saude Publica 2008; 24 (suppl 3): S390-98.

BARROZO, L. Técnicas em Geografia da Saúde. In: VENTURI, L. A. B. (Ed.). Geografia: práticas de campo, laboratório e sala de aula. São Paulo: Sarandi, 2011. cap. 12, p.287- 308 .

BETTIOL, H. et al. Factors associated with preterm births in southeast Brazil: a comparison of two birth cohorts born 15 years apart. Paediatr Perinat Epidemiol 2000; 14: 30-38.

BEZERRA-FILHO, J. G.; KERR-PONTES, L. R. S.; BARRETO, M. L. Mortalidade infantil e contexto socioeconômico no Ceará, no período de 1991 a 2001. Rev. Bras. Saúde Matern. Infant, v. 7(2), p. 7, 2007.

BUZAI, G. \& PYCKENHAYN, J. (Org.) Salud y enfermedad en geografía. Lugar 
Editorial. Buenos Aires, 2009.

CAIAFFA, W. et al. Saúde urbana: a cidade é uma estranha senhora, que hoje sorri e amanhã te devora. Ciência \& Saúde Coletiva, 13 (6):1785-1796, 2008.

CÂMARA, G. et al. Análise espacial de dados geográficos. Brasília, EMBRAPA, 2002 (ISBN: 85-7383-260-6). Disponível em http://www.dpi.inpe.br/gilberto/livro/analise/

CARSTAIRS, V. et al. Deprivation and health in Scotland. Aberdeen: Aberdeen University Press; 1991.

CARVALHO, M. S; CRUZ, O. G; NOBRE, F.F. Spatial partitioning using multivariate cluster analysis and a contiguity algorithm, Statistics in Medicine, 15 (in press), 1996.

CARVALHO, M. S; SOUZA SANTOS, R. Análise de dados espaciais em saúde pública: métodos, problemas, perspectivas. Caderno de Saúde Pública, 21 (2): 361-78, 2005.

CHARREIRE, E., COMBIER, E. Poor pre-natal care in an urban area: a geographic analysis. Health \& Place 2009; 15: 412-419.

CID-10. Classificação Estatística Internacional de Doenças e Problemas Relacionados à Saúde. 10a rev. (v. 1). São Paulo: Universidade de São Paulo, 1997.

CORRÊA, R. L. Região e Organização Espacial. São Paulo. Ática, 1989.

CORRÊA, R. L A Rede Urbana. São Paulo. Ática, 1994.

CORRÊA, R. L. Estudos sobre a rede urbana. Rio de Janeiro. Bertrand doBrasil, 2006.

CUMMINS, S. et al. Measuring neighbourhood social and material context: generation and interpretation of ecological data from routine and non-routine sources. Health \& Place 1, (2005), 249 - 260.

D’ORSI, E. \& CARVALHO, M. S. Perfil de nascimentos no Município do Rio de Janeiro: uma análise espacial. Cad. Saúde Pública, Rio de Janeiro, 14(2):367-379, abrjun, 1998.

DATASUS. Departamento de Informática do SUS, Ministério da Saúde, Informações de Saúde: demográficas e socioeconômicas. Disponível em http://www2.datasus.gov.br/DATASUS/index.php?area=0206.

DINIZ, S. G. et al. Equity and women's health services for contraception, abortion and childbirth in Brazil. Reproductive Health Matters 2012; 20(40): 94-101.

DRUCK, S., CARVAlho, M. S., CAMARA, G., MONTEIRO, A. M. V. Análise espacial de dados geográficos, 2002. Livro on line. Disponívem em : http://www.dpi.inpe.br/gilberto/livro/analise/ 
EMPLASA. Empresa Paulista Metropolitana de Planejamento. Disponível em: Acesso em:

http://www.emplasa.sp.gov.br/portalemplasa/infometropolitana/rmsp/rmsp_dados.asp .

22 de julho de 2010.

ESCUELA, M. Pobreza y Salud. In: Salud y enfermedad en geografía. PICKENHAYN, J. (org.). Buenos Aires, Lugar Editorial, 2009.

FRICHE, A.L. et al. Indicadores de saúde materno infantil em Belo Horizonte, Minas Gerais, Brasil, 2001: análise dos diferenciais intra-urbanos. Cad. Saúde Pública, Rio de Janeiro, 22(9):1955-1965, set, 2006.

GATREEL, A. C.; ELLIOTT, S.J. Geographies of Health: an introduction. Second ediction, Wiley-Blackwell, 2009.

GOLDANI, M. Z. et al.. Increasing pre-term and low-birth-weight rates over time and their impact on infant mortality in south-east Brazil. J Biosoc Sci 2004;36: 177-88.

GOLDEMBERG, R. L et al. Epidemilogy and causes of preterm birth. Lancet 2008; 371:75-84.

GUIMARÃES, M. T. Avaliação de desfechos relacionados à gestação em áreas contaminadas na região do estuário de Santos e São Vicente. Tese de Doutorado em Patologia, apresentada à Faculdade de Medicina da Universidade de São Paulo, 2012.

GUIMARÃES, R. Políticas de salud y escala geográfica. In: PYCKENHAYN, J. (Org.) Salud y enfermedad en geografía. Lugar Editorial. Buenos Aires, 2009.

GUMUCHIAN, H. \& MAROIS, C. Initiation à la reserche en géographie: Aménamegement, développment territorial, environnement. Montreal, Les Presses de L' Université de Montreal/Ed. Econômica, 2000, 425 p.

HARVEY, D. A Justiça Social e a cidade. São Paulo, Hucitec, 1980, p. 291.

HAU, L. C., NASCIMENTO, L. F. C., TOMAZINI J. E. Geoprocessamento para identificar padrões do perfil de nascimentos na região do Vale do Paraíba. Rev. Brás. Ginecol. Obstet;31(4):171-6, 2009.

IBGE. Instituto Brasileiro de Geografia e Estatística. Indicadores sociodemográficos e de saúde no Brasil. Estudos e Pesquisas: informação demográfica e socioeconômica, $\mathrm{n}^{\circ}$ 25, 2009. Disponível em: http://www.ibge.gov.br/home/estatistica/populacao/indic_sociosaude/2009/indicsaude.p $\underline{\mathrm{df}}$

IBGE. Instituto Brasileiro de Geografia e Estatística. Sistema Cidades. Disponível em : http://cidades.ibge.gov.br/xtras/uf.php?lang=\&coduf=35\&search=sao-paulo. 
KULLDORFF, M. INFORMATION MANEGEMENT SERVICES, INC. SatScan (TM)v.7.03: Software for the spatial and space-time scan statisctics. Disponível em: http://www.satscan.org. Acessado em 29 de setembro de 2010; 2010.

LEAL, M. C.et al. Birth in Brazil: national survey into labour and birth. Reproductive Health 2012, 9:15.

LIMA, M.C.B.M. et al. A desigualdade espacial do Baixo Peso ao Nascer no Brasil. Ciência \& Saúde Coletiva, 18(8):2443-2452, 2013.

MACINTYRE, S.; ELLAWAY, A. e CUMMINS, S. "Place effects on health: how can we conceptualise, operationalise and mesure them? Soc. Sci. Med; 2001.

MALLOY, M. H. Impact of cesarean section on neonatal mortality rates among very preterm infants in the United States, 2000-2003. Pediatrics 2008, 122(2):285-292.

MARTINS, Eunice Francisca. Mortalidade perinatal e avaliação da assistência ao pré-natal, ao parto e ao recém-nascido em Belo Horizonte, Minas Gerais. 2010.Tese (Doutorado em Enfermagem), Escola de Enfermagem, Universidade Federal de Minas Gerais, Belo Horizonte, 2010.

MATTHEWS, S. A. Mapping the results of local statistics: Using geographically weighted regression. Demographic Research: Volume 26, Article 6, pp. 151-166, 2012.

MEDEIROS, A. \& GOUVEIA, N. Relação entre baixo peso ao nascer e a poluição do ar no município de São Paulo. Rev. Saúde Pública, v. 39, nº, 2005, pp. 965-72.

MEDRONHO, R A Geoprocessamento e saúde - uma nova abordagem do espaço no processo saúde doença. Rio de Janeiro: FIOCRUZ/CICT/NECT; 2009.

MELLO JORGE, M. H. P.; GOTLIEB, S. L. D.; SOBOLL, M. L. M. S.; ALMEIDA, M. F.; LATORRE, M. R. D. O. Avaliação do sistema de informação sobre nascidos vivos e o uso de seus dados em epidemiologia e estatísticas de saúde. Revista de Saúde Pública. São Paulo, v. 27, supl. 6, 1993.

MINISTÉRIO DA SAÚDE/SVS/FIOCRUZ. Introdução à Estatística espacial para saúde pública. In: SANTOS, S. M. \& SOUZA, W. V. (orgs) - Série: Capacitação e atualização em geoprocessamento em saúde, vol.3. Brasília, DF, 2007.

MONTERO, Claudia Valencia. Analise espacial da mortalidade neonatal na Região Sul do Município de São Paulo - 2002. 2004. 149 f.Tese (Doutorado em Epidemiologia) - Faculdade de Saúde Pública, Universidade de São Paulo, São Paulo, 2004.

NEUTRA, R. et al. Changes in the spatial pattern of low birth weight in a southern California county: the role of individual and neighborhood level factors. Social Science \& Medicine 56 (2003) 2073-2088.

NOBRE, C. A. et al. Vulnerabilidades das megacidades brasileiras às mudanças climáticas: Região Metropolitana de São Paulo - Sumário Executivo 2010. 
NOGUEIRA, H. \& REMOALDO, P. C. Olhares Geográficos sobre a Saúde. Edições Colibri, Lisboa, 2010, P.157.

O'CAMPO, P. et al. Maternal and child health and neighborhood context: The selection and construction of area-level variables. Health \& Place 12 (2006) 547 - 556.

OMS. Organização Mundial da Saúde. Disponível em: http://new.paho.org/bra/index.php?option=com_content\&task=view\&id=1095\&Itemid= 457. Acesso em: 8 de março de 2013

PASTERnAK, S.; BÓGUS, L. Urbanização, Meio Ambiente e Saúde em São Paulo. Interfacehs, Revista de Saúde, Ambiente e Sustentabilidade. São Paulo. 6: 20 p. 2011.

RASPANTINI, Priscila Ribeiro. Rede de atenção ao nascimento e fatores de risco associados ao parto cesáreo em três regiões de saúde do Estado de São Paulo. 2012. Dissertação (Mestrado em Epidemiologia) - Faculdade de Saúde Pública, Universidade de São Paulo, São Paulo, 2012.

REIS, M. M. dos. Poluição atmosférica e os efeitos adversos em um município industrializado no estado do Rio de Janeiro. Tese de Doutorado em Patologia, apresentada à Faculdade de Medicina da Universidade de São Paulo, 2009.

RIBEIRO, H. Patologias do ambiente urbano: Desafios para a Geografia da Saúde. In: SILVEIRA, M. L. (Ed.). Questões territoriais na América Latina. São Paulo: CLACSO Livros, 2006. p.277-293.

ROJAS, L.I. La diferenciacion territorial de la salud en la recuperacion de los contextos. In: BARCELOS, C. (Org.). A geografia e o contexto dos problemas de saúde. Rio de Janeiro, ABRASCO, 2008.

SALCEDO, N. et al. Does the effect of gender modify the relationship between deprivation and mortality? BMC Public Health. 2012;12:1-9.

SANTANA, P. - "Por uma Cidade Saudável", in: JANUS 2009 - Portugal no Mundo "Aspecto da Conjuntura Internacional. A Saúde no Mundo". Jornal Público/ Universidade Autónoma de Lisboa, 2009, p.83-84.

SANTANA, P. et al. Geografias da diabetes mellitus em Portugal, Acta Med Port 2014 May-Jun;27(3):309-317.

SANTANA, P. Geografias da Saúde e do Desenvolvimento: evolução e tendências em Portugal. Editora: Almedina. Coimbra, 2005.

SANTANA, P. Saúde, Território e Sociedade: Contributo para uma Geografia da Saúde. Colecção Textos Pedagógicos e Didácticos, Faculdade de Letras, Universidade de Coimbra, 2004.

SANTANA, P;; SANTOS, R. \& NOGUEIRA, H. - "The link between local environment and obesity: a multilevel analysis in the Lisbon Metropolitan Area, Portugal". Social Science and Medicine, vol. 68(4), 2009, p. 601-609. 
SANTANA, P. Saúde, Território e Sociedade: Contributo para uma Geografia da Saúde. Coimbra: Universidade de Coimbra, 2004.

SANTANA, P.; SANTOS, R.; NOGUEIRA, H. The link between local environment and obesity: a multilevel analysis in the Lisbon Metropolitan Area, Portugal. Soc Sci Med, v. 68 , n. 4, p. 601-9, Feb 2009. ISSN 0277-9536 (Print)

0277-9536 (Linking). Disponível em: http://www.ncbi.nlm.nih.gov/pubmed/19135287 >.

SANTOS, M. A urbanização brasileira. São Paulo: EDUSP, 2005. ISBN 9788531408601. Disponível em: < http://books.google.com.br/books?id=cOHkKZgOtwUC >.

SANTOS, P. C. et al. Análise espacial dos aglomerados de nascimentos ocorridos em hospitais SUS e não SUS do município de São Paulo, Brasil. Ciência \& Saúde Coletiva, 19(1):235-244, 2014.

SANTOS, R.; SANTANA, P.; MACHADO, M. "Effects of neighbourhoods deprivation on adverse birth outcomes in an urban area of Lisbon metropolitan area", in: European Journal of Public Health, Vol.18 (1): 5 (p. 134), 2008.

SEADE. Atlas SEADE da Economia Paulista, 2010 a. Disponível em: http://www.seade.gov.br/produtos/atlasecon/notas/cap2_nota.pdf

SEADE. O retrato das mães paulistas e seus filhos recém-nascidos, Boletim SP Demográfico - Resenhas Vitais do estado de São Paulo, $n^{\circ}$. 4, 2010 b

SILVA, J. B. de S. Encontros e Desencontros na trajetória percorrida pelos adolescentes a partir da gravidez. Dissertação de Mestrado em Saúde Pública, Área de Concentração: Saúde da Mulher. Universidade Federal de Santa Catarina, Florianópolis, 2004.

SILVA, M. R. et al. Fatores de risco para nascimentos pré-termo em Londrina, Paraná, Brasil. Cad. Saúde Pública. 2009 Out;25(10):2125-2138.

SILVA, Zilda Pereira da. Perfil dos nascimentos e da mortalidade neonatal precoce, segundo local de parto, complexidade hospitalar e rede SUS e não-SUS, região metropolitana de São Paulo - 2006. 2008. Tese (Doutorado em Epidemiologia) Faculdade de Saúde Pública, Universidade de São Paulo, São Paulo, 2008.

SILVEIRA et al. Aumento da prematuridade no Brasil: revisão de estudos de base populacional. Rev. Saúde Pública, v.42, n5, 2008, pp. 957-64.

SILVEIRA, M. F. et al. Determinants of preterm birth: Pelotas, Rio Grande do Sul State, Brazil, 2004 birth cohort. Cad. Saúde Pública, Rio de Janeiro, 26(1):185-194, jan, 2010.

SINASC. Sistema Nacional de Informações dos Nascidos Vivos, Ministério da Saúde, Secretaria Estadual de Saúde de São Paulo. Disponível em 
http://tabnet.datasus.gov.br/cgi/deftohtm.exe?sinasc/cnv/nvsp.def.

SOUTH, A. P. et al. Spatial Analysis of Preterm Birth Demonstrates Opportunities for Targeted Intervention - Matern Child Health J (2012) 16:470-478.

SUSUKI, C. M., CECCON, M. E. J., FALCÃO, M. C., VAZ, F. A. C. Análise comparativa da frequência de prematuridade e baixo peso entre filhos de mães adolescentes e adultas. Rev. Bras. Crescimento Desenvolv. Hum.; vol. 17(3), 2007, pp. $95-103$.

SZWARCWALD, C. L. et al. Estimação da mortalidade infantil no Brasil: o que dizem as informações sobre óbitos e nascimentos do Ministério da Saúde? Cad Saude Publica, v. 18, p. 1725-1736, 2002. ISSN 0102-311X. Disponível em: < http://www.scielo.br/scielo.php?script=sci_arttext\&pid=S0102-

311 X2002000600027\&nrm=iso >.

VICTORA, C. G. et al. Saúde de mães e crianças no Brasil: progressos e desafios. The Lancet - saúde no Brasil, p. 15, 2011.

WILLIAMSON, R. et al. Multivariate bayesian spatial model of preterm birth and cardiovascular disease among georgia women: Evidence for life course social determinants of health. Spatial and Spatio-temporal Epidemiology 6 (2013) 25 - 35 .

WILKINSON, R. G.; MARMOT, M. Social determinants of health : the solid facts. 2nd. Copenhagen: WHO Regional Office for Europe, 2003. 31 p. ISBN 9289013710 9289043709 (Russian)

9289033703 (German). Disponível em: < http://www.euro.who.int/document/e81384.pdf >.

ZHEN, H. et al. Geospatial Health 2(2), 2008, pp. 173 -182.

ZORZAM, Bianca Alves de Oliveira. Informação e escolhas no parto: perspectivas das mulheres usuárias do SUS e da saúde suplementar. 2013. Dissertação (Mestrado em Saúde, Ciclos de visa e sociedade. Faculdade de Saúde Pública, Universidade de São Paulo, São Paulo, 2013. 